\section{OAK RIDGE NATIONAL LABORATORY}

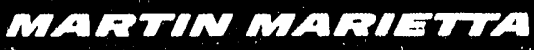

\section{Electromagnetic Pulse (EMP) Survey of the Idaho State Emergency Operating Center, Boise, Idaho}

\author{
R. I. Crutcher \\ M. E. Buchanan \\ R. W. Jones
}


This report has been reproduced directly from the best avallable copy.

Available to DOE and DOE contractors from the Office of Scientific and Technical Information. P.O. Box 62, Oak Ridge, TN 37831 ; prices avallable from (615) 576-8401, FTS 626-8401.

Available to the public from the National Technical Information Service, U.S. Dopartment of Commerce, 5285 Port Royal Rd., Springfield, VA 22.161.

This report was prepared as an account of work sponsored by an agency of the United States Government. Neither the United States Government nor any agency thereof, nor any of their employees, makes any warranty, express or implied, or assumes any legal liability or responsibility for the accuracy, completeness, or usefulness of any information, apparatus, product, or process disclosed, or represents that its use would not infringe privately owned rights. Reference herein to any specific commercial product, process, or service by trade name, trademark, manufacturer, or otherwise, dues not necessarily constitute or imply its endorsement, recommendation, cr favoring by the United States Government or any agency thereof. The views and opinions of authors expressed herein do not necissarily state or reflect those of the United States Government or any agency theroof. 


\title{
ELECTROMAGNETIC PULSE (EMP) SURVEY OF THE IDAHO STATE EMERGENCY OPERATING CENTER, BOISE, IDAHO
}

\author{
R. I. Crutcher \\ M. E. Buchanan
}

R. W. Jones

Date Published-February 1992
Notice: This document contains information of a preliminary nature. It is subject to revision or correction and therefore does not represent a final report.

\section{Prepared for the \\ FEDERAL EMERGENCY MANAGEMENT AGENCY \\ Washington, DC 20472}

under Interagency Agreement DOE 1459-1086-A1/FEMA EMW-84-E1459

Prepared by the

OAK RIDGE NATIONAL LABORATORY

Oak Ridge, Tennessee 37831-6285 managed by MARTIN MARIETTA ENERGY SYSTEMS, INC. for the U.S. DEPARTMENT OF ENERGY under contract DE-AC05-84OR21400 


\section{TABLE OF CONTENTS}

LIST OF FIGURES $\ldots \ldots \ldots \ldots \ldots \ldots \ldots \ldots \ldots \ldots \ldots \ldots \ldots$

LIST OF FEMA DRAWINGS $\ldots \ldots \ldots \ldots \ldots \ldots \ldots \ldots \ldots \ldots \ldots \ldots$

I. GENERAL $\ldots \ldots \ldots \ldots \ldots \ldots \ldots \ldots \ldots \ldots \ldots \ldots \ldots \ldots \ldots$

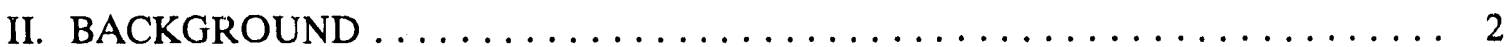

III. POWER SYSTEM PROTECTION $\ldots \ldots \ldots \ldots \ldots \ldots \ldots \ldots \ldots \ldots \ldots \ldots$

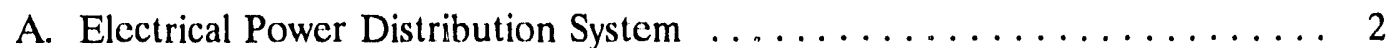

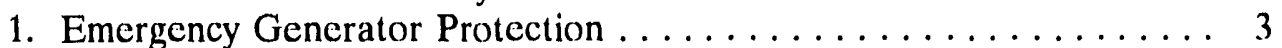

2. Main Panel Protection ..................... 3

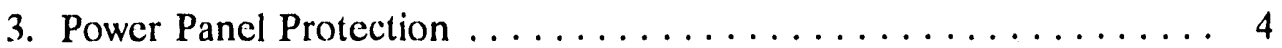

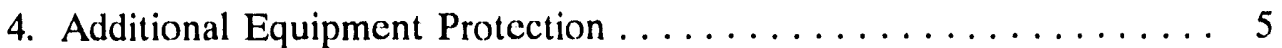

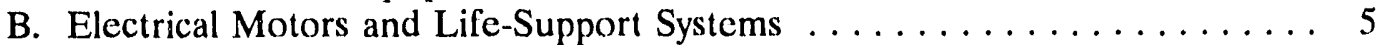

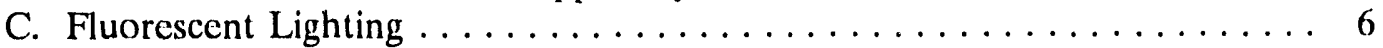

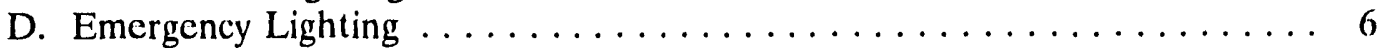

IV. ANTENNA AND RADIO SYSTEM $\ldots \ldots \ldots \ldots \ldots \ldots \ldots \ldots \ldots \ldots$

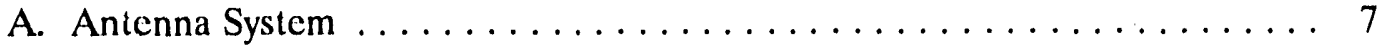

1. Roof-Level Antenna Grounding .............. 7

2. Electrical Chase Coaxial Cable Grounding ............ 9

3. Subbasement Coaxial Cable Grounding .............. 9

4. Remote Antenna and Cable Grounding ............. 11

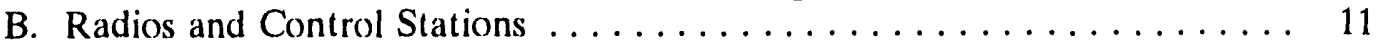

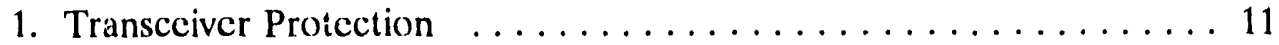

2. Control Station and Terminal Protection $\ldots \ldots \ldots \ldots \ldots \ldots$

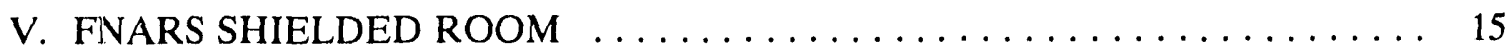

VI. TELEPHONE AND CONTROL LINES $\ldots \ldots \ldots \ldots \ldots \ldots \ldots \ldots \ldots \ldots \ldots$

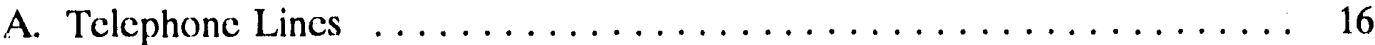

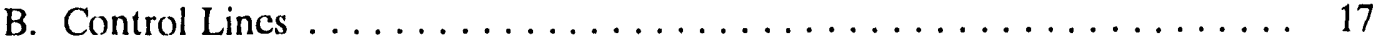

1. Communications Room Grounding and Cable Protection . . . . . . 17

2. Granger Control Cable Protection ................ 17

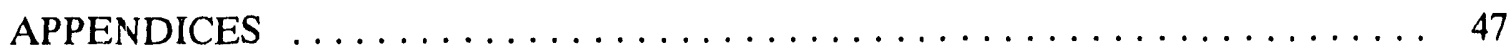




\section{LIST OF FIGURES}

Figure

Page

$1 \quad$ Emergency generator and day tank $\ldots \ldots \ldots \ldots \ldots \ldots \ldots \ldots \ldots$

2 Starter solenoid for the emergency generator $\ldots \ldots \ldots \ldots \ldots \ldots \ldots$

3 Battery-charging generator for the emergency generator $\ldots \ldots \ldots \ldots \ldots 20$

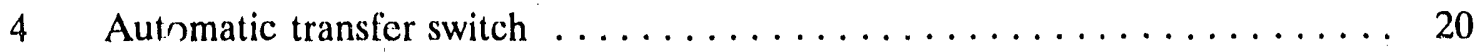

$5 \quad$ Panel $E M$ in the equipment room $\ldots \ldots \ldots \ldots \ldots \ldots \ldots \ldots \ldots \ldots \ldots$

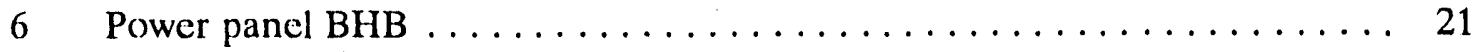

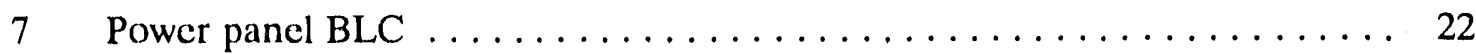

8 Power panel HEM in the electrical and mechanical ronm $\ldots \ldots \ldots \ldots \ldots 22$

9 Step-down transformer TR6 in the subbasement $\ldots \ldots \ldots \ldots \ldots \ldots \ldots$

$10 \quad$ Power panel LR in Room $57 \ldots \ldots \ldots \ldots \ldots \ldots \ldots \ldots \ldots \ldots \ldots$

11 Input to one of two power filters for the shielded room $\ldots \ldots \ldots \ldots \ldots 24$

1 12 Power panel inside the shielded room $\ldots \ldots \ldots \ldots \ldots \ldots \ldots \ldots \ldots$

13 Circuit breaker box in the Harris transmitter cabinet $\ldots \ldots \ldots \ldots \ldots \ldots$

14 Motor controller for the emergency well pump $\ldots \ldots \ldots \ldots \ldots \ldots \ldots$

15 Overall front view of the motor control center $\ldots \ldots \ldots \ldots \ldots \ldots \ldots \ldots$

16 Control contactor for one of the pumping systems $\ldots \ldots \ldots \ldots \ldots \ldots \ldots$

17 Emergency lighting unit for the office area $\ldots \ldots \ldots \ldots \ldots \ldots \ldots \ldots$

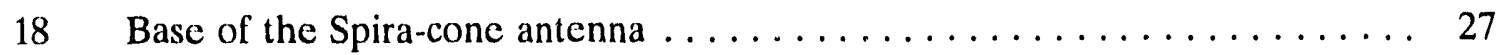

19 Spira-cone antenna on the eastern end of the roof $\ldots \ldots \ldots \ldots \ldots \ldots$

20 Balun for the state high-frequency fan doublet antenna $\ldots \ldots \ldots \ldots \ldots 28$

21 State antennas on the roof of the building $\ldots \ldots \ldots \ldots \ldots \ldots \ldots$ 


\section{LIST OF FIGURES (continued)}

$22 \quad$ FM receive antenna mounted on the fire standpipe $\ldots \ldots \ldots \ldots \ldots \ldots 29$

23 Entry point for the state coaxial cables in the third-floor electrical room . . . 30

24 Coaxial cables and conduits in the third-floor electrical room $\ldots \ldots \ldots \ldots \ldots$

25 Coaxial cables and conduits in the basement clectrical room $\ldots \ldots \ldots \ldots . .31$

26 Junction box in the air ventilation duct adjoining the subbasement $\ldots \ldots \ldots 31$

27 Three ground rods in the air duct adjacent to the subbasement $\ldots \ldots \ldots \ldots 32$

28 Penetration where coaxial cables enter the subbasement from the air duct .. 32

29 Point in the subbasement where coaxial shields are grounded $\ldots \ldots \ldots \ldots .33$

$30 \quad$ Ground rod adjacent to transformer TR6 $\ldots \ldots \ldots \ldots \ldots \ldots \ldots \ldots \ldots$

31 Penctration for state coaxial cables into the subbasement $\ldots \ldots \ldots \ldots \ldots$

32 Water and drain lines used as a ground for the shielded room $\ldots \ldots \ldots \ldots 34$

33 Remote receive antennas for the Harris system $\ldots \ldots \ldots \ldots \ldots \ldots \ldots$

34 Coaxial cables from the Harris remote receive antennas $\ldots \ldots \ldots \ldots \ldots \ldots$

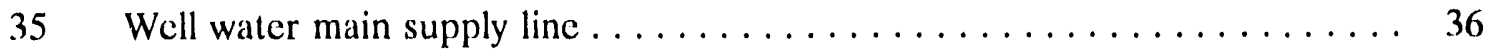

36 National Guard radio in the communications room $\ldots \ldots \ldots \ldots \ldots \ldots$

37 State Emergency Operating Center high-frequency radio . . . . . . . 37

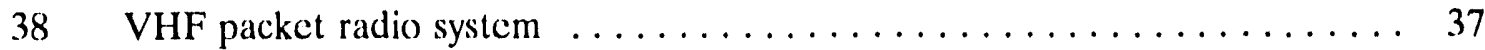

39 Emergency Broadcasting System remote pickup in the

Hall of Mirrors Building $\ldots \ldots \ldots \ldots \ldots \ldots \ldots \ldots \ldots \ldots$

40 Rear of the Emergency Broadcasting System remote pickup

in the Hall of Mirrors Building $\ldots \ldots \ldots \ldots \ldots \ldots \ldots \ldots \ldots \ldots$

41 Datapoint terminal on the Department of Transportation network . . . . . 39

42 Modem for the Datapoint terminal $\ldots \ldots \ldots \ldots \ldots \ldots \ldots \ldots \ldots \ldots$ 


\section{LIST OF FIGURES (continued)}

43 Telephone connecting to the National Warning System network . . . . . . 40

44 Control station for the Civil Defense microwave network $\ldots \ldots \ldots \ldots \ldots$. 40

45 Equipment for the Federal Emergency Management Agency National

Teletype System and the Idaho Law Enforcement Teletype System . . . . . 41

46 Motorola remote handset control for the Emergency Broadcasting

System remote pickup station $\ldots \ldots \ldots \ldots \ldots \ldots \ldots \ldots \ldots \ldots$

47 Entrance door to the shielded enclosure $\ldots \ldots \ldots \ldots \ldots \ldots \ldots \ldots$

48 Honeycomb filter on the air intake for the shielded room $\ldots \ldots \ldots \ldots \ldots 2$

49 Fan and honeycomb filter for the air exhaust for the shiclded room . . . . . 43

50 Coaxial cable penetrations to the shielded room $\ldots \ldots \ldots \ldots \ldots \ldots$

51 Protection block for signal lines entering the shielded room . . . . . . . . 44

52 Telephone connection blocks for the EOC and the communications room . . 44

53 Penetration at the rear of one console $\ldots \ldots \ldots \ldots \ldots \ldots \ldots \ldots \ldots$

54 Rear of the console with control line terminal blocks . . . . . . . . . . 45

55 Control box for the high/low : witch on the Granger Spira-cone antenna $\ldots 46$ 


\section{LIST OF FEMA DRAWINGS}

FEMA

No.

Page

0023-001 Idaho State Emergency Operating Center single line electrical power diagram $\ldots \ldots \ldots \ldots \ldots \ldots$

0023-002 Idaho State Emergency Operating Center partial basement and communications room equipment grounding system $\ldots \ldots \ldots$

0023-003 Idaho State Emergency Operating Center roof grounding system and :ntenna counterpoise system $\ldots \ldots \ldots .61$

0023-004 Idaho State Emergency Operating Center antenna counterpoise system hardware details

0023-005 Idaho State Emergency Operating Center sub-basement grounding system $\ldots \ldots \ldots \ldots \ldots \ldots \ldots$

0023-006 Idaho State Emergency Operating Center shiclded room elevation, control wiring, and antenna

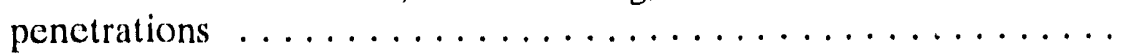

0023-007 Idaho State Emergency Operating Center communications room grounding system 


\section{GENERAL}

The purpose of this report is to develop an engineering design package to protect the Federal Emergency Management Agency (FEMA) National Radio System (FNARS) facilities from the effects of high-altitude electromagnetic pulses (HEMPs). This report was developed specifically for the Idaho State Emergency Operating Center (EOC) in Boise, Idaho.

It is highly probable that there will be a heavy dependence upon high-frequency (hf) radio communications for long-haul communications following a nuclear attack on the continental United States, should one occur. To maintain the viability of the FEMA hf radio network during such a situation, steps must be taken to protect the FNARS facilities against the effects of HEMP that are likely to be created in a nuclear confrontation.

The FNARS equipment has already been designed, built, and installed so that little opportunity exists for equipment design changes that could raise the threshold levels at which malfunctions occur. The solution must then be to reduce HEMP-induced stresses on the system by means of tailored retrofit hardening measures using commercial protection devices when available.

It is the intent of this report to define the particular hardening measures that will minimize the susce, ibility of system components to HEMP effects. To the extent economically viable, protective actions have been recommended for implementation, along with necessary changes or additions, during the period of the FNARS upgrade program.

This report addresses electromagnetic pulse (EMP) effects only and disregards any condition in which radiation effects may be a factor. It has been established that, except for the source region of a surface burst, EMP effects of high-altitude bursts are more severe than comparable detonations in either air or surface regions. Any system hardened to withstand the more extreme EMP environment will survive the less severe EMP conditions. The threatening environment will therefore be limited to HEMP situations. (In this report, HEMP will be referred to as EMP.)

This report identifies the systems in the facility that are considered critical for emergency operation and analyzes them for EMP coupling paths. Upon establishing these paths into the system, the system is then analyzed for its failure threshold. The protection of a system from an EMP is most easily accomplished by the elimination or restriction of the EMP coupling paths. EMP coupling paths are identified as directly connected, directly induced, and/or secondarily induced paths. Directly connected EMP paths are provided by power distribution systems, telephone lines, control cables, water pipes, etc. Directly induced EMP paths include doors, windows, ventilation systems, cooling systems, and any other physical opening into the facility. Secondarily induced EMP paths are associated with currents being induced into metal conductors in the vicinity of other conductors carrying EMPs. The elimination or restriction of these EMP coupling paths into the facility is of primaty importance in protecting the FNARS facility.

To identify the critical systems in the facility and the EMP coupling puins affecting these systems, an EMP survey of the facility was conducted. Results of the survey and 
of the survey and tests are presented along with recommendations for tailored retrofit hardening measures to be implemented to protect the facility from EMP.

\section{BACKGROUND}

An initial preliminary EMP survey of the Idaho State EOC in Boise was conducted July 25-27, 1989, by M. E. Buchanan, R. I. Crutcher, and R. W. Jones of Oak Ridge National Laboratory (ORNL) on behalf of FEMA. Fred Bretsch and Andrew Hendrickson of FEMA Region $\mathrm{X}$ assisted with the survey. Technical support was furnished by Pat Frischmuth of the Idaho Bureau of Disaster Services.

The initial site survey was performed to obtain firsthand information necessary to assess exposure potential, adequacy, and/or deficiencies in existing protection measures and to determine the amount of documentation and drawings available for use in the EMP protection engineering design package. Primary emphasis was placed on obtaining information about the protection of the FNARS radio room (communications shielded enclosure room). The original EMP protection and shielded communications room were installed in 1978. Because of the lapse of time since the installation of EMP protective devices and because new equipment has been added, it was determined that a comprehensive EMP survey was necessary.

\section{POWER SYSTEM PROTECTION}

\section{A. Electrical Power Distribution System}

The Idaho State EOC is in the basement of the Len B. Jordan (LBJ) Building, a multistory office structure, at 650 West State Street in Boise. The FNARS radio room/communications shielded enclosure room is in the basement, adjacent to the general communications center. Electrical power for the building is furnished from the commercial grid through underground lines and a transformer that provides $277 / 480-\mathrm{V}$ threc-phase grounded wye.

The electrical power system provides an excellent direct-connection EMP coupling path to critical communication equipment, and it must be considered in the development of the EMP engineering design protection plan. EMP protective measures for power connections are designed to protect principally against common-mode (phase-to-ground) transients. Localized protection distributed over the power system uses metal oxide varistors (MOVs) in the main breaker panel and critical power distribution panels. These devices are to be installed on the load side of any three adjacent breakers (phases) to metal case as a ground, with the device lead length as short as possible.

The materials list in Appendix A-1 will assist in identifying the specific protectors shown in various diagrams of the survey (see FEMA drawings). The basic protector number is shown inside the circle on the diagram, with the number of units required below and left of the circle. For example, the transfer switch shown in FEMA Dwg. 0023-001 indicates the symbol ${ }_{3}(4)$. Checking the materials list, we see that this is an MOV transient suppressor (4), a V275HE250 (o), and that three each are required at this location (3). 
All EMP transient arresters and jumpers recommended and shown in this report are to be located such that minimal lead lengths are required for their installation. Induced EMP transient currents have exceptionally fast leading-edge gradients, and protcetor lead inductance can result in significant inductive voltage drops, reducing a protector's effectiveness if it is not properly installed.

FEMA Dwg. 0023-(0)1 is a single-line electrical power distribution diagram showing the locations for installation of recommended EMP protection devices for the electrical power system at the EOC. These EMP suppressors will reduce the direct EMP coupling paths through the electrical power system to critical areas in the facility. FEMA Dwgs. 0023-001 through 0(023-(0)7, Figs. 1 through 55, and Appendix B describe the locations and methods for installing the protection devices.

\section{Emergency Generator Protection}

The emergency power generator for the EOC is in the basement electrical and mechanical room. FEMA Dwg. 0023-0(02 includes a placement drawing for the equipment room. An Onan 150-kW automatic-start generator supplies power for the EOC, the communications center, and the life-support equipment. The output of the generator is a 277/480-V three-phase grounded wye configuration.

Figure 1 shows the overall view of the generator and day tank. The conduit employed for the generator wiring does not contain a flexible section. The day tank pump, to the left of the generator, does have flexible conduit that has been paralleled by conductive jumpers. These jumpers are in good condition and should be left in place.

The starter solenoid for the emergency generator is shown in Fig. 2. This solenoid has V39ZA6 MOVs installed on the solenoid terminals. A bead of silicone rubber cement should be used to mount the body of the MOV to the solenoid housing to prevent vibration from breaking the MOV leads.

Figure 3 shows the de generator used to charge the starting batteries for the emergency power generator. The de generator has a V130LA10A MOV on the output terminal, and the voltage regulator has two V130LA10A MOVs installed. The body of each MOV should be fastened to the generator or voltage regulator structure with a bead of silicone rubber cement to prevent vibration from breaking the leads.

An external ac-powered battery charger is not installed on this generator. The batteries are kept charged by running the generator once every two weeks.

\section{Main Pancl Protection}

The design philosophy of the power system calls for staged protection with MOVs installed in successive power panels. The single-line power diagram with the recomnended protection is shown in FEMA Dwg. 0023-001. The 277/480-V power enters througin a 2000-A main panel that can be opened by only the building electrical contra:tor. Therefore, the first stage of protection will be installed in the automatic transfier switch, shown in Fig. 4. The transfer switch had V480PA40 MOVs installed from each phase to ground on the commercial power terminals, the generator supply terminals, 
and the load terminals. Existing protection practices do not place MOVs on the generator side of the transfer switch, and these devices should be removed. The V480PA40 MOVs on the commercial power terminals should be removed and replaced with V275HE250 MOVs installed from each phase to ground. The HE type MOVs require that the second terminal be connected to ground, as illustrated in Appendix B-1. It is important to keep lead lengths short when making these connections. The V480PA40 MOVs on the load side of the transfer switch should be removed and replaced by V275PA40A MOVs. The new MOVs can be mounted in place of the existing devices. The remote start line between the generator and the transfer switch has V39ZA6 MOVs installed at the terminals inside the transfer switch cabinet. These MOVs should be leit in place.

From the transfer switch, the emergency power feeds to the EM section of the electrical switchgear. Several of the circuit breakers in the EM pancl are shown in Fig. 5. V275PA40A MOVs should be installed on the load side of the breaker marked "Panel BHB." Install the MOVs on the metal wall to the right of the wires and attach the ieads to the breaker terminals.

\section{Power Pancl Protection}

The power panel BHB, shown in Fig. 6, had V480) PA40 MOVs installed during the original EMP protection effort. The $48(0) \mathrm{V}$ devices are installed from phase to ground on the 277-V line and do not provide the level of clipping protection that is required. These devices should be replaced by V275PA40A MOVs installed from each phase to ground on the output of three adjacent breakers. The 275-V MOVs can be installed in the physical position occupied by the existing 48()-V devices.

Figure 7 shows the MOVs in power pancl BLC, which supplies $120 / 208-\mathrm{V}$ power to the EOC area. The panel has V130PA20 MOVs installed from each phase to ground and from the neutral to ground and requires no further protection. Panel LEB is adjacent to panel BLC and is fed from panel BLC. The proximity and wiring configuration are such that protection is not required for panel LEB.

Pand HEM in the electrical and mechanical room is shown in Fig. 8. This panel is wired for 277/480 V and has V480PA40 MOVs installed from each phase to ground. These MOVs should be replaced by V275PA40A MOVs installed with the same electrical and mechanical connections.

Step-down transformer TR6, in the subbasement below the EOC, is shown in Fig. 9. This transformer reduces the 277/480-V feed from panel EM to $120 / 208 \mathrm{~V}$ to supply panel LR in the communications room. The flexible conduits on TR6 should be shunted by No. 4 AWG copper conductors. The clamps on the flexible conduit have screws that can be used to attach lugs for the cropper eonductor.

Figure 10 shows panel LR in Room 57. The panel has V130PA20 MOVs installed from each phase to ground and is considered to be adequately protected.

The input to one of the power liiters at the shielded room penetration is shown in Fig. 11. A V130PA20A MOV should be installed on the input of each filter, from the 
line terminal to case ground. Use care when installing the MOV to avoid breaking the filter insulator.

Figure 12 shows the power panel inside the shielded room. The filter output terminals are in the bottom of the pancl and feed into the panel main breaker. The circuits inside the shielded room should be protected by installing V130PA20A MOVs on the outputs of two adjacent breakers in this box.

\section{Additional Equipment Protection}

In addition to the MOVs installed for power protection at the panels or the equipment, plug-in MOVs will be installed at the receptacles feeding equipment at several locations. The plug-in devices are employed in those locations where a sensitive piece of electronic equipment is powered from a receptacle and the power conductor terminals are not accessible for installing prolectors with leads.

A plug-in MOV should be installed in the rece ptacle that powers the National Guard radio and Datapuint terminal in the communications room. A plug-in MOV should also be installed on the receptacle that powers the Civil Defense microwave control station. The FEMA National Teletype System (FNATS) equipment and the Idaho Law Enforement Teletype System equipment also require a plug-in protector unit.

The Emergency Broadcasting System (EBS) remote pickup (RPU) station in the Hall of Mirrors Building will require a plug-in MOV on the ac power receptacie fecding the station equipment. A plug-in MOV and grounded cube tap will be required for the power to the EBS RPU control head in the EOC office area.

The Harris FNARS radio equipment in the shielded room does not now have EMP protection past the filtering at the power panel. Although the filtering may be sufficient to protect the equipment, additional proteciion would be obtained by installing MOVs at the power box in the transmitter rack. The circuit breaker box, shown in Fig. 13, should have V130PA20A MOVs installed from the terminals on the load side of the breaker to ground.

\section{B. Electrical Motors and Life-Support Systems}

Electrical motors with essential loads (life-support equipment) should receive further EMP protection by placing MOVs as close to the motors as possible. The back electromotive forec caused by the electrical breaking of inductive ioadis will cause premature failure of installed MOVs; therefore, EMP protection of this type should consist of MOVs installed on the electrical line side of the electrical motor starting/stopping contactors, rather than on the load side.

The main motor control distribution panel is a portion of the EM section of the switchgear. The switchgear will receive protection as described in Sect. III.A.2 of this report. Individual motor controllers will have the EMP protection upgraded as detailed below. 
A detail of the controller and contactor for the emergency well pump is shown in Fig. 14. The incoming electrical line is now protected by V480PA40 MOVs installed from each phase to panel ground. These MOVs should be replaced by V275PA40A devices installed in the same location as the old units. The control coil has a V130LA10A MOV installed across the coil terminals. This MOV should be left in place.

Figure 15 shows an overall front view of the motor control center in the EM section of the switchgear. Other contactors in this panel besides the well water pump include the EOC air supply fan, the EOC air return fan, and the fire pump. Each of these is currently protected with V480PA40 MOVs, which should be replaced by V275PA40 devices as described for the well pump.

A control contactor for one of the pumps is shown in Fig. 16. The line side of this contactor is fed from the adjacent power panel HEM in the electrical and mechanical equipment room. Because panel HEM will receive protection, no devices will be installed in the pump control box.

The refrigeration equipment in the kitchen area is not connected to emergency power. The state EOC personnel should determine whether the emergency generator will handle the additional load from the refrigerators and, if feasible, connect the refrigeration circuits to emerge cy power. Transient protection should be added to the refrigeration circuits if these ar a placed onto an emergency power circuit.

\section{Fluorescent Lighting}

The fluorescent lights in the EOC should be EMP protected by installation of an MOV directly across the ballast transformer of the light fixture to be protected (see Appendix B-2). The fluorescent lamps in the EOC area operate from $277 . \mathrm{V}$ power. These fixtures should be protected by installing a V275LA20A MOV inside the fixture housing across the ac power leads to the ballast. Heat-shrinkable tubing should be used to insulate the bare leads of the MOV.

The EOC communications area, offices, hallways, operations room, cafeteria, and kitchen have a total of 289 fluorescent lighting fixtures. Half of these fixtures (145) should be protected in the manner described above. The fixtures receiving protection should be chosen such that the locations of the surviving lights will be distributed around the area of need.

\section{Emergency Lighting}

The emergency lighting unit for the office area is shown in Fig. 17. This type of lighting unit has a solid state charger circuit with EMP-susceptible diode rectifiers that should be EMP protected. EMP protection can be best accomplished by installing MOVs on the primary side of the step-down transformer, from the high (phase) side of the ac line to the low (neutral) side of the ac line, and from the high (phase) side of the ac line to ground. The input to this lighting unit is $120 \mathrm{~V}$ and should be protected with V130LA10A MOVs installed from the line to neutral and line to ground. The low-voltage secondary of the supply is contained within the localized area, and protectors are not required on the secondary side of the light. 
Two additional emergency lighting units are installed in the hallway of the EOC area. These lights are identical to the one in Fig. 17 and should be protected in a similar manner with V130LA10A MOVs installed on the ac line from hot to neutral and from hot to ground.

\section{ANTENNA AND RADIO SYSTEM}

\section{A. Antenna System}

The Granger Spira-cone antenna and the state hf and vhf antennas for the EOC are installed on the roof above the third floor of the building. Two receive antennas for the Harris equipment are installed on the roof of another building. The coaxial cables between the roof-mounted antennas and the EOC take two separate paths on opposite sides of the building. The coaxial cables from the remote antennas take a third route. Discussion of antenna protection will begin with grounding on the roof level. Grounding of the coaxial cables for the vertical runs through the electrical chases will be discussed next, followed by the grounding for the coaxial cables in the subbasement area. Finally, protection will be discussed for the remote receive antennas and their associated coaxial cables.

\section{Roof-Luvel Antenna Grouncing}

Most antennas for the EOC are situated on the third-floor roof the building. The grounding for these antennas and the associated roof-mounted equipment is not considered sufficient for the system to survive an EMP event. Recommendations are made in this section for installation of a counterpoise grounding network at roof level to equalize the voltage potential among the various pieces of equipment. Personnel from FEMA Region $X$ have taken exception to the installation of a counterpoise on the basis that the Spira-cone and hf antennas are not designed to be operated in close proximity to a counterpoise. Although the theoretical patterns for these antennas are calculated for elevated operation, practical installations encounter stecl reinforcing rods in the roof, sheet metal panels beneath the eoncrete, and metal structures above the roof. The Spira-cone at Boise is installed adjacent to a metal penthouse with one of the tubular booms of the antenna within $2 \mathrm{ft}$ of the penthouse. The penthouse wall will affect the radiation pattern of the Spira-cone to a much greater extent than would a counterpoise at roof level, especially considering that the Andrew Corporation catalog confirms that the Model 3002 antenna can be either roof or ground mounted. Installation of a similar counterpoise under a Spira-cone at another state EOC did not appear to affect the pattern of the antenna. For these reasons, this report will recommend installation of the counterpoise, although Region X personnel may choose not to install it.

As mentioned in the preceding paragraph, the grounding of the roof-mounted antennas is not sufficient to protect the equipment in the event of an EMP occurrence. The Spira-cone antenna has one No. 8 AWG ground wire that runs from the tower base, shown in Fig. 18, to a ground rod in the subbasement. The balun for the state fan doublet antenna has a single ground wire that connects to an electrical conduit on the third floor. The lack of availability of a good earth ground dictates that a counterpoise be established at the roof level. This counterpoise will connect to the metal masts and towers of the antennas, the balun for the fan doublet, and the metal penthouse as building 
structure. FEMA Dwg. 0023-003 gives the layout for the existing antennas and the recommended routing and placement of counterpoise grounding conductors. The counterpoise should attach to all metal components and assemblies on the roof to form a unified metal structure for the reflection and conduction of EMP currents.

Figure 19 shows the Spira-cone antenna on the east corner of the roof. The tower for the Spira-cone will serve as the hub for the castern portion of the counterpoise, as illustrated in FEMA Dwg. 0023-003. The balun for the fan doublet on the state hf radio is shown in Fig. 20. The center of the fan doublet antenna will locate the hub of the western portion of the counterpoise. The ground connection for the balun should be attached to the center of the hub. The state antennas for the vhf packet radio and the National Guard radio, a support tower for the fan doublet, and the remote radiation monitor are shown in Fig. 21. These antenna mounts and the radiation detector should be attached to the counterpoise at the points illustrated in FEMA Dwg. 0)23-(003.

The details of the grounding eounterpoise for the roof level are shown in FEMA Dwg. 0(123-()()4. The counterpoise will be constructed from 1/4-in. copper tubing with littings at the tubing connection points. A length of No. 4 AWG copper wire should be soldered into a tee at those points where physical connections will be made to towers, masts, the penthouse structure, and the two wires that will run to the grounds in the subbasement. Details of the connections to the structures are given in FEMA Dwg. 0023-004. The tubing for the counterpoise should be attached to the roof by plastic roofing cement applied at the cross points and periodically along the perimeter of the outer loops.

A manifold assembly will be designed, in accordance with FEMA Dwg. (0)23-0()4, to fit around the pedestal of the Spira-cone and provide a tic point for the eight radials around the Spira-cone. The other ends of these radials will terminate in a ring that bounds the roof area on two sides and the penthouse on two sides. An intermediate connection ring will reduce the area of each enclosed loop. Reducing the enclosed area raises the resonant frequency of the loop and irnproves the loss mechanism of the counterpoise by creating intermediate circulating currents to shunt the EMP energy. A No. 4 AWG copper conductor will run from the base of the Spira-cone/hub assembly to ground points in the subbasement, following the route of the existing coaxial cables.

A hub assembly for the counterpoise under the state antennas will be fabricated as detailed in FEMA Dwg. (0023-(0)4. This portion of the counterpoise consists of eight radials forming a circle under the fan doublet antenna. The balun will ground to the enter of the counterpoise circle, and the other state antennas, the fan doublet support masts, and the radiation detector will ground to the counterpoise at connection points indicated in FEMA Dwg. (0)23-(0)3. The radials under the state antennas are bounded by an outer perimeter loop and divided by an inner loop to raise the resonant frequency and EMP loss mechanisms. The state counterpoise and the Spira-cone counterpoise are connected by three conductors: two around the penthouse and one diagonal. The state counterpoise has a No. 4 AWG copper conductor connected at the northwest end. This copper eonductor will follow the path of the existing state coaxial cables, grounding to the electrical conduits in the electrical chase and to several pipes in the subbasement. 
The FM antenna shown in Fig. 22 will not be connected to the counterpoise at this time. This antenna is mounted to a vertical fire standpipe that is not attached to either the building ground or the water system. The standpipe can act as an antenna for EMP with unwanted currents conducted onto the counterpoise if the standpipe and counterpoise are connected. The shicld of the coaxial cable to the FM antenn i will be grounded at the subbasement level, but it is recommended that the FM antenna be relocated from the standpipe to a smaller mast, if possible. The smaller mast can then be attached to the counterpoise without affecting operation of the counterpoise.

\section{Electrical Chasc Coaxial Cable Grounding}

The coaxial cables for the state antennas are routed over the edge of the roof and through a wall penetration to the electrical chase. The entry point for the eoaxial cables is shown in Fig. 23. The existing ground from the hf antenna balun is connected to the conduits in the top of the figure. This ground should be removed when the balun is grounded to the counterpoise.

A No. 4 AWG copper conductor should connect to the northwest end of the counterpoise and run with the coaxial cable bundle to grounding points in the subbasement. The inductance of the grounding connection can be reduced by paralleling the wire with an electrical eonduit that extends from the basement to the third floor. Figure 24 shows the electrical conduit in the third floor electrical room. The No. 4 AWG conductor should be routed with the coaxial eable bundle to the right of the conduit. A 4-in. grounding clamp should be added a few inches above the floor to make electrical connection between the copper conductor and the electrical conduit.

Figure 25 shows the same conduit on the basement level. The No. 4 AWG grounding conductor that will be a. ed to the coaxial bundle should be bonded to the conduit with a 4-in. grounding clat $p$ a $\mathrm{few}$ inches above floor level. The conductor will continue into the subbasement where connections will be made to other grounding points. It should be noted that the vertical conduits shown in Fig. 25 are resting on polyvinylchloride (PVC) sweep ells at the floor level. As a matter of electrical safety, the building electrician should verify that an electrical ground exists between the building electrical system and the boxes attached to this conduit.

\section{Subbasement Coaxial Cable Grounding}

Coaxial cables are routed from the roof antennas through two separate vertical shafts to the subbasement before entering the communications room. Several grounding points are accessible on the subbasement level, and these will be utilized to drain transient currents from the coaxial cable shields. The No. 4 AWG copper eonductors from the roof counterpoise will be attached to these grounds. Layouts of the cable routing and grounding attachments are shown in FEMA Dwg. 0023-(0)5. As indicated in the drawing, the No. 4 AWG copper wire from the counterpoise under the state antennas will run with the state coaxial cables and attach to the water pipes that are a ground for the shielded room. Likewise, the No. 4 AWG ground from the Spira-cone antenna is routed with the coaxial cables from that antenna. This grounding wire will connect to a water line and to the grounding rod at transformer TR6. 
Figure 26 shows a junction box in the air ventilation duct adjoining the subbasement. The vertical conduit contains the coaxial cables from the Spira-cone antenna and the horizontal conduit contains the cables that go to the shielded room. Additionally, the No. 8 AWG ground wire from the Spira-cone antenna exits the conduit at this point and attaches to a ground rod. A No. 4 AWG copper grounding wire should be rouied through the junction box with these coaxial cables from the Spira-cone antenna to the shielded room ground. A branch from this grounding wire should be attached to the three ground rods shown in Fig. 27. The new No. 4 AWG grounding wire should connect to the three ground rods using clamps and should utilize the route of the existing No. 8 AWG wire to reach the junction box.

The penetration from the air duct to the subbasement is shown in Fig. 28. The No. 4 AWG grounding wire will be routed through this conduit. A black door connecting the subbasement to the air duct is to the right of the eonduit penetration. Caution should be exercised when opening this door because the differential air pressure between the subbasement and the ventilation duct causes the door to open abruptly. It should also be noted that the floor is 3 ft lower on the back side of the door than on the front side.

Figure 29 shows a point in the subbasement where the shiclds of the coaxial cables to the Spira-cone are grounded to water and waste lines. The No. 4 AWG copper wire that will be installed with the coaxial cable bundle should ground to these pipes as it passes this location.

The ground rod adjacent to transformer TR6 is shown in Fig. 30. This rod will be the terminating point for the No. 4 AWG ground from the Spira-cone antenna. The existing No. 4/0 AWG wire that is attached to the rod is one of the grounds to the shielded room. The existing ground wire should be left in place when the No. 4 AWG is added.

Figure 31 shows the state antenna coaxial cables entering the subbasement. A No. 4 AWG copper grounding conductor will be added to this bundle, extending from the counterpoise on the roof to the water and drain lines shown in Fig. 32. These lines now serve as one ground for the shielded room, and attachment to this point will reduce the differential voltages among the building grounds.

Branches from the No. 4 AWG should be routed to penetrations in the eciling that lead to the consoles in the basement. Routing for these lines is indicated on FEMA Dwg. 0023-005. The No. 4 AWG branches will be used to establish grounds for the console equipment, as discussed in Sect. VI.B.1.

The shiclds for the state coaxial cables should be grounded in the subbasement to the No. 4 AWG copper wire before penetrating to the communications room. This grounding can be accomplished by using linned braid, a hose clamp, and a conductive epoxy mixture. The connection is made by removing a small ring of the outer jacket insulation from the cable, exposing the cable shield. The void is filled with the conductive epoxy and wrapped with the tinned braid for approximately one and one-half turns before clamping with a stainless steel hose clamp. Conductive eement is used to fill any voids at this connection. Because these cables are in a dry location inside the building, PVC electrical tape is sufficient to seal the connection alter the epoxy dries. (Refer to 
Appendix B-3 for a pictorial view of a typical coaxial grounding connection without silicone and PVC tape.) A split bolt can be used for making a connection to the No: 4 AWG ground wire that will be routed with the coaxial cable bundle.

\section{Remote Antenna and Cable Grounding}

Remote receive antennas for the Harris equipment are mounted on the roof of the Towers Building, approximately $2000 \mathrm{ft}$ from the EOC. Figure 33 shows the vertical whip on the left and the B\&W antenna on the right. Both antennas are mounted to the metal siding of the penthouse on the Towers Building. Because of the remoteness of these antennas, further grounding will not be added at this location.

The coaxial eables from the antennas on the Towers Building are routed through an underground tunnel to the LBJ Building. The first convenient grounding point in the LBJ Building is in the electrical and mechanical equipment room. Figure 34 shows a horizontal wire bundle that contains the coaxial cables for the remote receive lines. The two RG-213 cables in this bundle should have the shields grounded to a No. 4 AWG copper conductor that will eonnect to the well water main supply line.

The coaxial cable shic!ls can be grounded by using tinned braid, a hose clamp, and a conductive epoxy mixtu, $\therefore$. The connection is made by removing a small ring of jacket insulation from the cable, exposing the cable shicld eonductor. The void is filled with the conductive epoxy and wrapped with the tinned braid for approximately one and one-half turns before clamping with a stainless steel hose clamp. Conductive cement is used to fill the voids at the connection. Because these cables are in a dry location inside the building, PVC electrical tape will be sufficient to seal the eonnection after the epoxy dries. The other end of the braid will be connected to a No. 4 AWG ground wire by using a split bolt clamp. A pictorial view of a typical coaxial grounding connection (without silicone and PVC tape) is shown in Appendix B-3.

The other end of the ground wire should attach to the water well main supply line, shown in Fig. 35. An additional grounding clamp should be added to the water pipe so that the existing ground wire and clamp are not disturbed.

\section{B. Radios and Control Stations}

The communications systems for the EOC include transecivers, control stations for remote links, and teletypes and terminals for text communications. This report will specify protection for the transeciver, but hardening of the remote links is beyond the scope of the current protection program. Likewise, the protection specified for the teletypes and terminals will limit the transients reaching the local equipment but will not safeguard the networks or the central computers.

\section{Transceiver Protection}

Most of the state radios that are to be protected are installed in the communications room. The locations and suggested protection devices for these radios are indicated in FEMA Dwg. 0023-002. Additionally, a summary of the protection devices recommended for the radio equipment is presented in Table 1. 


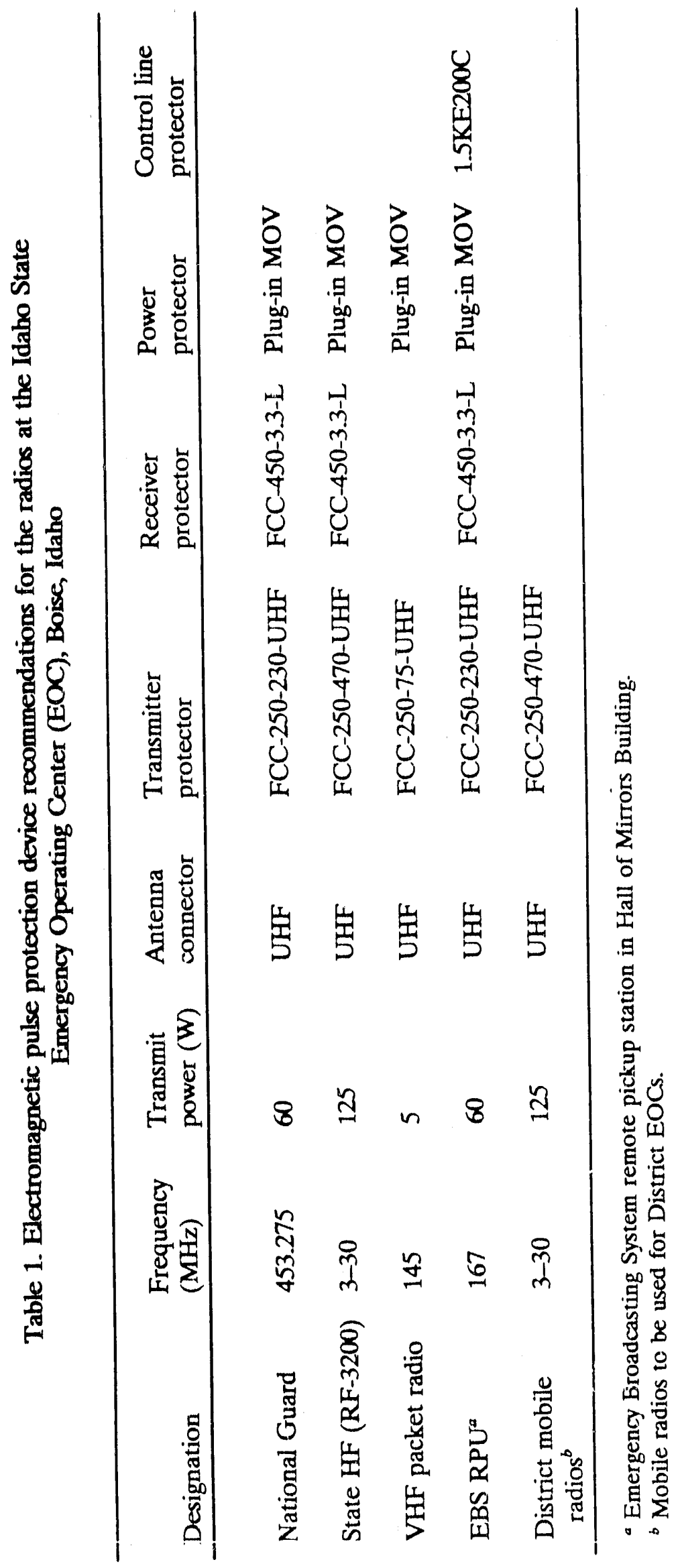


The National Guard radio is shown in Fig. 36. The radio in use at the time of the survey was a 60)-W station operating on $46.95 \mathrm{MHz}$. This station is scheduled to be replaced by a system operating on $453.275 \mathrm{MHz}$ with $60 \mathrm{~W}$ of transmit power. The transmitter on the new station should be protected by installing an FCC-25()-230-UHF coaxial protector on the antenna line at the rear of the station. The receiver should be protected by installing an FCC-45()-3.3-L diode bridge on the receive line inside the radio, after the transmit/receive (T/R) switch. Power to the radio will be protected by a plug-in MOV installed at the ac receptacle that powers the radio.

Figure 37 shows the state EOC hf radio. This radio is a Harris model RF-32(0) SSB unit that can deliver $125 \mathrm{~W}$ of power over the 3- to 30-MHz band. The transmitter should be protected by installing an FCC-25()-47()-UHF coaxial protector on the antenna cable at the back of the radio. The receiver should be protected by installing an FCC-450-3.3-L diode bridge across the receive line after the $T / R$ switch inside the radlo. A plug-in MOV should be installed at the receptacle that powers the radio.

The packet radio system is shown in Fig. 38. The system consists of a 5-W Kenwood walkic-lalkic operating in $145 \mathrm{MH}$, a modem unit, a computer, and a printer. The antenna line should be protected by installing an FCC-25()-75-UHF coaxial protector on the antenna lead at the UHF connector bulkhead in the rear of the cabinet. The walkic-talkie is powered by a de supply on a shelf of the cabinet. The ac power for the system should be protected by a plug-in MOV at the receptacle.

The state has six he mobile radios that will be carried to the district EOCs during an alert condition. These are 125-W radios that cover the 2- (1) 3()-MHz range. FCC-25()-47()-UHF coaxial tees will be supplied to protect the antenna input to these raddios.

Figure 39 shows the EBS RPU in the Hall of Mirrors Building. The station operates in the 167-MHz frequency range with a power of $60 \mathrm{~W}$. The transmitter should be protected by installing an FCC-25()-23()-UHF coaxial protector on the antenna input. The receiver should be protected by installing an FCC-45()-3.3-L diode bridge on the receive line after the $T / R$ switch. This station is wired for use with a battery backup, but the battery is not currently installed. The state should consider either replacing the battery or relocating the station to an area with emergency power. In either case, a plug-in MOV should be installed on the ac power receptacle fecding this station. The terminals for the control line are shown in Fig. 40. The control lines use a de current loop and should be protected by installing 1.5KE20)(C bipolar zener diodes from each conductor of the pair to chassis ground.

\section{Control Station and Terminal Protection}

Most of the control stations and terminals to be protected are in the communications room. FEMA Dwg, ()(2.3-()()2 is a placement diagram for these stations and terminals, and the recommended protection devices for this equipment are shown in the drawing. A complete listing of recommended protection devices for all the control stations and terminals is given in Table 2.

Figure 41 shows the Datapoint 8200) terminal that is used for electronic mail on the Idaho Department of Transportation network. The terminal is connected to a thin-wire Ethernet-type network through the modem in Fig. 42. An FCC-45()-3.3-BNC coaxial protector should be installed on the coaxial line at the modem. A plug-in MOV protector will be supplied for the receptacle that powers the terminal and modem. 
Table 2. Electromagnetic pulse protection device recommendations for the terminals and control stations at the Idaho State Emergency Operating Center (EOC), Boise Idaho

\begin{tabular}{|c|c|c|c|}
\hline Device & Function & Signal protector & Power protector \\
\hline $\begin{array}{l}\text { Datapoint } 8200) \\
\text { terminal }\end{array}$ & $\begin{array}{l}\text { Department of } \\
\text { Transportation } \\
\text { E-Mail }\end{array}$ & FCC-450)-3.3-BNC & Plug-in MOV \\
\hline $\begin{array}{l}\text { National Warning } \\
\text { Phone System }\end{array}$ & $\begin{array}{l}\text { FEMA }^{a} \text { Voice } \\
\text { Network }\end{array}$ & $\mathrm{CG}-230-\mathrm{L}^{b}$ & \\
\hline $\begin{array}{l}\text { Civil Defence } \\
\text { Microwave System }\end{array}$ & $\begin{array}{l}\text { State Civil Defense } \\
\text { Voice Control } \\
\text { Station }\end{array}$ & $\begin{array}{l}\mathrm{CG}-230-\mathrm{L}^{b} \\
1.5 \mathrm{KE} 2(0) \mathrm{C}\end{array}$ & Plug-in MOV \\
\hline $\begin{array}{l}\text { FEMA National } \\
\text { Teletype System }\end{array}$ & $\begin{array}{l}\text { FEMA Data } \\
\text { Network }\end{array}$ & CG-230-L & Plug-in MOV \\
\hline $\begin{array}{l}\text { Idaho Law } \\
\text { Enforcement } \\
\text { Teletype System }\end{array}$ & $\begin{array}{l}\text { Law En" recment } \\
\text { Data Network }\end{array}$ & CG-230-L & Plug-in MOV \\
\hline $\begin{array}{l}\text { Motorola Remote } \\
\text { Handset Control }\end{array}$ & EBS RPU ${ }^{d}$ & $1.5 \mathrm{KE} 2(x) \mathrm{C}$ & Plug-in MOV \\
\hline
\end{tabular}

"FEMA $=$ Federal Emergency Management Agency.

"Installed in U-channel strip on rear of console.

"Located in office area of EOC.

${ }^{d}$ EBS RPU $=$ Emergency Broadcasting System remote pick-up.

The telephone shown in Fig. 43 is a part of the National Warning System (NAWAS) network. This telephone will be protected by installing CG-230-L communications gas gaps from each line to ground in a U-channel grounding strip that will be installed behind the console. The U-channel strip is described in Sect. VI.B.1.

Figure 44 shows the control station for the Civil Defense Microwave System, a part of the Department of 'Transportation microwave network. The control station uses a de current loop to control a microwave transmitter on the Towers Building, approximately $200(\mathrm{ft}$ away. The line on the EOC end will be protected by installing CG-23()-L communications gas gaps in a U-channel strip on the rear of the console.

Second-level protection will be provided by $1.5 \mathrm{KE} 2(0) \mathrm{C}$ bipolar zener diodes installed from line to chassis ground inside the control station. The power for this station will be protected with a plug-in MOV. The microwave network itself will not be protected at this time.

The equipment for the FEMA National Teletype System (FNATS) and the Idaho Law Enforcement Teletype System is shown in Fig. 45. The incoming signal lines to these 
devices should be protected by installing CG-230-L communications gas gaps from line to ground on each incoming pair of wires. The power should be protected by installing a plug-in MOV at the power receptacle that supplics this equipment.

Figure 46 shows the Motorola remote handset control used for the EBS RPU station. The control line should be protected by installing $1.5 \mathrm{KE} 2(0) \mathrm{C}$ bipolar zener diodes from each line to chassis ground in the control station. Additionally, the power should be protected by installing a plug-in MOV and a cube tap at the receptacle that powers the station.

\section{FNARS SHIELDED ROOM}

The primary thrust for updating the EMP hardening of this facility is the protection of the FNARS equipment. A principal component in the FNARS radio equipment protection plan is the shielded room. This room contains the Harris SSB HF transmitter and receivers that will link this facility with the other state and federal facilities. The importanee of this equipment warrants that the integrity of the shielded room be inspected.

The shielded room, positioned in the corner of the communications center, is an 8 by $10 \mathrm{ft}$ enclosure with sheet metal walls inside and out. A metal door has linger stock that forms a radio-frequency (rf) seal around the door. All lines into the enclosure are protected by filtering and transient arresters.

The physical integriiy of the shielded room is considered excellent. Figure 47 illustrates the door into the shiclded enclosure. The finger stock on this door is in good condition and does not require repair or upgrading. The honeycomb filter on the air intake vent, shown in Fig. 48, is intact and clean. Likewise, the honeycomb filter on the exhaust vent is intact, as shown in Fig. 49.

Details of the cable penetration area are given in FEMA Dwg. ()(23-()()6. An elevation view of the penetration area shows the power filters near the top with the signal lines entering below to the left and the coaxial cable penetrations below to the right. Details of the cable layout and recommended protectors are given in the drawing.

The box containing the coaxial cable penetrations is shown in Fig. 50. The 1000-W transmitter lines are protected at the bulkhead by $1000-\mathrm{V}$ gas discharge coaxial protectors, and the 100)-W transmitter line is protected by a $230-\mathrm{V}$ device. One of the receiver inputs is protected by an FCC-250-75-N protector, but the other receive antenna does not have protection installed. An FCC-250-75-UHF coaxial protector should be installed on the second receive line at the bulkhead of the shielded room. Second-stage protection for the Harris receivers should be implemented by installing FCC-450-6.8-BNC coaxial tees at the inputs to the receivers.

Figure 51 shows the protection block for the control and signal lines entering the shielded enclosure. The linss are identified in FEMA Dwg. 0023-(0)6 along with the recommended protectors. The eight conductors on the upper right terminal block are the control lines for the Spira-cone pattern elevation adjustment. The terminal strip has V39ZA6 MOVs installed from the terminals to the copper grounding strip, but the 
terminal blocks are split in the center and bridging clips are not installed. This condition leaves the conductors unprotected because the MOVs are not in the circuit. Either bridging clips or a soldered eopper jumper wire should be installed on these eight lines to ensure that the protectors are connected to the wires entering the shiclded room.

The three thermostat vires on terminals 6,7 , and 8 are protected with V130LA10A MOVs from line to ground. The MOVs on liase lines should be changed to V39ZAf, devices to provide a clipping level that is closer to the $24-\mathrm{V}$ control voltage used for the thermostat.

Telephone pairs on terminals $9 / 10$ and $20 / 21$ are now protected with V130LA10A MOVs. These MOVs should be changed to CG-23()-L communications gas gap devices.

\section{TELEPHONE AND CONTROL LINES}

Telephone and control lines establish a direct connection path by which EMP can reach the electronic equipment within a facility. Measures must be taken to limit the voltages on incoming lines to protect both the equipment that is directly connected to the line and the localized equipment that is subjected to secondarily indueed currents.

\section{A. Telephone Lines}

The telephone company lines enter the building through underground ducts to a telephone terminal area in the Boise State University elassroom. Currently, no gas gaps or earbon blocks are installed on these lines. The FEMA EMP program cannot place protective devices onto telephone company equipment, but it is recommended that the EOC personnel contact the telephone company concerning the installation of a gas discharge arrester block on these lines. Installation of these arresters will provide protection for all equipment in the building from both EMP and the threat of lightning.

The telephone lines that leave the main connection area are routed to localized connection blocks around the building. The connection blocks for the EOC and the communications room are shown in Fig. 52. The covered terminal block in the center of the figure connects a 25-pair cable that is used for the EOC lines. EOC personnel should contact the telephone company concerning the installation of a gas discharge arrester block for this group of lines.

The telephone system in the EOC has a local battery backup system that is charged from a power supply connected to the ac line. A plug-in MOV will be supplied to protect the receptacle that powers the battery charger.

During the survey, EOC personacl expressed interest in the possibility of protecting the internal telephone system. The existing EMP protection program does not extend protection to the full internal telephone system and electronic switchgear. The state does have an unused 8 by $10 \mathrm{lt}$ shielded room however, and this room would make an excellent EMP protection enclosure for the state-owned telephone switching equipment. The conductors for the power ean be filtered, and the penctrations for the telephone lines can have voltage-limiting deviees installed. With proper installation of the equipment in the 
shielded enclosure and with protection devices at the penetration, the internal telephone system could be expected to survive an EMP event.

\section{B. Control Lines}

\section{Communications Room Grounding and Cable Protection}

The control lines entering the EOC communications room from peripheral areas will be protected with communications gas gaps installed in a copper U-channel grounding strip. Protection in this manner will reduce the EMP damage threat to both directly connected equipment and to nearby equipment that may be inductively coupled to the lines. The lines to be protected in this manner include leased pairs and state-owned cables.

It is necessary that a grounding network be established in the communications room to provide for proper installation of the U-channel grounding strips. FEMA Dwg. (K)23-(0)2 shows a floor plan for the communications area. Grounds will be established on the rear of the two console clusters shown in the drawing.

The ground for the shielded radio room is established by eonnection to water pipes and a transformer grounding rod in the subbasement. This grounding network should be extended to the basement level to provide grounds for the equipment in the consoles. Figure 53 shows a penetration at the rear of the console with coaxial cables entering the room. A No. 4 AWG copper conductor should be routed through this penetration, extending from the back panel of the console to the grounding network that will be established in the subbasement. The No, 4 AWG conductor should connect to a 3-in. copper strap that will be attached to the rear of the console. Details of the layout and connection are given in FEMA Dwg. (0)23-(0)7. Ground connections should be made from the copper strap to the National Guard radio, the Harris hl radio, and the Department of Transportation electronic mail system.

A second copper strap should be installed on the rear of the console that is in the eenter of the room. The strap can be grounded by using a No. 4 AWG copper conductor that is routed through an existing penctration to the subbascment grounding system. The penetration is indicated as item 16 in FEMA Dwg. (0)23-002. The copper strap should establish a ground for the packet radio system, the Civil Defense microwave control station, and the NAWAS station.

Figure 54 shows the rear of the eonsole area with the control line terminal blocks. Filteen pairs should be protected by U-channel grounding strips that are mounted to the 3-in. copper strap. CG-23()-L communications gas gaps should be installed on the terminal blocks, from each conductor to the U-channel ground. Details are available in FEMA Dwg. 0)23-007.

\section{Granger Control Cable Protection}

A multiconductor cable extends from the antenna controls in the FNARS shielded enclosure to the pattern control box on the Granger Spira-cone antenna at the roof. The control box used for high/low pattern switching is shown on the right in Fig. 55, with the 
EMP protection boxes for if on the left. The electronics on both ends of the cable are protected by $1.5 \mathrm{KE} 36 \mathrm{~A}$ zener diodes that were installed at the factory. The control cable has additional MOVs installed at the penetration to the shielded enclosure. Guidelines for protection of the Granger equipment are under evaluation, and an addendum to this report will be issued if further protection is determined to be necessary. 


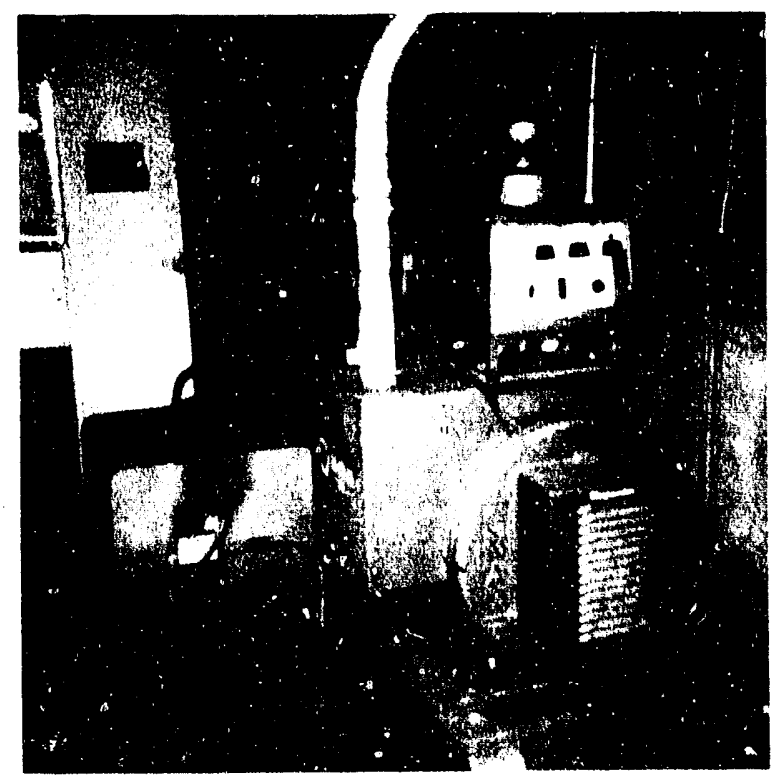

Fig. 1. Emergency generator and day tank. The flexible conduits on the fuel pump have copper jumpers that should remain in place. The generator does not have flexible conduits and requires no jumpers.

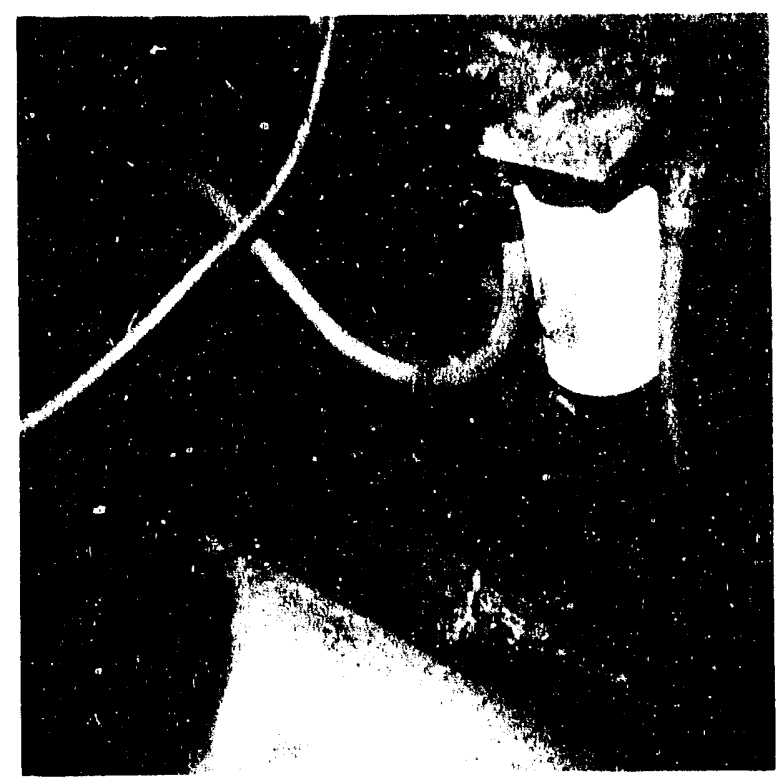

Fig. 2 Starter solenoid for the emergency generator. V39ZA6 MOVs are installed on the solenoid terminals. A bead of silicone rubber cement should tic used to mount the body of the MOV to the solenoid housing. 


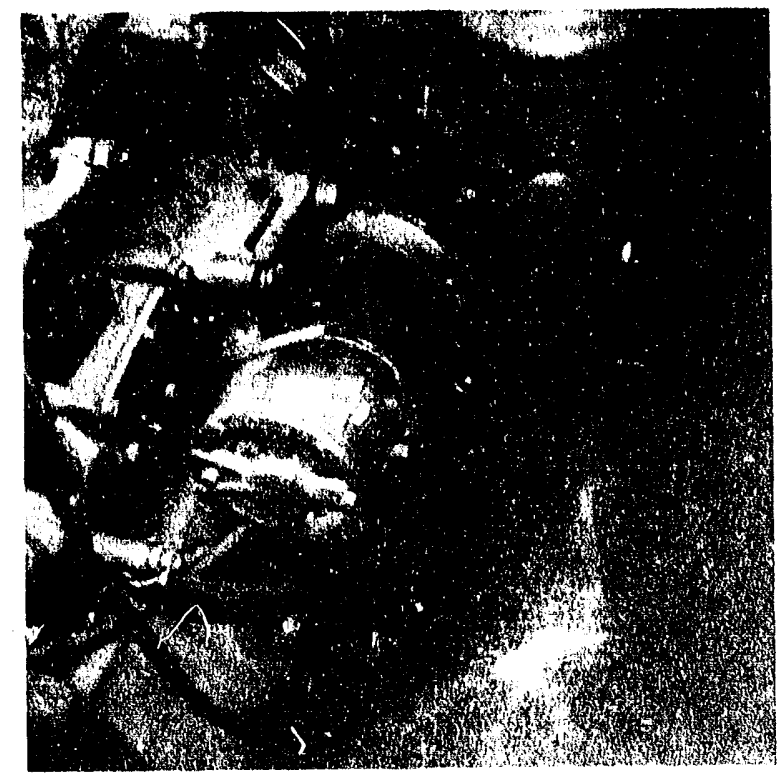

Fig. 3. Battery-charging generator for the emergency generator. The generator and voltage regulator have V130LA10A MOVs installed. A bead of silicone rubber cement should be used to mount the body of the MOV to the generator or voltage regulator.

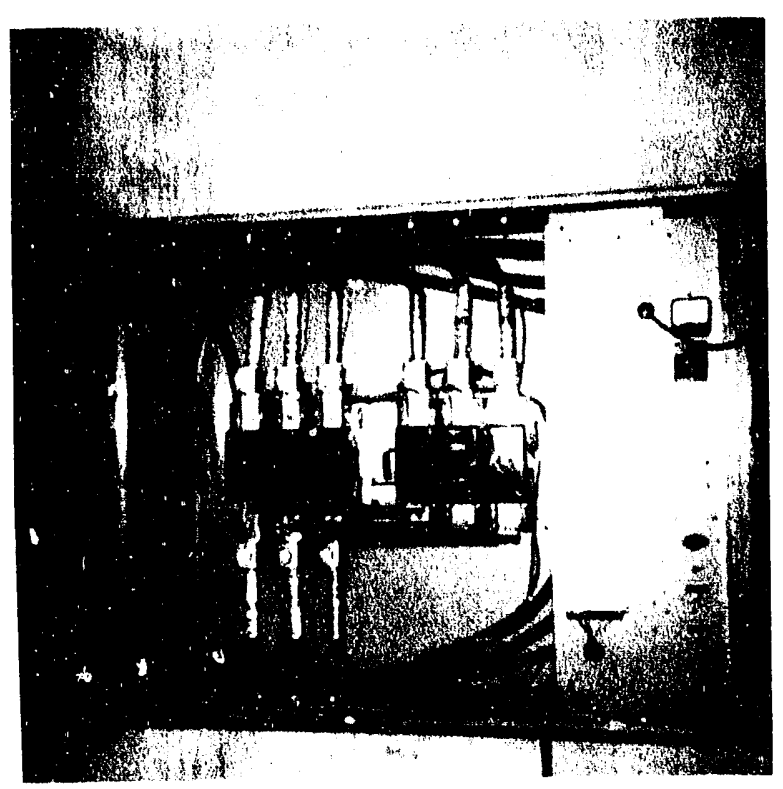

Fig. 4. Automatic transfer switch. The existing V480PA40 MOVs should be removed. V275HE250 MOVs should be installed from phase to ground on the commercial power side of the transfer switch. V275PA40A MOVs should be installed on the load side of the transter switch, from phase to ground. Refer to Appendix B-1 for details of MOV installation. 


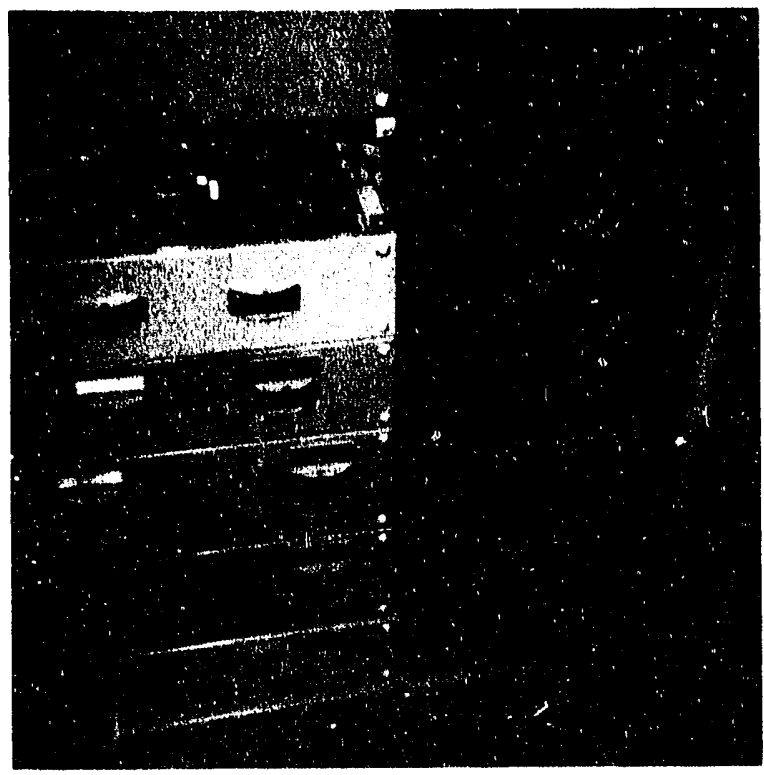

Fig. 5. Panel EM in the equipment room. V275PA40A MOVs should be installed from each phase to ground on the load side of the breaker marked "Panel BHB." The metal plate to the right can be used as ground.

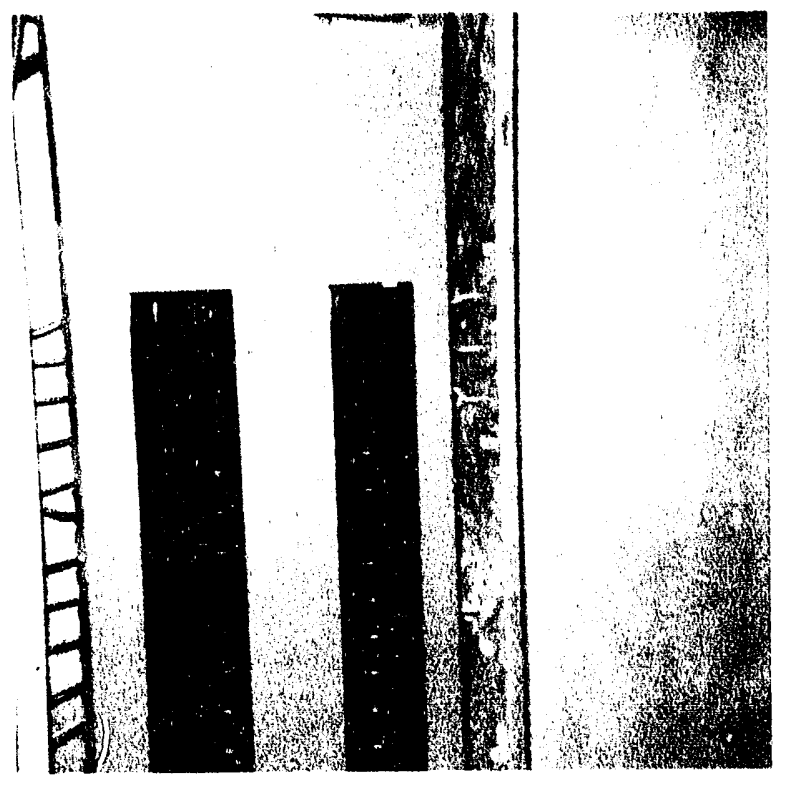

Fig. 6. Power panel BHB. Remove the existing V480PA40 MOVs.

V275PA40A MOVs should be installed on the load side of three adjacent breakers, from line to phase ground. 


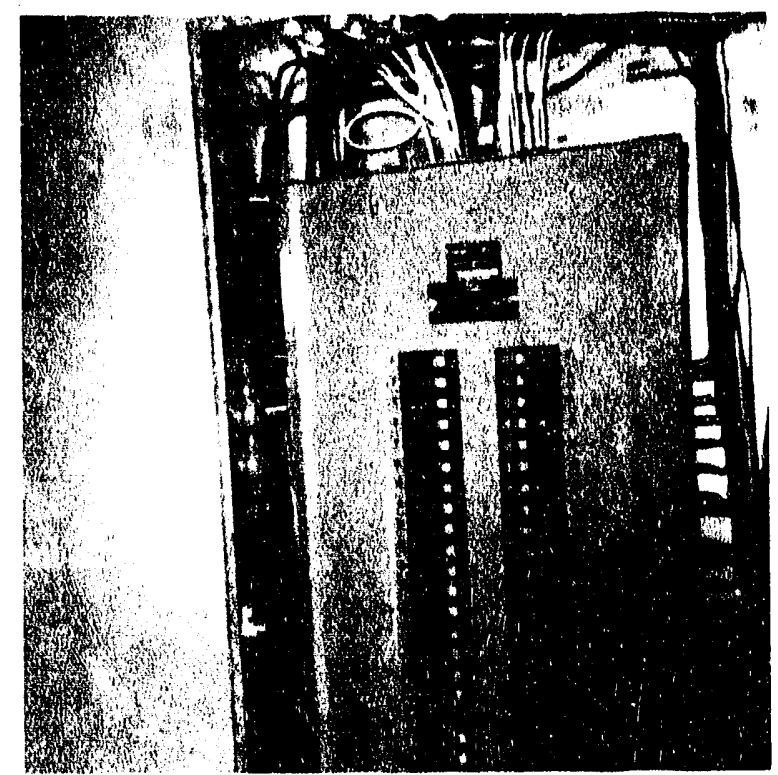

Fig. 7. Power panel BLC. This panel has V130PA20 MOVs installed from each phase to ground and from neutral to ground. These MOVs should be left in place.

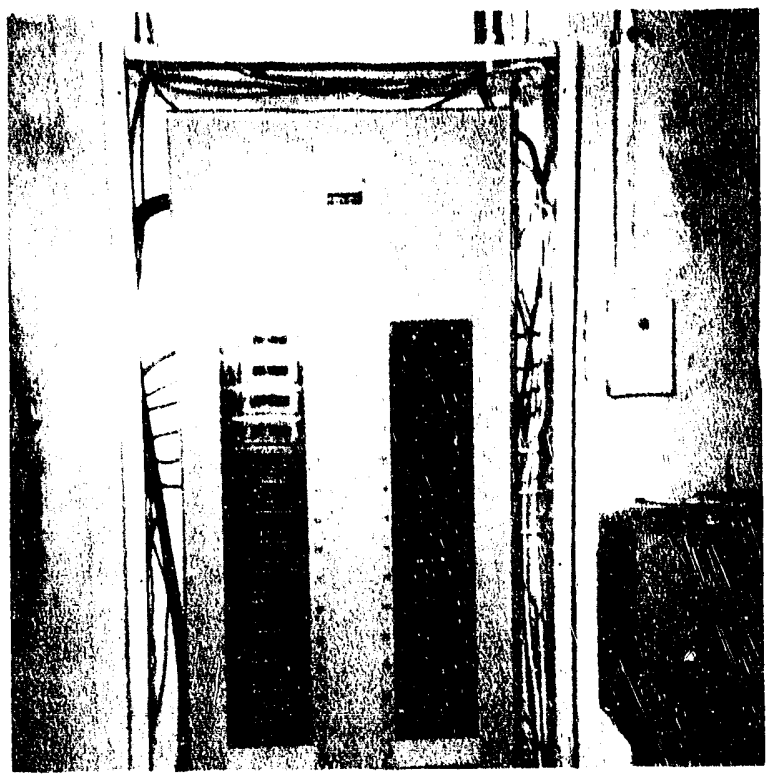

Fig. 8. Power panel HEM in the electrical and mechanical room. The existing V480PA40 MOVs should be removed and replaced by V275PA40A devices, installed from each phase to case ground. 


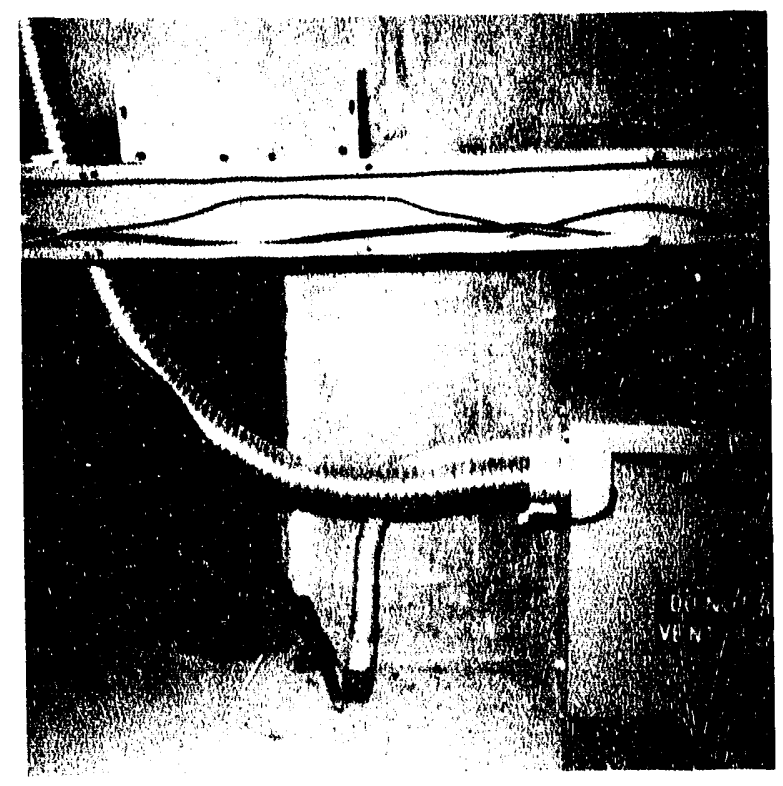

Fig. 9. Step-down transformer TR6 in the subbasement. The flexible conduits should be shunted by No. 4 AWG copper conductors.

Fig. 10. Power pancl LR in Room 57. The pancl has V130PA20 MOVs installed from each phase to ground and is adequately protected. 

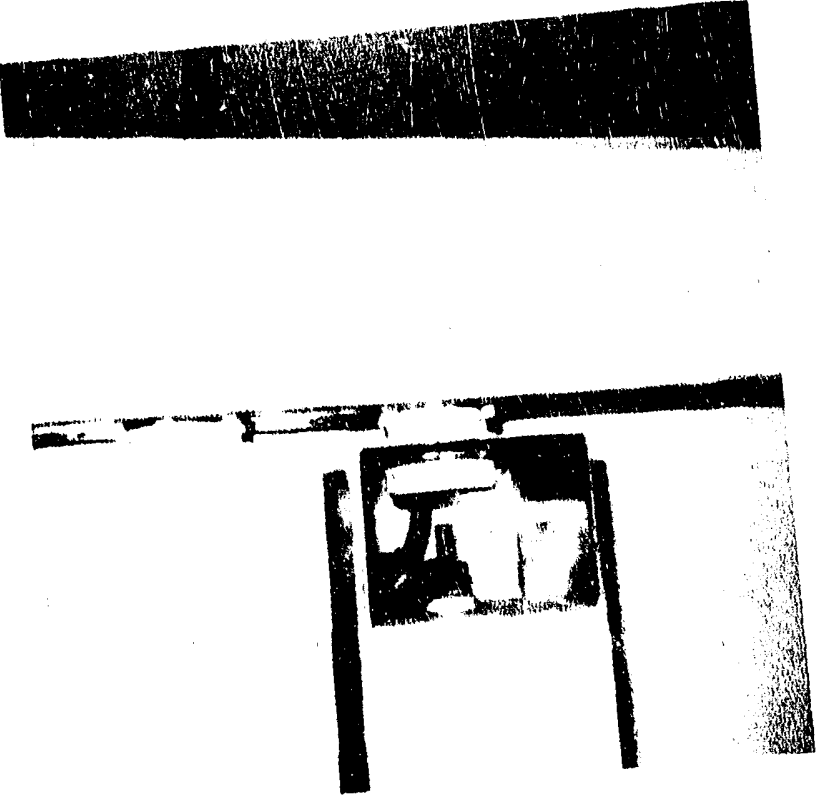

Fig. 11. Input to one of two power fers for the shiclded room. A

PA20A MOV should be installed on the input for each filter, from the line to case ground.

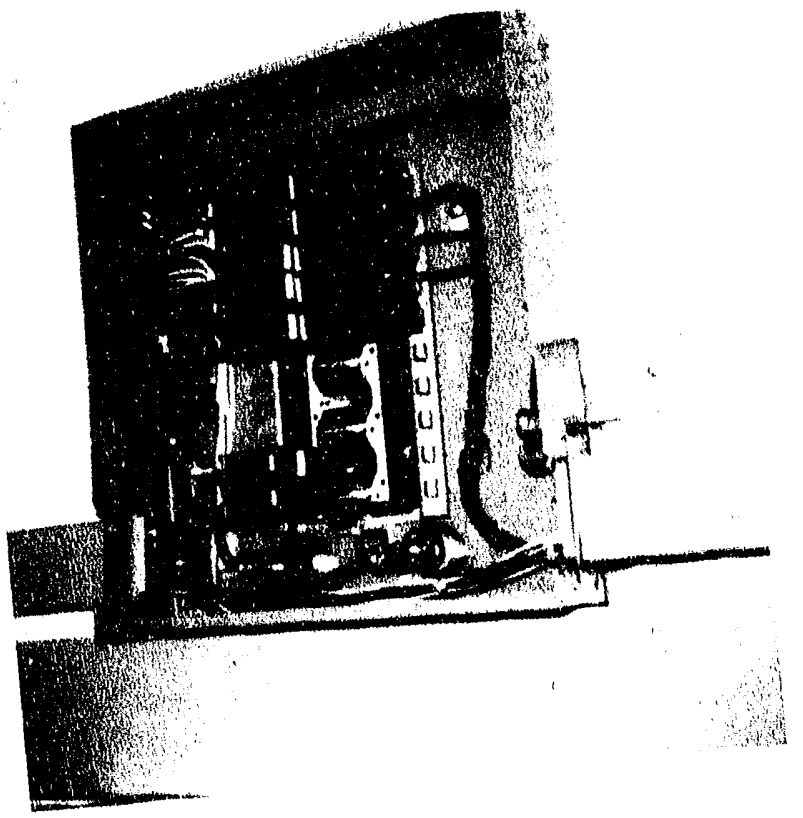

Fig. 12. Power panel inside the room. V130PA20A MOVs shiclded room. should be installed fres to case ground. two adjacent breakers to 


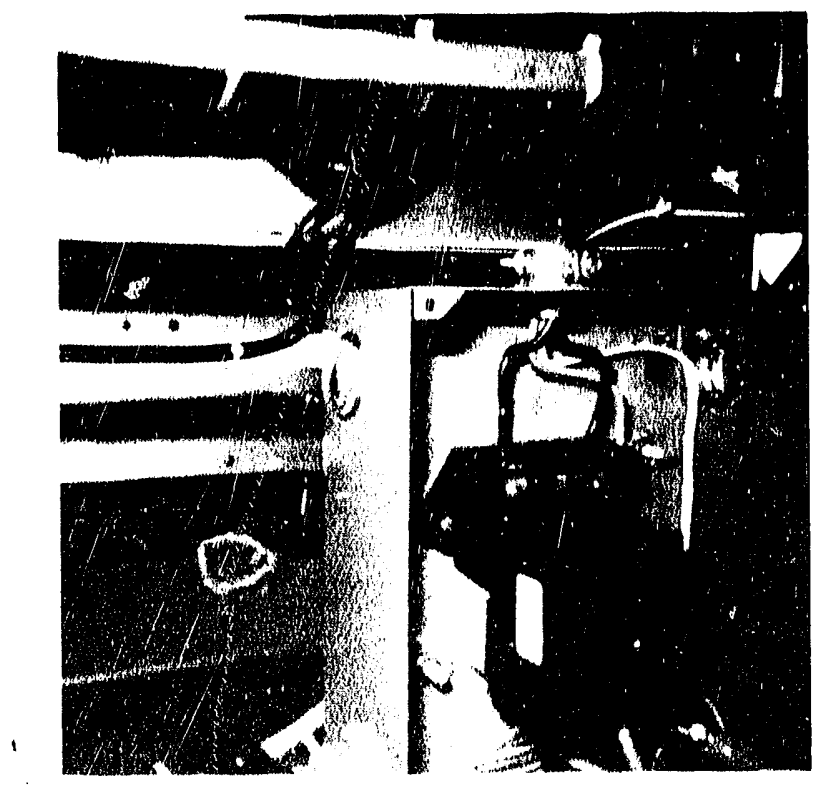

Fig. 13. Circuit breaker box in the Harris transmitter cabinct. V130PA20A MOVs should be installed from the terminals on the load side of the breaker to case ground.

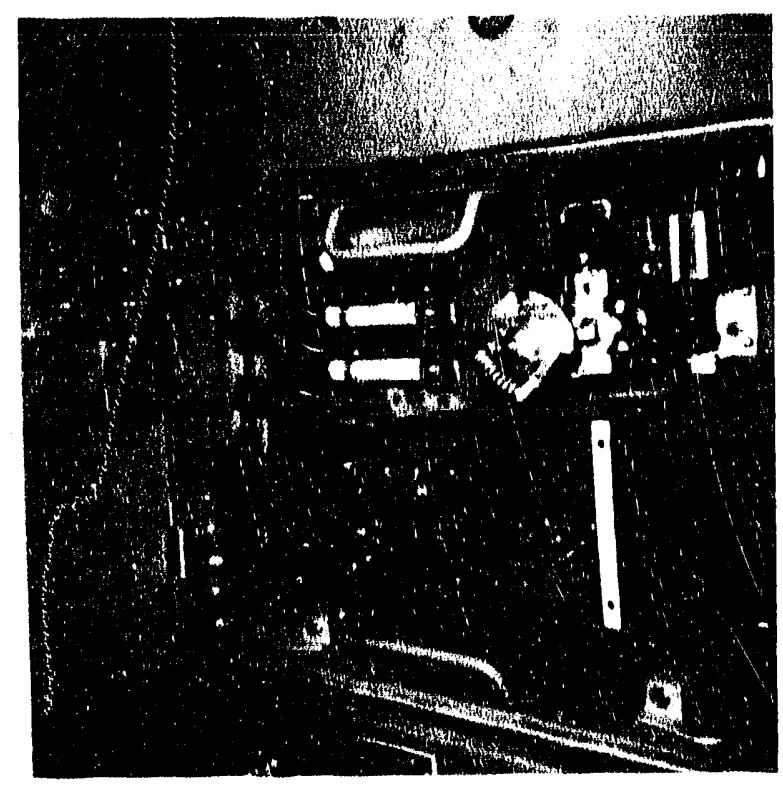

Fig. 14. Motor controller for the emergency well pump. The existing V480PA40 MOVs should be removed and replaced by V275PA40A devices. The control coil has a V130LA10 MOV installed across the coil. 


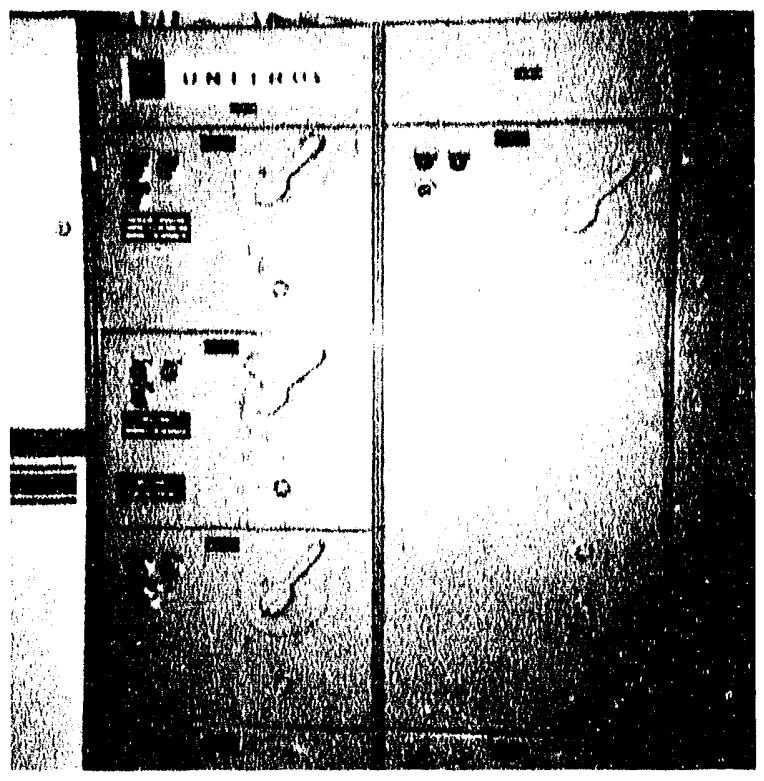

Fig. 15. Overall front vicw of the motor control center. This center controls the well water pump, EOC air supply fan, EOC air return fan, and fire pump. The existing V480PA40 MOVs in each of these contactors should be replaced by V275PA40A devices.

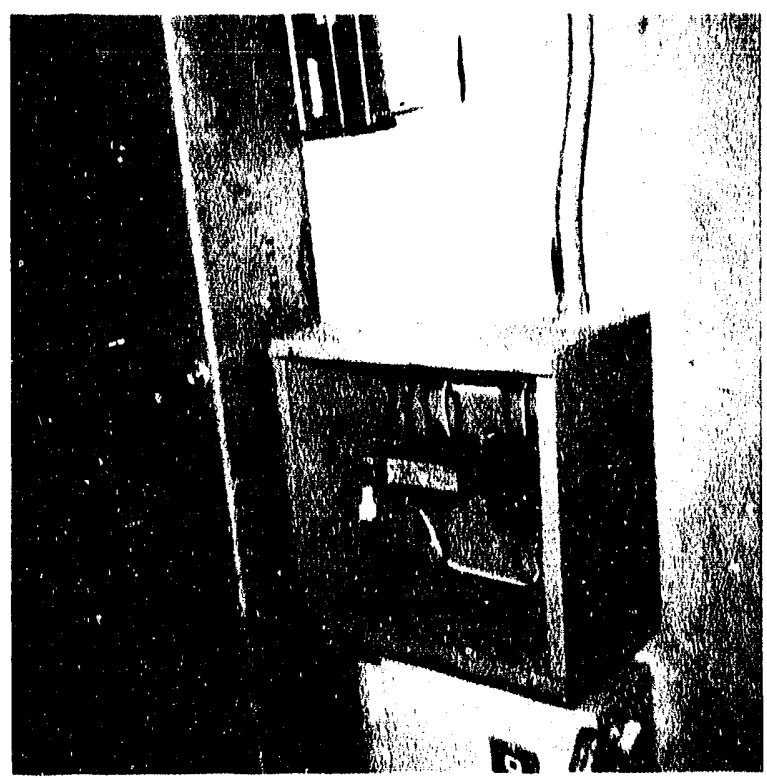

Fig. 16. Control contactor for one of the pumping systems. This contactor is adjacent to power panel HEM and requires no protection. 


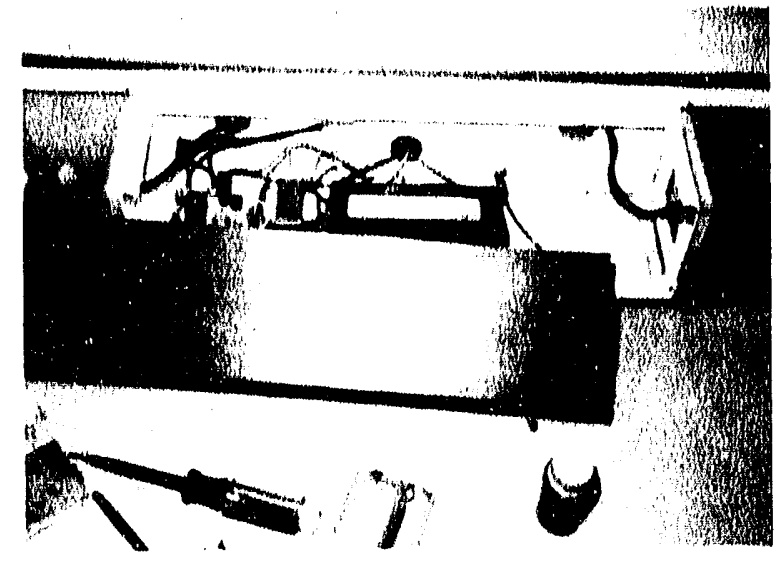

Fig. 17. Emorgency lighting unit for the office area. The light should be protected by installing V130LA10A MOVs on the ac line from hot to neutral and from hot to ground. This light is typical of three units.

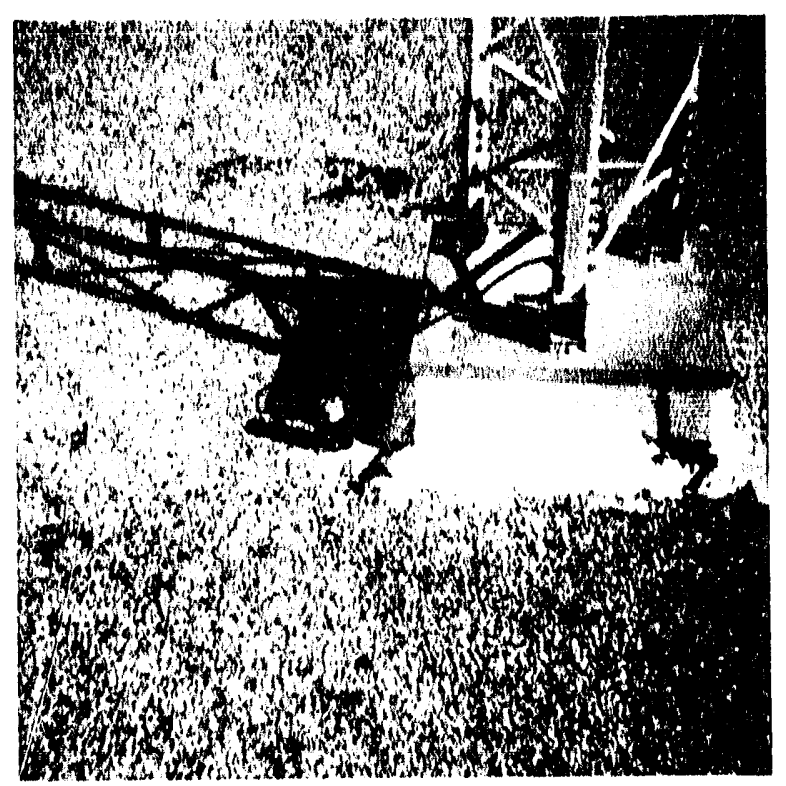

Fig. 18. Base of the Spira-cone antenna. The single No. 8 AWG ground is considered insufficient. The Spira-cone base will serve as the center for the castern portion of a counterpoise. 


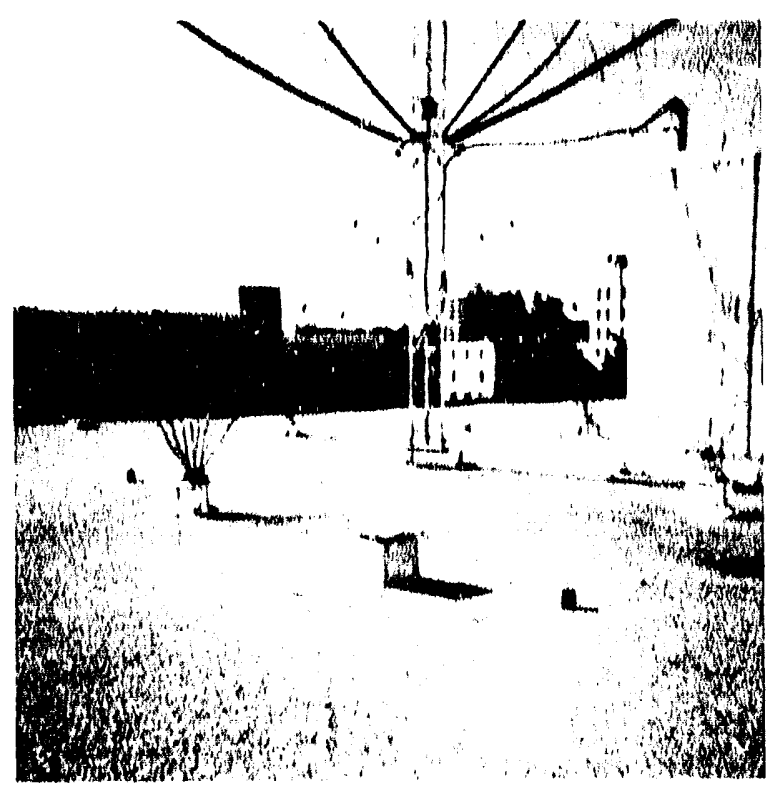

Fig. 19. Spira-cone antenna on the eastern end of the roof. The tower for the Spira-cone will serve as the hub for a counterpoisc.

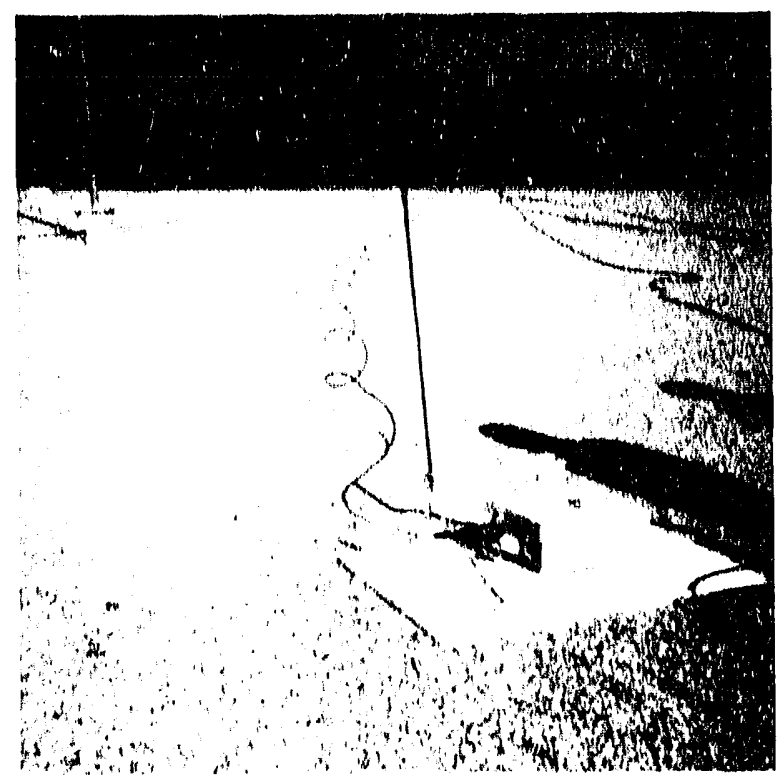

Fig. 20. Balun for the state highfrequency fan doublet antenna. The center of the fan doublet will locate the hub for the western portion of the counterpoise. 

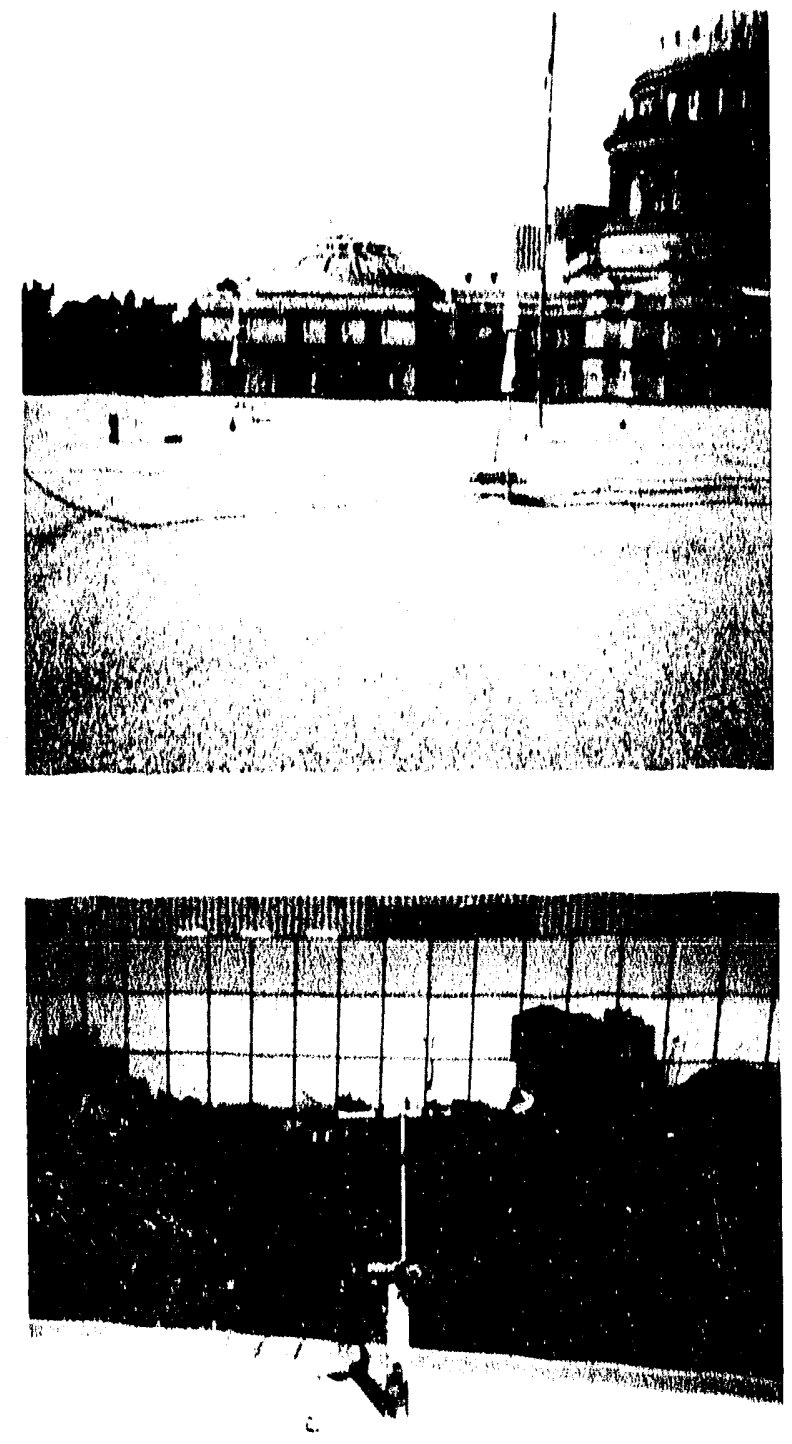

Fig. 21. State antennas on the roof of the building. The antennas for the VHF packet radio, the National Guard radio, a support tower for the fan doublet, and the radiation monitor should all be connected to the counterpoise.
Fig. 22. FM receive antenna mounted on the fire standpipe. This antenna should be relocated to a small mast mount if possible. The standpipe will act as an antenna and should not be attached to the counterpoise. 

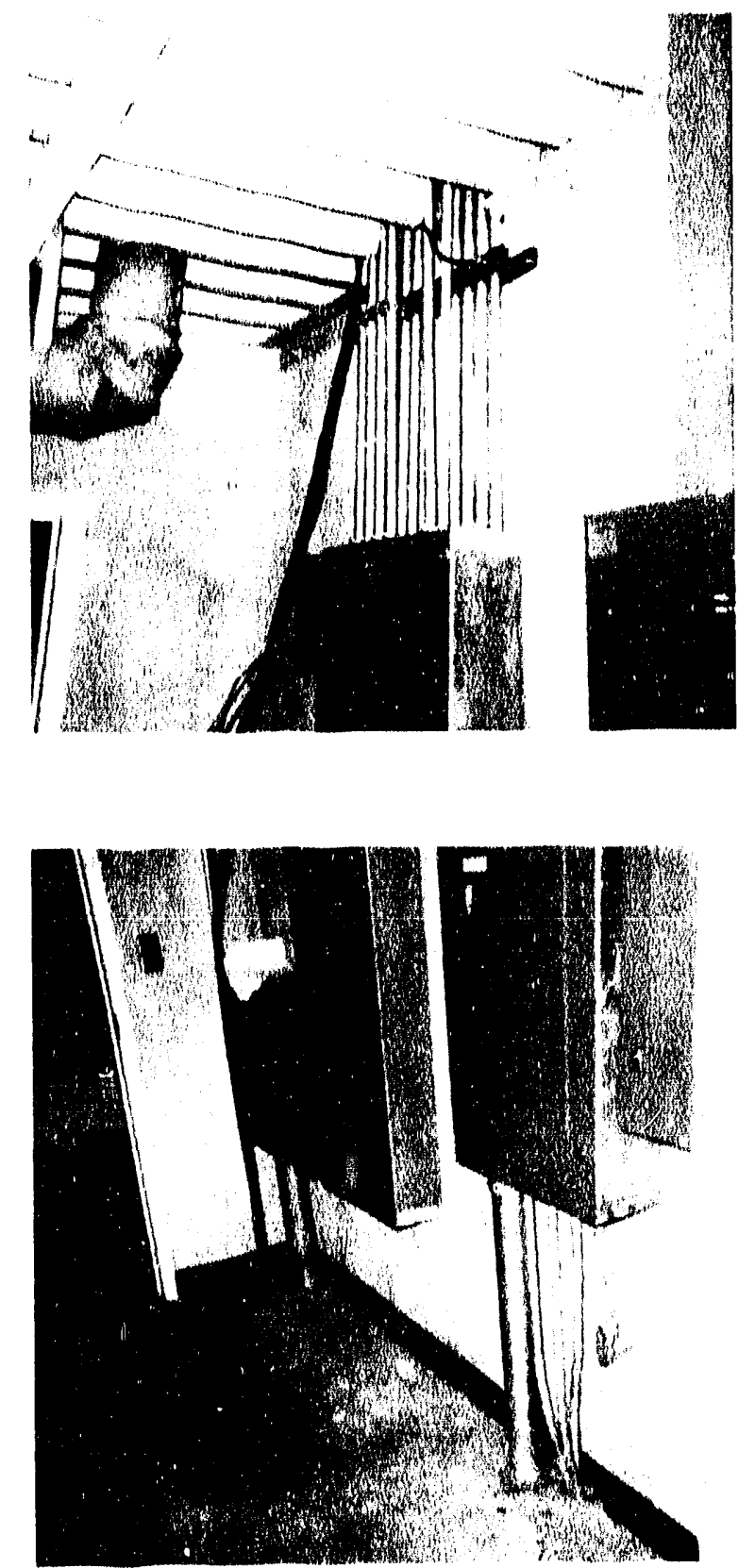

Fig. 23. Entry point for the stato coaxial cables in the third-floor electrical room. The existing ground for the hf balun can be removed after the counterpoise is installed.
Fig. 24. Coaxial cables and conduits in the third-floor electrical room. A No, 4 AWG copper conductor will be routed with the coaxial cables and should be bonded to the 4 -in. conduit with a grounding clamp. 


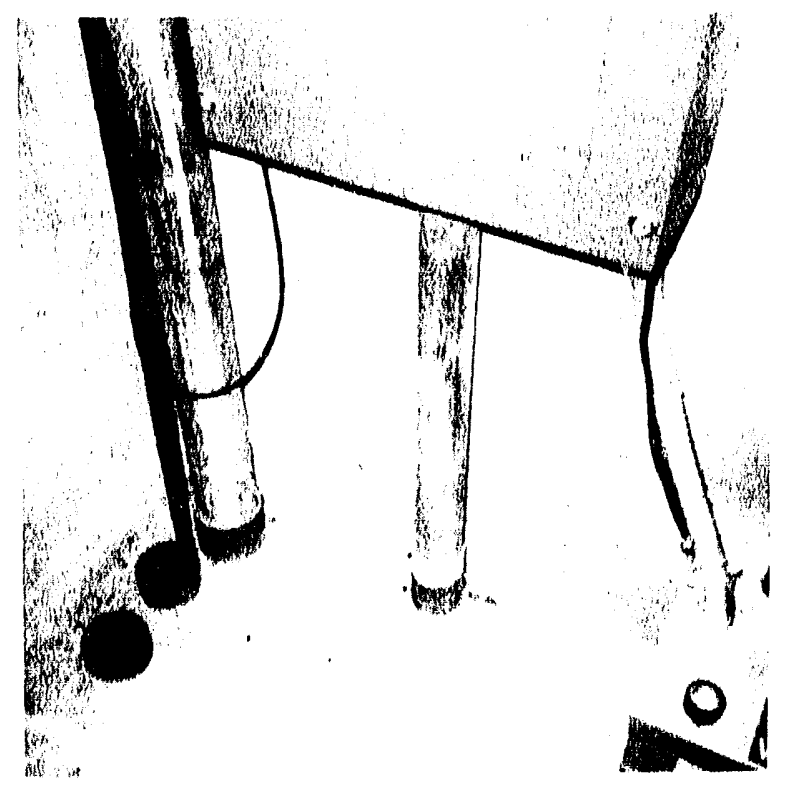

Fig. 25. Coaxial cables and conduits in the basement electrical room. A grounding clamp should be used to bond the No. 4 AWG that is routed with the coaxial cables to the 4-in. conduit.

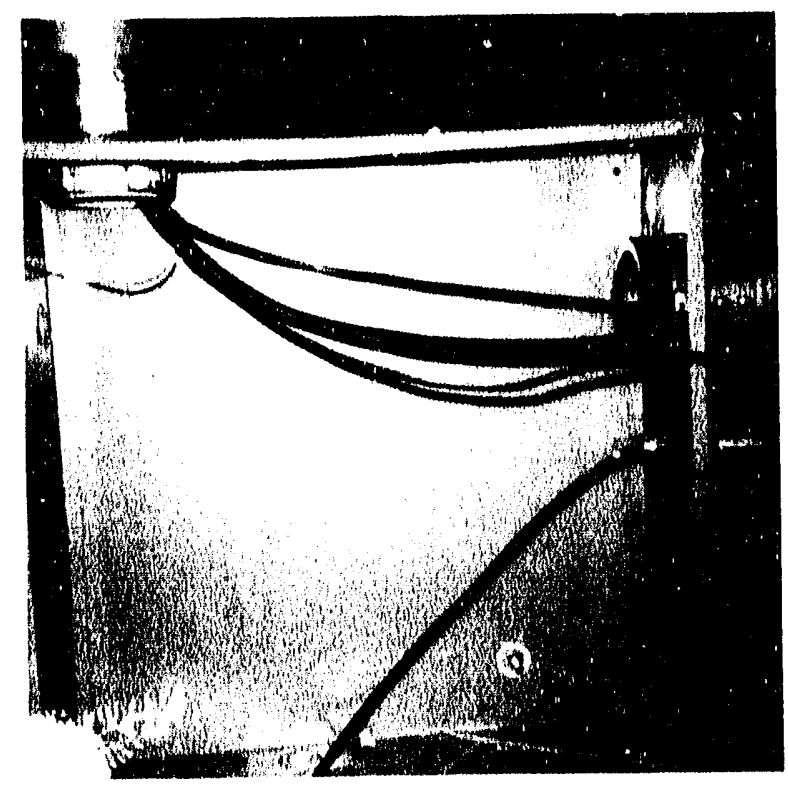

Fig. 26. Junction box in the air ventilation duct adjoining the subbasement. A No. 4 AWG copper conductor should be routed with these coaxial cables. A branch of the copper conductor will connect to three ground rods in the duct. 


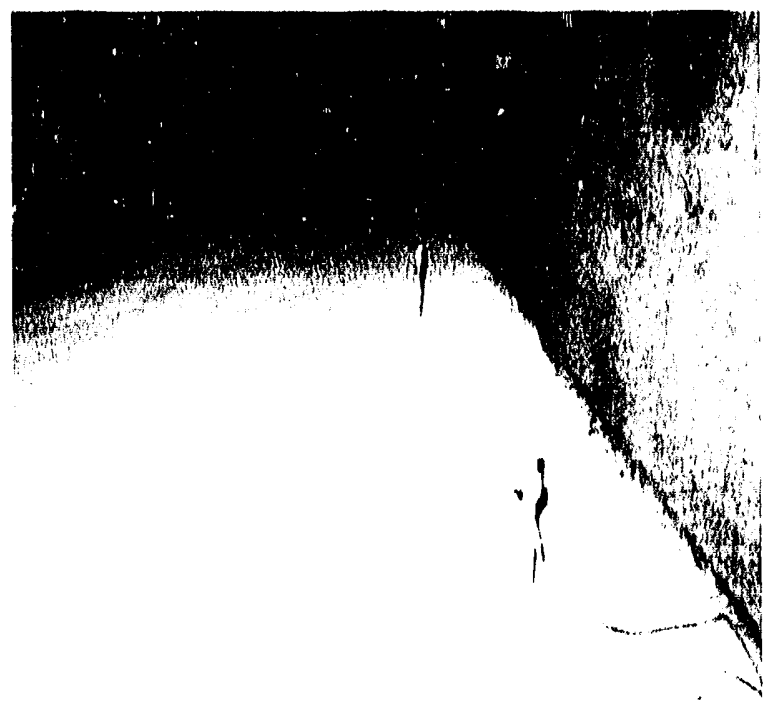

Fig. 27. Three ground rods in the air duct adjacent to the subbasement. A No. 4 AWG copper conductor should be attached to these grounds. The other end of the conductor should attach to the copper conductor that will run with the coaxial cables from the roof.

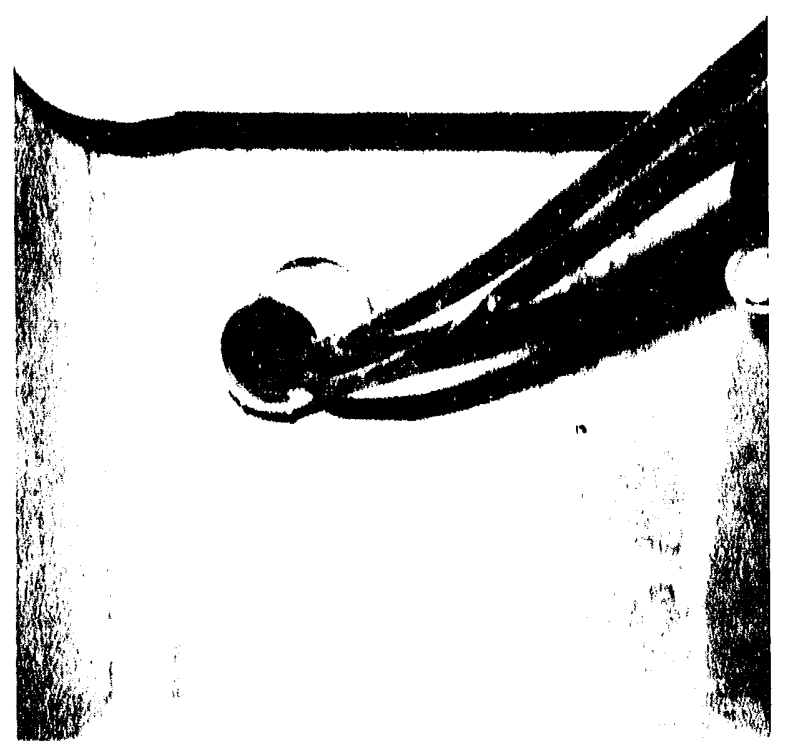

Fig. 28. Penctration where coaxial cables enter the subbasement from the air duct. A No. 4 AWG copper conductor will be routed with these cables. See the text for precautionary notes concerning the door to the right of this penetration. 

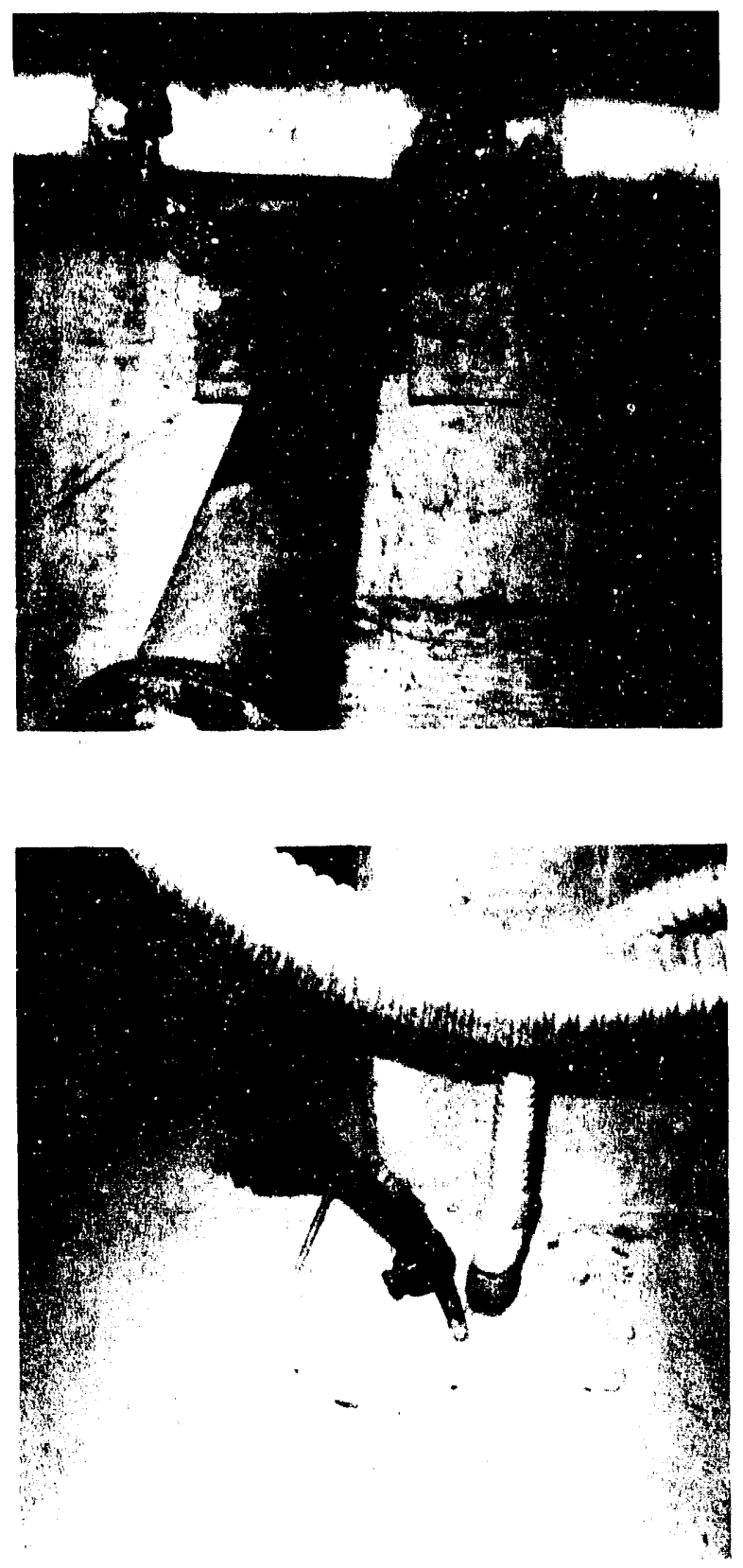

Fig. 29. Point in the subbasement where coaxial shields are grounded. The No. 4 AWG conductor that will be added should ground to these pipes as it passes this point.
Fig. 30. Ground rod adjacent to transformer TR6. This rod will be the terminating point for the No. $4 \mathrm{AWG}$ copper conductor that runs from the counterpoise to the subbasement on the eastern end. 


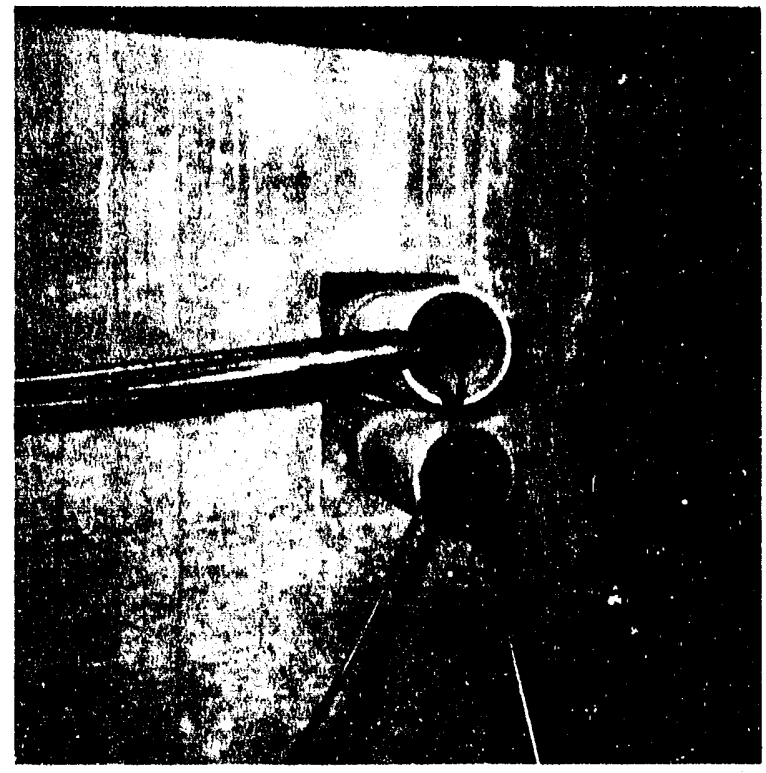

Fig. 31. Penetration for state coaxial cables into the subbasement. A No. 4 AWG copper grounding wire will be added to this bundle, running from the counterpoise to grounds in the subbasement.

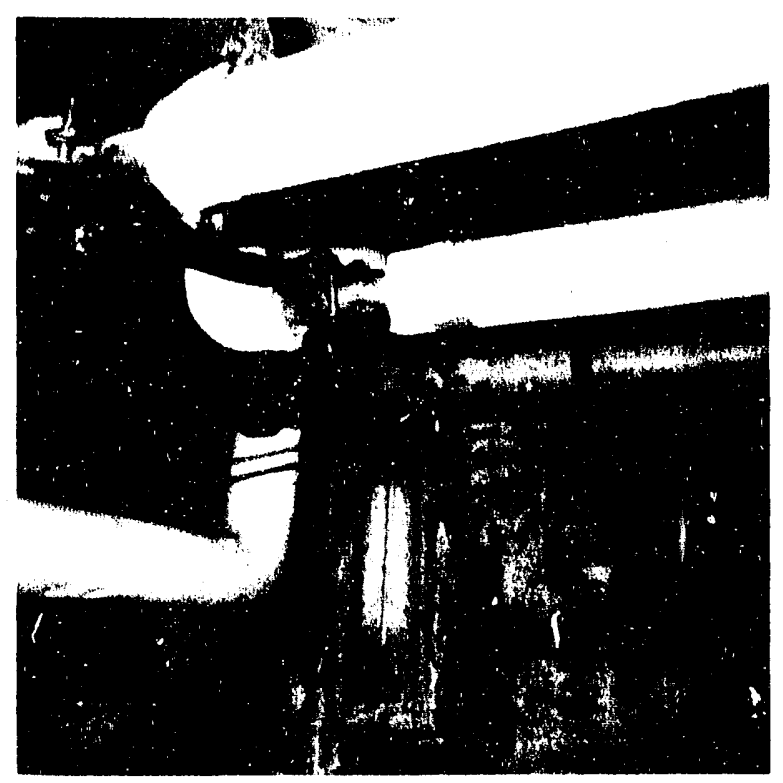

Fig. 32. Water and drain lines used as a ground for the shiclded room. The No. 4 AWG copper conductor from the counterpoise under the state antennas should be attached to these pipes. 


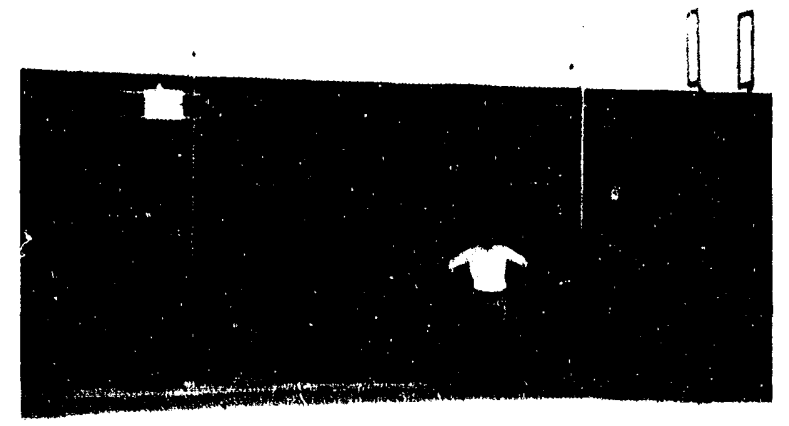

Fig. 33. Remote receive antennas for the Harris system. The vertical whip ard the $B \& W$ antennas are mounted to the metal penthouse on the Towers Building. No additional protection will be installed at this location.

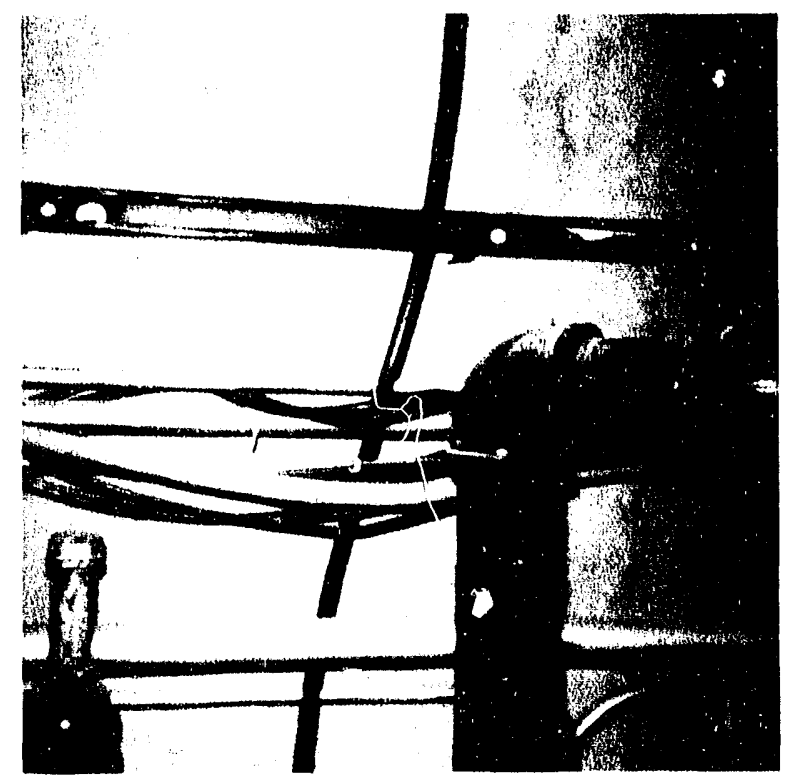

Fig. 34. Coaxial cables from the Harris remote receive antennas. The two RG-213 cables should have the shields grounded to a No. 4 AWG copper conductor that will attach to the well water pipe. Refer to the text and Appendix B-3 for details on coaxial shield grounding. 

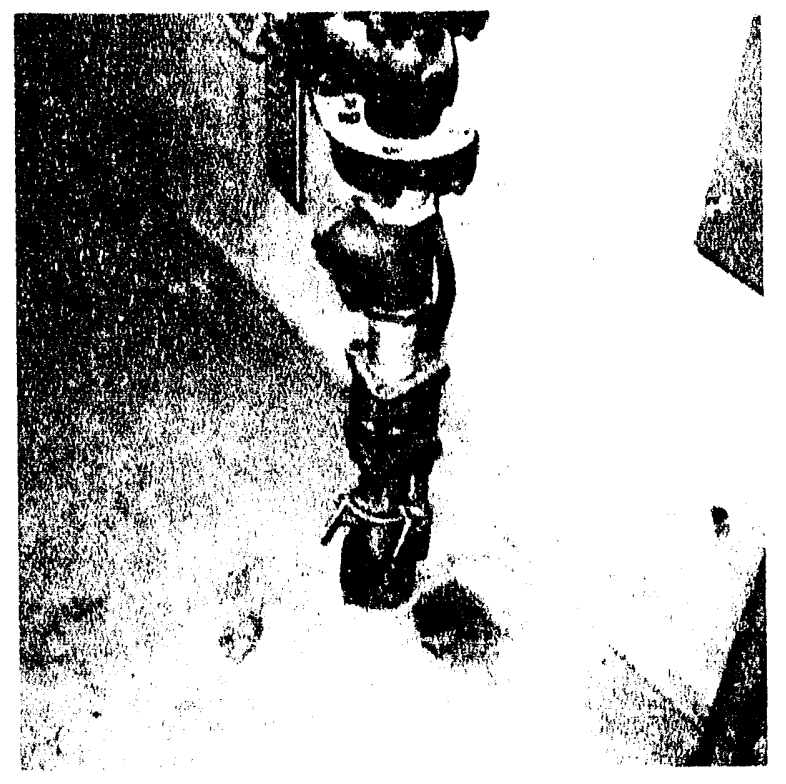

Fig. 35. Well water main supply line. The pipe will serve as a ground for the coaxial cable shields from the Harris remote receive antennas. A grounding clamp should be added beneath the existing clamp.

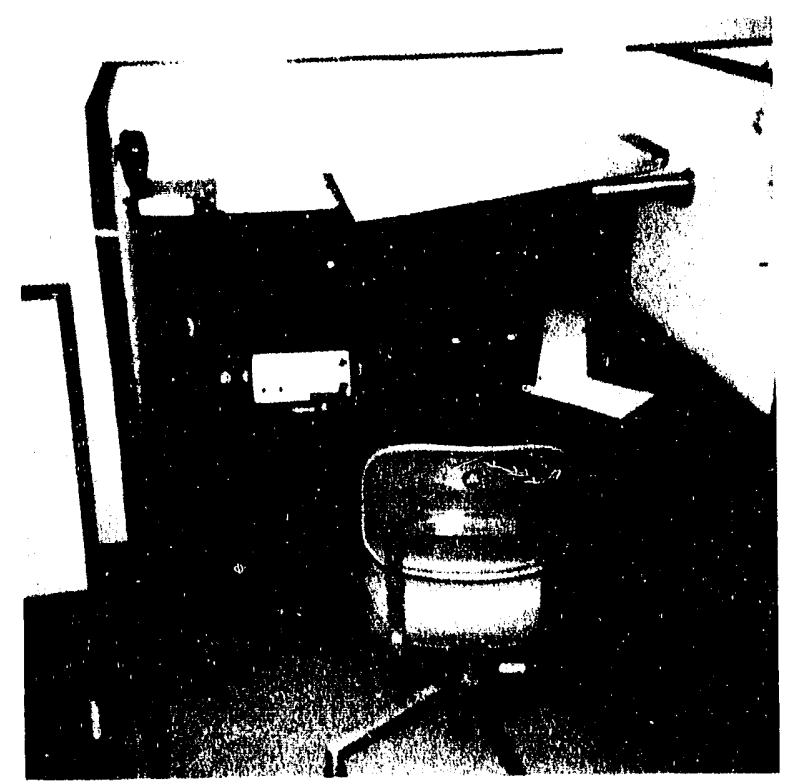

Fig. 36. National Guard radio in the communications room. An

FCC-250-230-UHF coaxial protector should be installed on the antenna line at the rear of the radio. The receiver should be protected by installing an FCC-450-3.3-L diode bridge insicie the radio, on the receive side of the transmit/receive switch. A plug-in MOV should be installed at the power receptacle. 


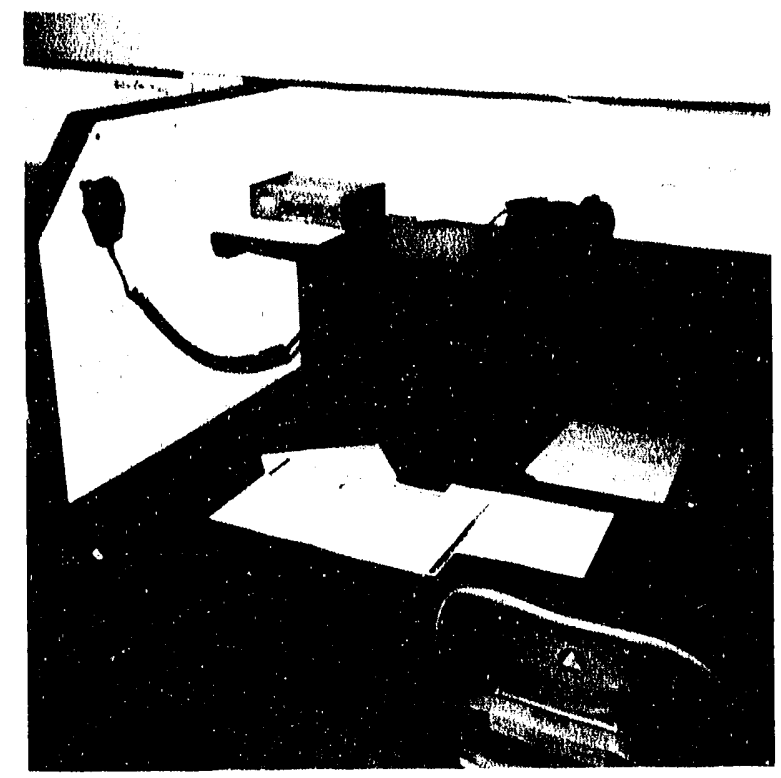

Fig. 37. State Emergency Operating Center high-frequency radio. Protect the transmitter by installing an FCC-250-470-UHF coaxial protector on the antenna line. An FCC-450-3.3-L diode bridge should be installed across the receive line after the transmit/receive switch. The power will be protected by a plug-in MOV at the receptacle.

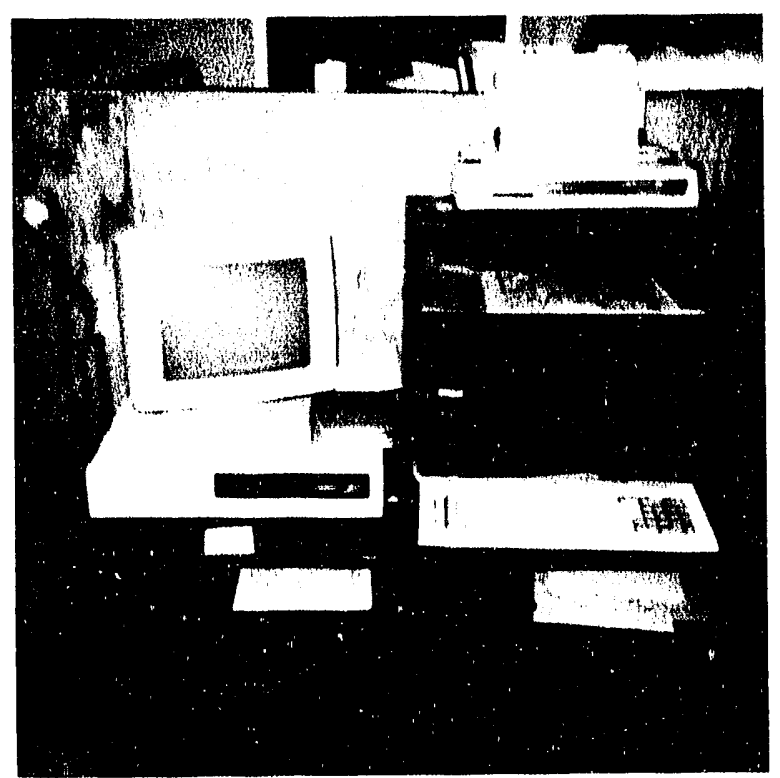

Fig. 38. VHF packet radio system. The radio should be protected by an FCC-250-75-UHF coaxial protector installed on the antenna line at the bulkhead connector in the rear of the cabinet. A plug-in MOV should be installed on the receptacle that supplies the power to the radio. 

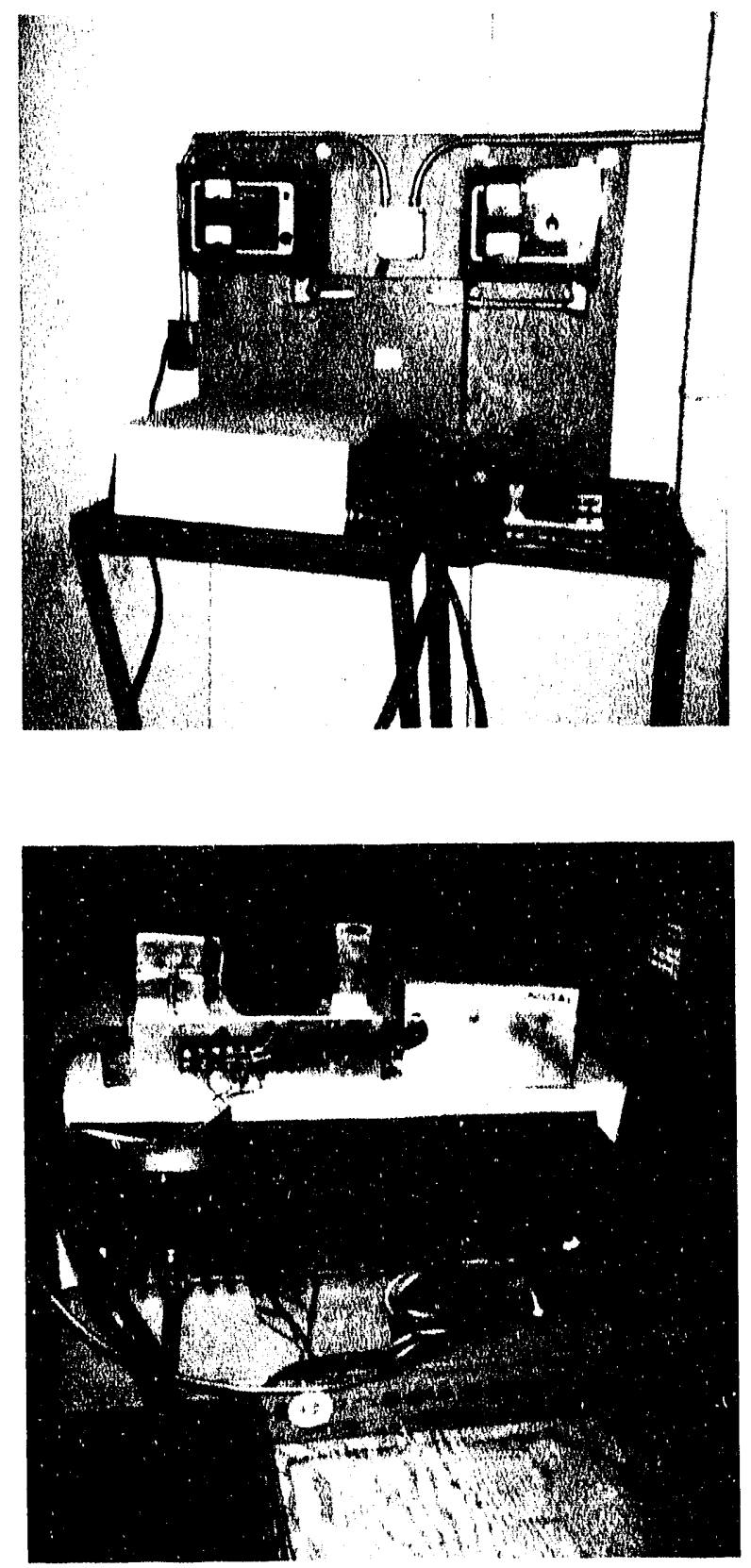

Fig. 39. Emergency Broadcasting System remote pickup in the Hall of Mirrors Building. The transmitter should be protected by installing an FCC-250-230-UHF coaxial protector on the antenna line at the rear of the chassis. The receiver should be protected by an FCC-450-3.3-L diode bridge installed on the receive side of the transmit/receive switch. Protect the control lines by installing 1.5KE200C bipolar zener diodes from each line to chassis ground. Install a plug-in MOV at the receptacle that supplies power to this transceiver.

Fig. 40. Rear of the Emergency Broadcasting System remote pickup in the Hall of Mirrors Building. The antenna line where the coaxial protector will be installed is to the left of the radio. The control lines that will receive the $1.5 \mathrm{KE} 200 \mathrm{C}$ diodes are attached to the screw terminals. 


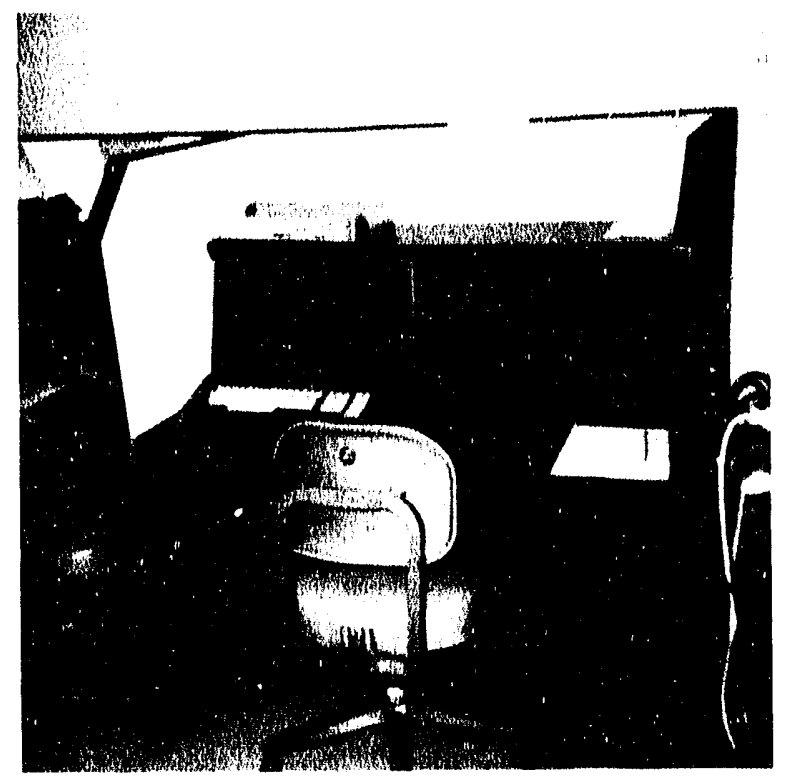

Fig. 41. Datapoint terminal on the Department of Transportation network. Protection for this unit will consist of a plug-in MOV for the power and a coaxial protector for the cable connecting to the modem.

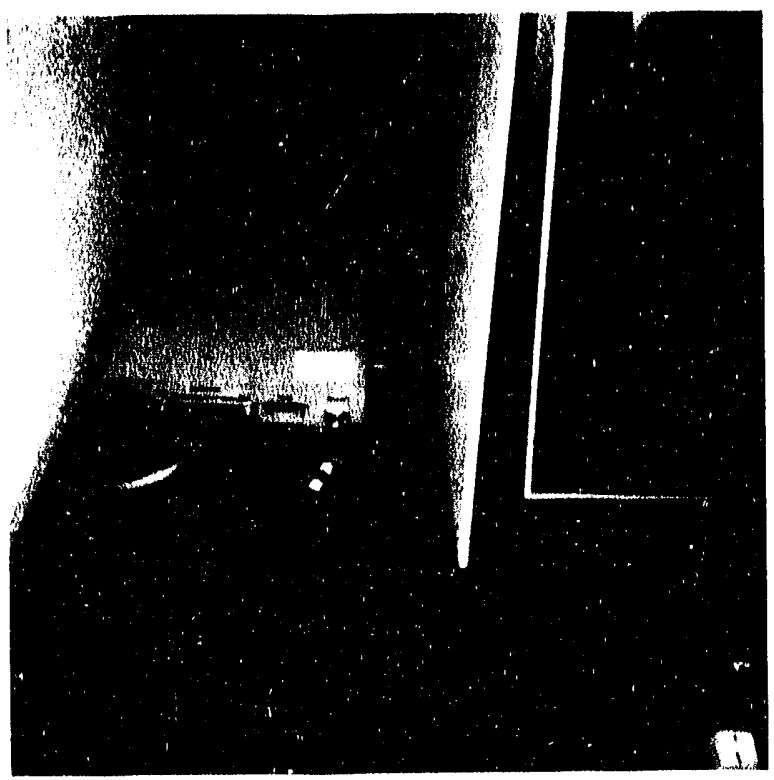

Fig. 42. Modem for the Datapoint terminal. An FCC-45()-3.3-BNC coaxial protector should be installed on the network line at the rear of the modem. 

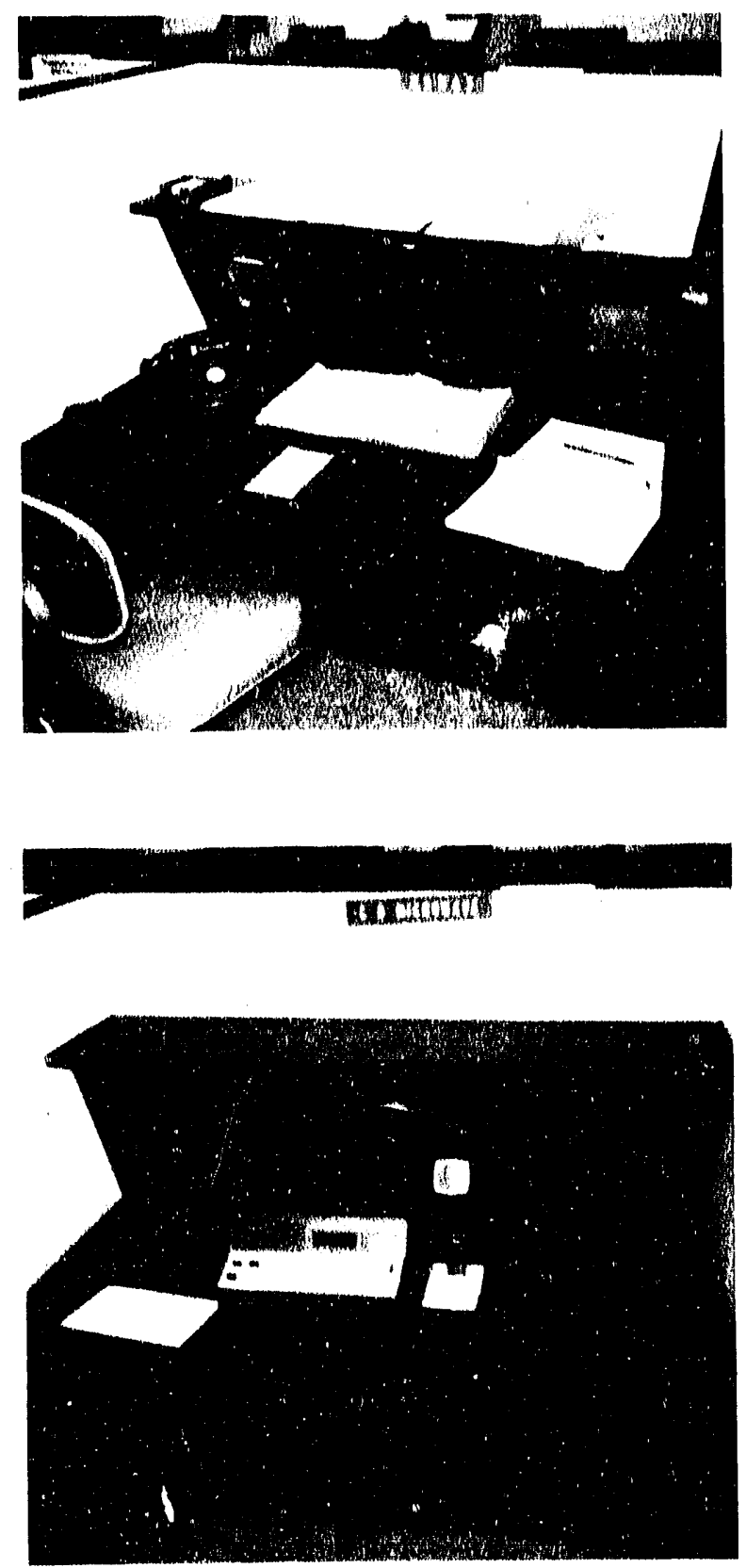

Fig. 43. Telephone connecting to the National Warning System network. The telephone will be protected by installing CG-23()-L communications gas gaps in a U-channel on the rear of the console.
Fig. 44. Control station for the Civil Defense microwave network. The control lines should be protected by installing $1.5 \mathrm{KE} 20(\mathrm{C}) \mathrm{C}$ bipolar zener diodes from each line to chassis ground inside the chassis. The control lines will also have CG-230-L communications gas gaps installed in the U-channel on the rear of the console. A plug-in protector will be added to the receptacle that powers this station. 


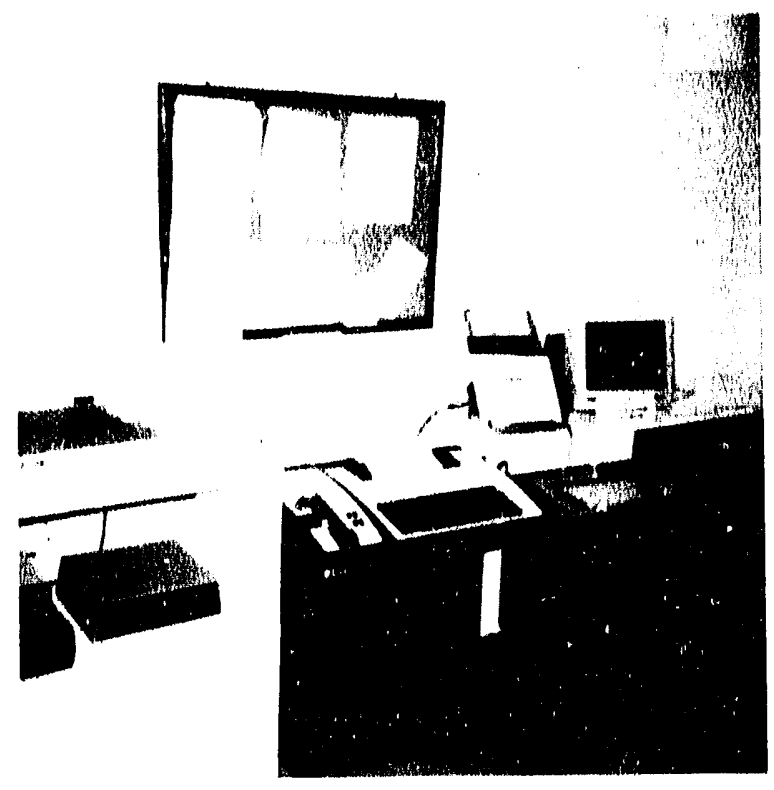

Fig. 45. Equipment for the Federal Emergency Management Agency National Teletype System and the Idaho Law Enforcement Teletype System. The incoming lines should have CG-23()-L communications gas gaps installed from each line to ground. A plug-in MOV will be supplied for the receptacle that powers this equipment.

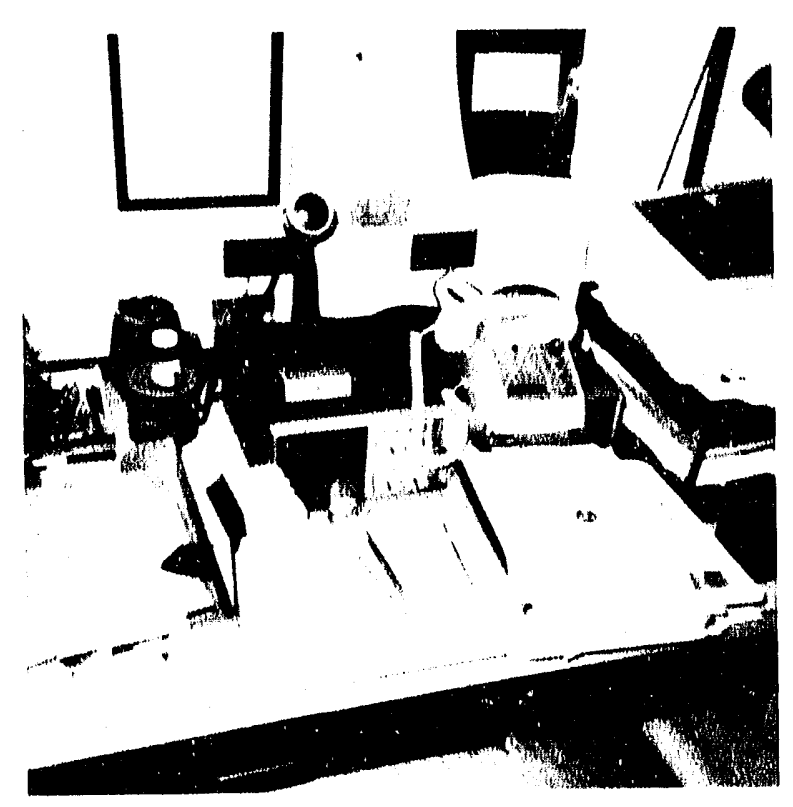

Fig. 46. Motorola remote handset control for the Emcrgency Broadcasting System remote pickup station. Protect the control line by installing $1.5 \mathrm{KE} 200 \mathrm{C}$ bipolar zener diodes from each line to chassis ground on the control lines. A plug-in MOV and grounded cube tap should be installed at the receptacle that supplies power to the station. 


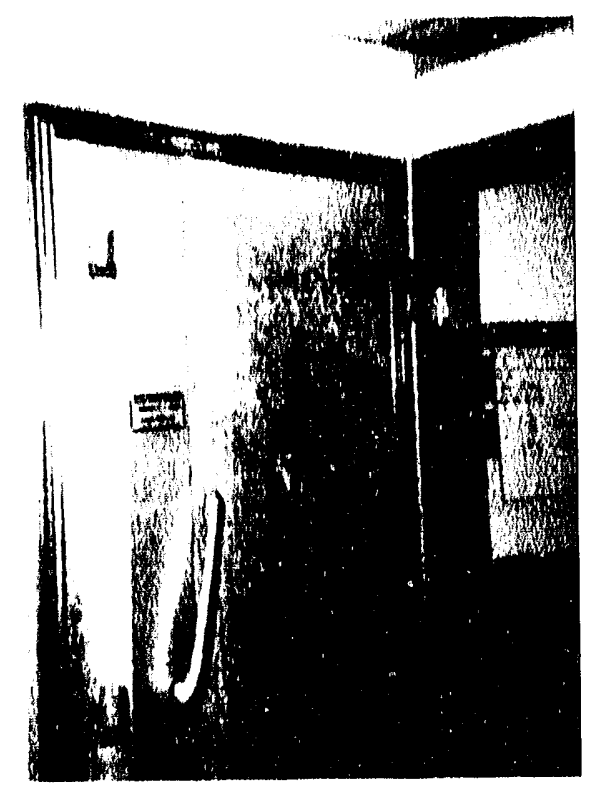

壮

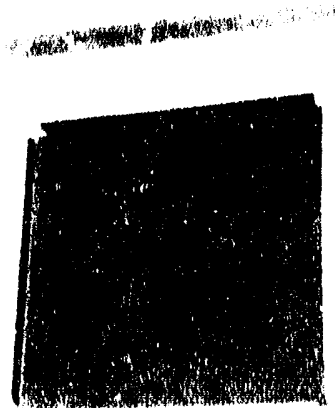

Fig. 47. Entrance door to the shielded enclosure. The finger stock on this door is in good condition and requires no repair or upgrading.
Fig. 48. Honcycomb filter on the air intake for the shielded room. The Honeycomb filter is clean and in good condition. 


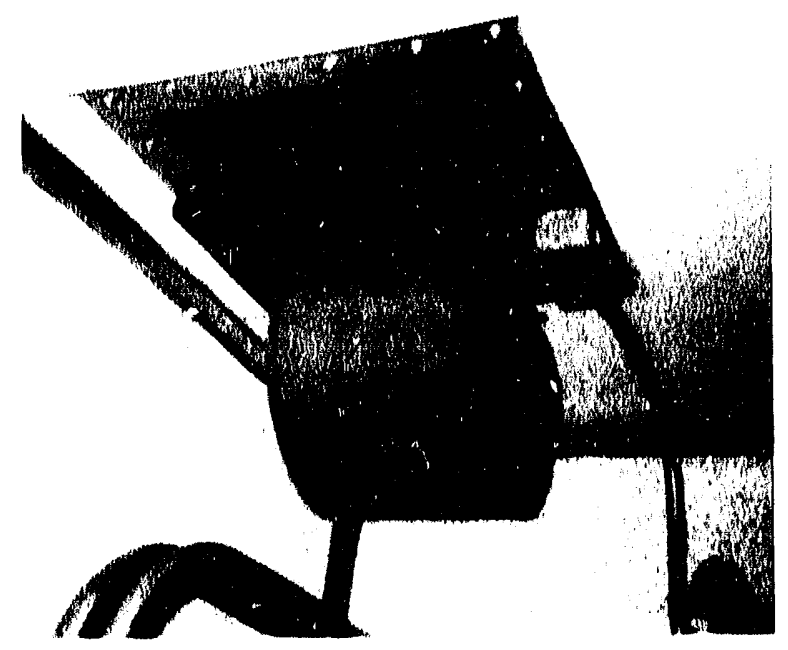

Fig. 49. Fan and honeycomb filter for the air exhaust for the shielded room. The honeycomb filter is intact and requires no attention at this time.

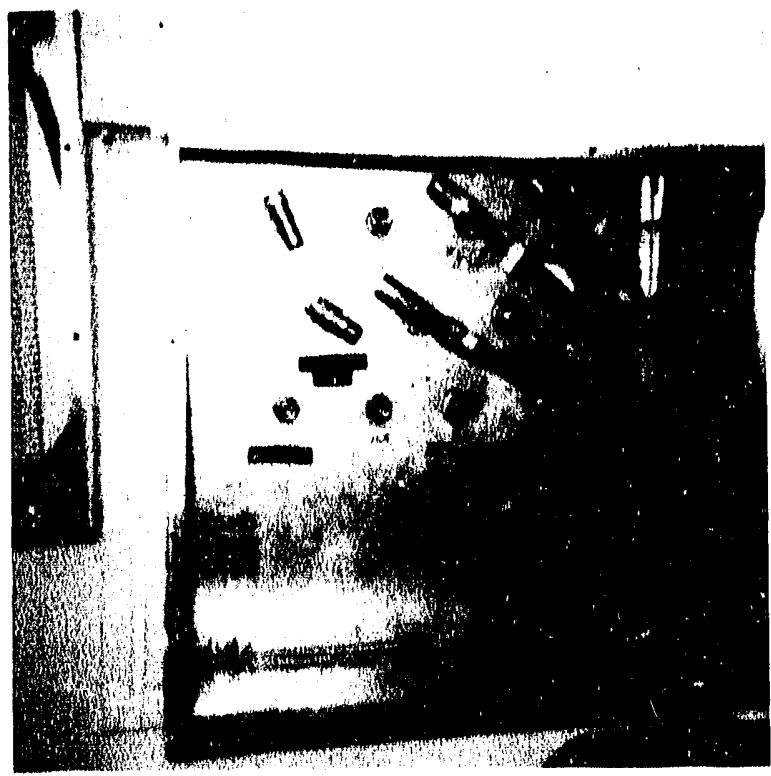

Fig. 50. Coaxial cable penetrations to the shielded room. Coaxial protectors are now installed on all but one receive-only line. This receive cable should be protected by installing an FCC-250-75-UHF coaxial protector at the bulkhead. 


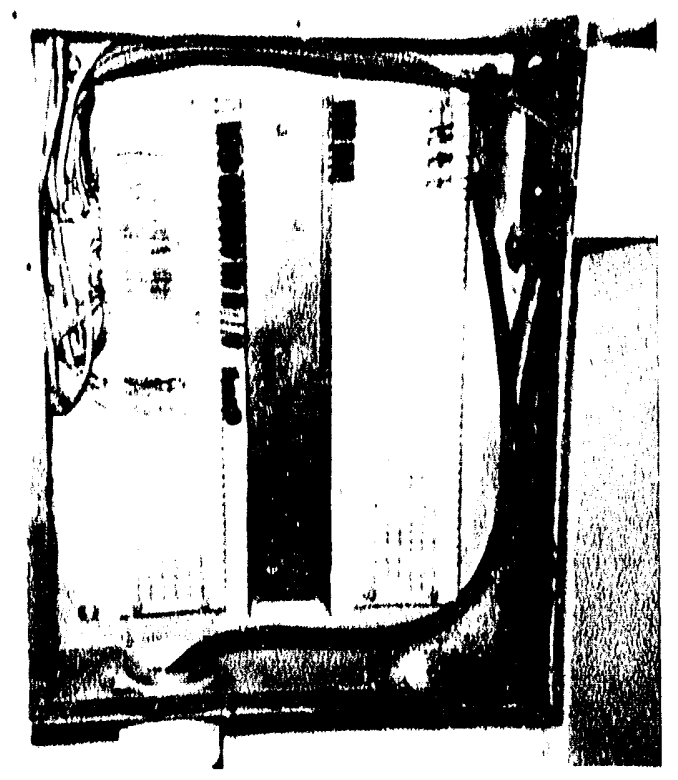

Fig. 51. Protection block for signal lines entering the shiclded room.

Bridging clips should be added to the terminals on the upper right side. Several of the MOVs on the left strip should be replaced. See the text and FEMA Dwg. (0)23-(0)6 to identify the correct protectors.

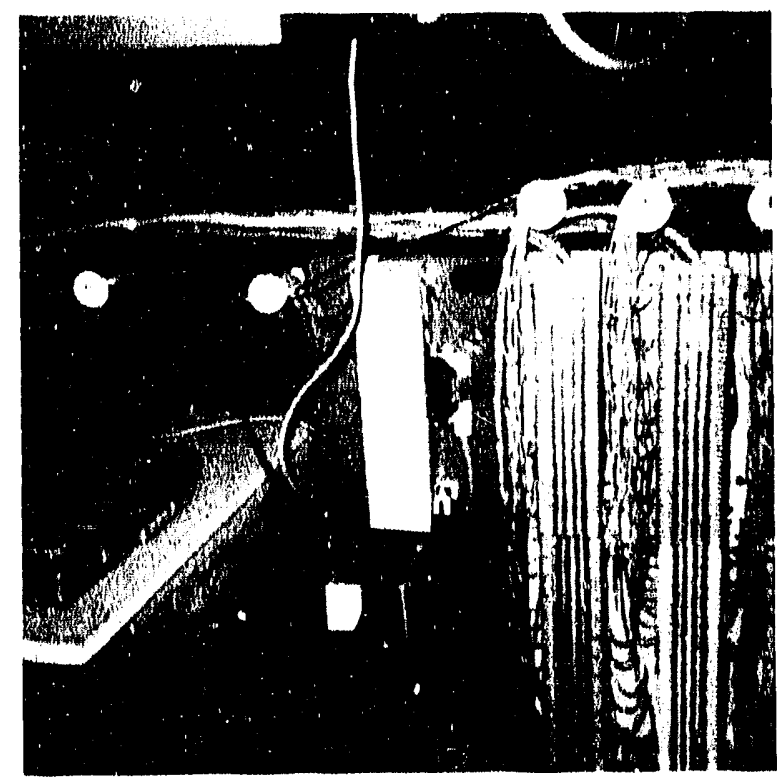

Fig. 52. Telephonc connection blocks for the EOC and the communications room. The EOC personnel should contact the telephone company concerning the installation of a gas discharge arrester block. 


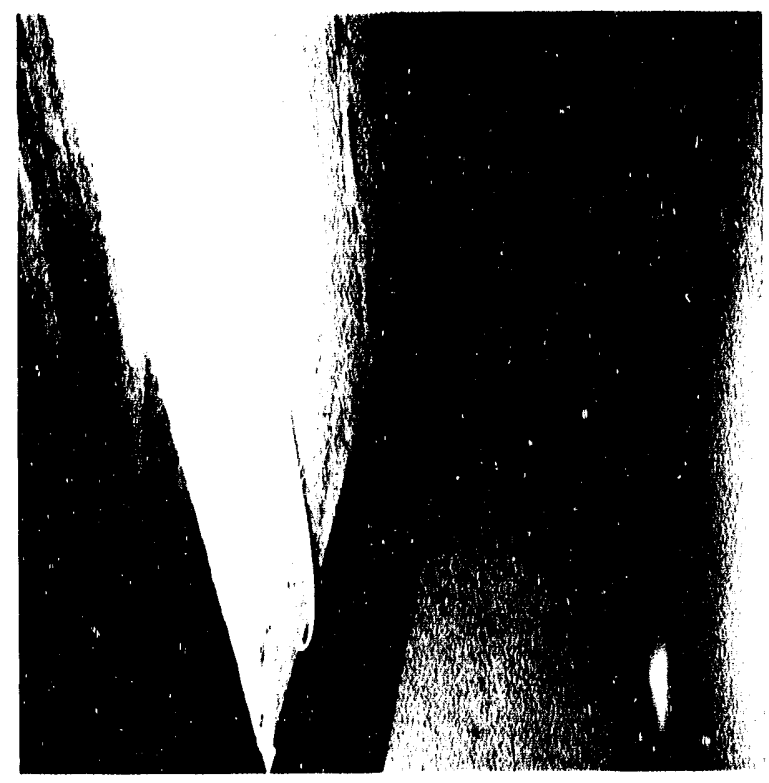

Fig. 53. Penctration at the rear of one console. A No. 4 AWG copper conductor will be routed with these coaxial cables to provide a ground path for a 3-in. copper strip that will be mounted on the rear of the console.

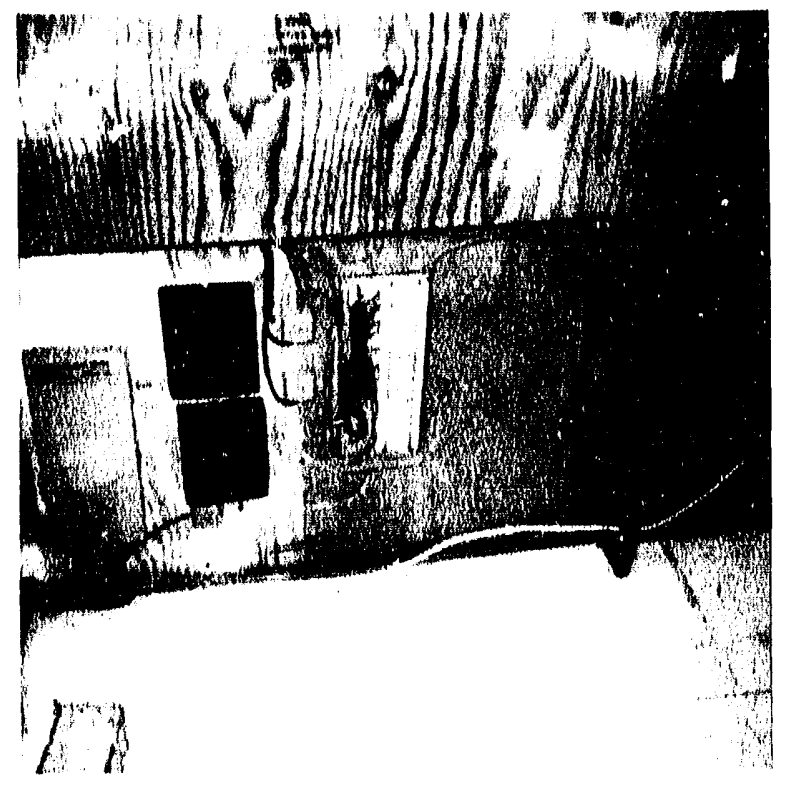

Fig. 54. Rear of the console with control line terminal blocks. Fifteen pairs of wires should be protected by a U-channel with CG-230-L gas gaps installed. Refer to FEMA Dwg. 0023-007 for details of the installation. 


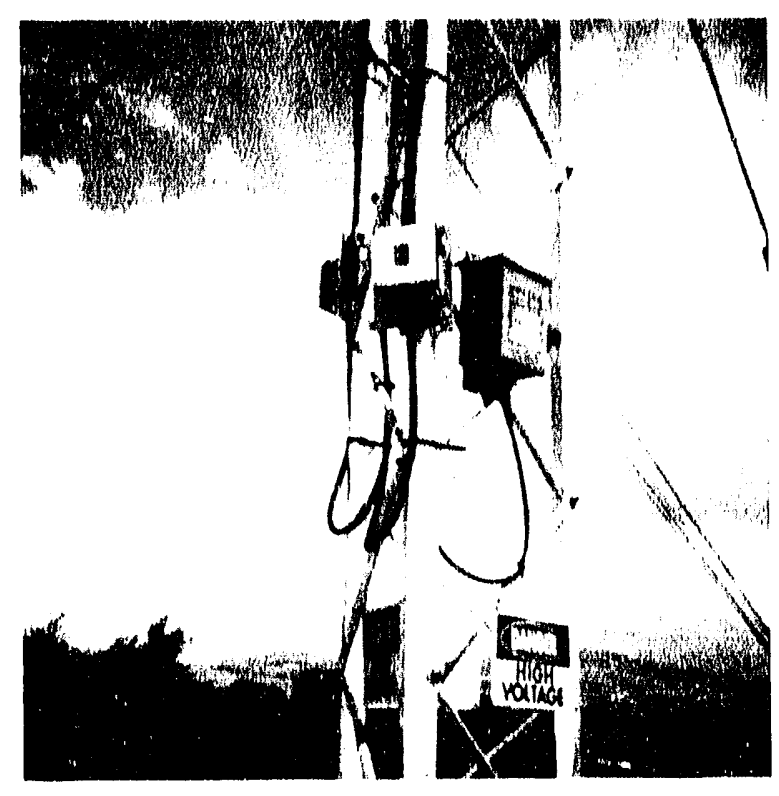

Fig. 55. Control box for the high/low switch on the Granger Spira-cone antenna. The electronics in the control are protected by $1.5 \mathrm{KE} 36 \mathrm{~A}$ zener diodes. 


\section{APPENDIX A-1}

Electromagnetic Pulse Materials List for

Idaho State Emergency Operating Center, Boise, Idaho

\begin{tabular}{|c|c|c|c|c|c|}
\hline \multirow{2}{*}{$\begin{array}{l}\text { Stock } \\
\text { code }\end{array}$} & \multirow{2}{*}{$\begin{array}{l}\text { Description } \\
\text { FCC-250-75-UHF coaxial tee }\end{array}$} & \multicolumn{2}{|c|}{ Quantity } & \multicolumn{2}{|c|}{$\begin{array}{l}\text { FEMA } \\
\text { symbol }\end{array}$} \\
\hline & & 2 & ea & 1 & $\mathrm{a}$ \\
\hline 55001 & FCC-250-230-UHF coaxial tec & 3 & $\mathrm{ca}$ & 1 & $\mathrm{c}$ \\
\hline 55003 & FCC-250-470-UHF coaxial tec & 7 & ea & 1 & o \\
\hline 55008 & FCC-450-3.3-UHF coaxial tec & 1 & $\mathrm{ca}$ & 1 & 1 \\
\hline 55016 & FCC-450-3.3-BNC coaxial tec & 1. & ea & 1 & $\mathrm{i}$ \\
\hline 55017 & FCC-450-6.8-BNC coaxial tec & 2 & ea & 1 & $\mathrm{k}$ \\
\hline 55019 & FCC-450-3.3-L diode bridge & 3 & $\mathrm{ca}$ & 3 & $\mathrm{a}$ \\
\hline 55022 & V-39-ZA-6 MOV & 3 & $\mathrm{ca}$ & 4 & ea \\
\hline 55025 & V-130-LA-10A MOV & 6 & ea & 4 & $\mathbf{a}$ \\
\hline 55026 & V-130-PA-20A MOV & 6 & ea & 4 & $b$ \\
\hline 55030 & $\mathrm{~V}-275-\mathrm{HE}-250 \mathrm{MOV}$ & 3 & ea & 4 & 0 \\
\hline 55031 & V-275-LA-20A MOV & 145 & ea & 4 & $c$ \\
\hline 55032 & V-275-PA-40A MOV & 24 & ca & 4 & $\mathrm{~d}$ \\
\hline 55042 & 1.5-KE-200-C bipolar zener & 6 & ea & 5 & j \\
\hline 55047 & Plug-in protector, req. 1 receptacle & 8 & ea & 7 & $\mathrm{~d}$ \\
\hline 55048 & Cube Tap, Grounded (pkg of 1) & 2 & $\mathrm{pkg}$ & 12 & $\mathrm{~m}$ \\
\hline 55050 & CG-230-L or J-2001-06, 230 VDC & 52 & ea & 2 & $\mathrm{~b}$ \\
\hline 55061 & Connector, female tab ( $\mathrm{kgg}$ of 25 ) & 2 & pkg & 10 & $\mathrm{e}$ \\
\hline 55062 & Connector, male tab (pkg of 10 ) & 1 & $\mathrm{pkg}$ & 10 & $\mathrm{~d}$ \\
\hline
\end{tabular}


APPENDIX A-1 (continued)

\begin{tabular}{|c|c|c|c|c|c|}
\hline \multirow{2}{*}{$\begin{array}{l}\text { Stock } \\
\text { code }\end{array}$} & \multirow{2}{*}{$\begin{array}{l}\text { Description } \\
\text { Connector, spade tongue (pkg of 25) }\end{array}$} & \multicolumn{2}{|c|}{ Quantity } & \multicolumn{2}{|c|}{$\begin{array}{l}\text { FEMA } \\
\text { symbol }\end{array}$} \\
\hline & & 1 & $\mathrm{pkg}$ & 10 & $b$ \\
\hline 55064 & Connector, ring tongue (pkg of 25 ) & 1 & $\mathrm{pkg}$ & 10 & a \\
\hline 55065 & Connector, butt splice (nkg of 10 ) & 1 & pkg & 10 & c \\
\hline 55066 & Lug, for No. 4-14 AWG & 20 & ea & 6 & o \\
\hline 55067 & Terminal block, 20 contacts & 2 & ea & 12 & $\mathrm{~h}$ \\
\hline 55068 & Grounding clamp, 1 in. & 3 & $\mathrm{ca}$ & 6 & j \\
\hline 55069 & Grounding clamp, 2 in. & 2 & ea & 6 & k \\
\hline 55070 & Grounding clamp, 4 in. & 3 & $\mathrm{ca}$ & 6 & 1 \\
\hline 55071 & Clamp, hose, $\max 1$-in. ID & 8 & ca & 6 & $\mathrm{~h}$ \\
\hline 55072 & Clamp, hose, max 2-in. ID & 2 & ca & 6 & $\mathrm{i}$ \\
\hline 55073 & Grounding strip, U-channel & 2 & $\mathrm{ca}$ & 12 & $\mathrm{i}$ \\
\hline 55079 & Shect metal screw, No. $8 \times 3 / 8(20 / \mathrm{pkg})$ & 1 & $\mathrm{pkg}$ & 11 & $\mathrm{i}$ \\
\hline 55084 & Washer, lock, No. 8 (pkg of 50) & 1 & $\mathrm{pkg}$ & 11 & $\mathrm{j}$ \\
\hline 55086 & Washer, flat, No. 8 (pkg of 25) & 1 & pkg & 11 & 1 \\
\hline 55087 & Washer, star lock, $1 / 4$ in. & 20 & ca & 11 & $\mathrm{n}$ \\
\hline 55088 & Pop rivet, $1 / 8 \times 3 / 8$ in. $(50 / \mathrm{pkg})$ & 2 & pkg & 11 & $\mathrm{~m}$ \\
\hline 55089 & Tubing, Teflon, 0.034-in. ID & 2 & ea & 12 & $\mathrm{~g}$ \\
\hline 55090 & Shrink tubing, $1 / 4$-in. OD $(2 \mathrm{ft})$ & 1 & ea & 12 & $\mathfrak{f}$ \\
\hline 55091 & Shrink tubing, $3 / 8$-in. OD $(2 \mathrm{ft})$ & 2 & ca & 12 & $\mathrm{n}$ \\
\hline 55092 & Shrink tubing, $1 / 2$-in. OD $(2 \mathrm{ft})$ & 1 & ea & 12 & o \\
\hline 55003 & Wire, hook-up, Teflon & 40 & $\mathrm{ft}$ & 12 & 1 \\
\hline
\end{tabular}


APPENDIX A-1 (continued)

\begin{tabular}{|c|c|c|c|c|c|}
\hline $\begin{array}{l}\text { Stock } \\
\text { code }\end{array}$ & Description & Quan & & $\begin{array}{l}\text { FEMA } \\
\text { symbol }\end{array}$ & \\
\hline 55094 & Braid, tinned copper & 6 & $\mathrm{ft}$ & 6 & a \\
\hline 55097 & Wire, No. 4 AWG, stranded copper & 540 & $\mathrm{ft}$ & 6 & $\mathrm{p}$ \\
\hline 55098 & Copper strip, 3 in. wide & 16 & $\mathrm{ft}$ & 6 & $q$ \\
\hline 55099 & Crimping tool & 1 & ca & 12 & $b$ \\
\hline 55100 & Riveting tool & 1 & ea & 12 & $\mathrm{c}$ \\
\hline 55101 & Tap, thread cutting, No. 10-32 & 1 & $\mathrm{ca}$ & 12 & $\mathrm{c}$ \\
\hline 55102 & Drill bits, No. 21 and No. 29 (1 ca) & 1 & $\mathrm{pkg}$ & 12 & $\mathrm{~d}$ \\
\hline 55104 & Emery cloth, shect & 2 & sheets & 6 & $\mathrm{~g}$ \\
\hline 55105 & Labcl, "EMP SUPPRESSOR" (pkg of 25) & 1 & $\mathrm{pkg}$ & 12 & a \\
\hline 55106 & Wire ties, nylon, 7 in. & 100 & ea & 12 & j \\
\hline 55107 & Tape, electrical, $3 / 4$ in. & 1 & roll & 6 & $d$ \\
\hline 55108 & Adhesive, RTV (3-oz tube) & 1 & tube & 6 & $\mathrm{c}$ \\
\hline 55109 & Conductive epoxy, (1/2-lb jar) & 1 & set & 6 & b \\
\hline 55177 & Bolt, $1 / 4-20 \times 1 / 2$ in. & 20) & ea & 11 & $\mathrm{~g}$ \\
\hline TBP & Nut, 1/4-20, hex & 20) & ea & & \\
\hline TBP & Clamp, for 5/8-in. ground rod & 3 & ca & & \\
\hline TBP & Split bolt, for No. 4 AWG wire & 20) & ea & & \\
\hline TBP & Hub, grounding, per ORNL ${ }^{a}$ design & 1 & ca & & \\
\hline TBP & Manifold, grounding, per ORNL ${ }^{a}$ design & 1 & ca & & \\
\hline TBP & Copper tubing, $1 / 4$ in. $(50 \mathrm{ft})$ & 36 & rolls & & \\
\hline TBP & Ell, copper, $1 / 4$ in. & 10 & ca & & \\
\hline
\end{tabular}


APPENDIX A-1 (continued)

\begin{tabular}{llrl}
\hline $\begin{array}{l}\text { Stock } \\
\text { code }\end{array}$ & Description & Quantity & $\begin{array}{c}\text { FEMA } \\
\text { symbol }\end{array}$ \\
\hline TBP & Tee, copper, $1 / 4$ in. & 35 & ea \\
TBP & Cross, copper, $1 / 4$ in. & 25 & ea \\
TBP & Coupling, copper, $1 / 4$ in. & 35 & ea \\
TBP & Solder, rosin core & 2 & lb \\
TBP & Cement, plastic roofing & 5 & gal \\
\hline
\end{tabular}

${ }^{a}$ ORNL = Oak Ridge National Luboratory. 
APPENDIX A-2

Recommended Electromagnetic Pulse Materials Spare Parts List for Idaho State Emergency Operating Center, Boise, Idaho

\begin{tabular}{|c|c|c|c|c|c|}
\hline \multirow{2}{*}{$\begin{array}{l}\text { Stock } \\
\text { code }\end{array}$} & \multirow{2}{*}{$\begin{array}{l}\text { Description } \\
\text { FCC-250-230-UHF coaxial tee }\end{array}$} & \multicolumn{2}{|c|}{ Quantity } & \multicolumn{2}{|c|}{$\begin{array}{l}\text { FEMA } \\
\text { symbol }\end{array}$} \\
\hline & & 1 & ea & 1 & $\mathbf{c}$ \\
\hline 55003 & FCC-25()-47()-UHF coaxial tee & 1 & $\mathrm{ca}$ & 1 & 0 \\
\hline 55008 & FCC-450-3.3-UHF coaxial tee & 1 & $\mathrm{ca}$ & 1 & 1 \\
\hline 55016 & FCC-45()-3.3-BNC coaxial tec & 1 & $\mathrm{ca}$ & 1 & $\mathrm{i}$ \\
\hline 55017 & FCC-450-6.8-BNC coaxial tee & 1 & ea & 1 & $\mathrm{k}$ \\
\hline 55019 & FCC-450-3.3-L diode bridge & 1 & $\mathrm{ca}$ & 3 & a \\
\hline 55022 & V-39-ZA-6 MOV & 3 & ca & 4 & $\mathrm{e}$ \\
\hline 55025 & V-130-LA-10A MOV & 5 & ea & 4 & a \\
\hline 55026 & V-130-PA-20A MOV & 3 & ea & 4 & $\mathrm{~b}$ \\
\hline 55030 & $\mathrm{~V}-275-\mathrm{HE}-250 \mathrm{MOV}$ & 3 & ca & 4 & 0 \\
\hline 55031 & V-275-LA-20A MOV & 10 & ea & 4 & $\mathrm{c}$ \\
\hline 55032 & V-275-PA-40A MOV & 6 & ea & 4 & $\mathrm{~d}$ \\
\hline 55042 & 1.5-KE-20)-C bipolar zener & 2 & ca & 5 & $\mathrm{j}$ \\
\hline 55050 & CG-230-L or J-2001-06, 230 VDC & 10 & ea & 2 & $\mathrm{~b}$ \\
\hline 55111 & 3-A pico-fuse (plug-in protector) & 3 & ca & 7 & b \\
\hline
\end{tabular}




\section{APPENDIX A-3}

Electromagnetic Pulse Materials Cost Estimate to Harden Idaho State Emergency Operating Center,

\section{Boisc, Idaho}

Stock

code Description
Cost Quantity cach

(\$)
Total cost

$(\$)$

\begin{tabular}{|c|c|c|c|c|c|}
\hline 55000$)$ & FCC-250-75-UHF coaxial tee & 2 & ea & 80.00 & 160.00 \\
\hline $55(0) 1$ & FCC-25()-230-UHF coaxial tec & 3 & ea & 80.00 & $240.00)$ \\
\hline $55(0) 3$ & FCC-250-47()-UHF coaxial tee & 7 & ea & 80.00 & 560.00 \\
\hline 55008 & FCC-450-3.3-UHF coaxial tee & 1 & ca & 80.00 & 80.00 \\
\hline 55016 & FCC-450)-3.3-BNC coaxial tee & 1 & $\mathrm{ca}$ & 80.00 & 80.00 \\
\hline 55017 & FCC-450-6.8-BNC coaxial tec & 2 & ea & 80.00 & 160.00 \\
\hline 55019 & FCC-450-3.3-L diode bridge & 3 & ca & 80.00 & 240.00 \\
\hline 55022 & V-39-ZA-6 MOV & 3 & $\mathrm{ca}$ & 1.00 & 3.00 \\
\hline 55025 & V-130-LA-10A MOV & 6 & ca & 1.00 & 6.00 \\
\hline $55026 \mathrm{~V}$ & V-130-PA-20A MOV & 6 & ea & 12.60 & 75.60 \\
\hline 55030 & V-275-HE-250 MOV & 3 & ea & 36.00 & 108.00 \\
\hline 55031 & V-275-LA-20A MOV & 145 & ea & 0.83 & 120.35 \\
\hline 55() 32 & V-275-PA-40A MOV & 24 & ea & 12.60 & 302.40 \\
\hline 55042 & 1.5-KE-200-C bipolar zener & 6 & ca & 2.00 & 12.00 \\
\hline 55047 & Plug-in protector, req. 1 receptacle & 8 & ca & 19.95 & 159.60 \\
\hline 55048 & Cubc tap, grounded (pkg of 1) & 2 & $\mathrm{pkg}$ & 3.95 & 7.90 \\
\hline 55050 & $\mathrm{CG}-230-\mathrm{L}$ or $\mathrm{J}-2001 \cdot 06,230 \mathrm{VDC}$ & 52 & ea & 3.00 & 156.00 \\
\hline 55061 & Connector, female tab (pkg of 25) & 2 & pkg & 0.10 & 5.00 \\
\hline $55(362$ & Connector, maic tab (pkg of iô) & $\mathbf{i}$ & pikg & 0.10 & 1.000 \\
\hline
\end{tabular}


APPENDIX A-3 (continued)

\begin{tabular}{|c|c|c|c|c|c|}
\hline $\begin{array}{l}\text { Stock } \\
\text { code }\end{array}$ & Description & & intity & $\begin{array}{l}\text { Cost } \\
\text { cach } \\
(\$)\end{array}$ & $\begin{array}{l}\text { Total } \\
\text { cost } \\
(\$)\end{array}$ \\
\hline 55063 & Connectur, spade tongue (pkg of 25) & 1 & $\mathrm{pkg}$ & 0.10 & 2.50 \\
\hline 55064 & Connector, ring tongue (pkg of 25) & 1 & $\mathrm{pkg}$ & 0.10 & 2.50 \\
\hline 55065 & Connector, butt splice (pkg of 10 ) & 1 & $\mathrm{pkg}$ & 0.10 & 1.00 \\
\hline 55066 & Lug, for No. 4-14 AWG & 20) & $\mathrm{ca}$ & 0.86 & 17.20 \\
\hline 55067 & Terminal block, 20 contacts & 2 & ea & 7.65 & 15.30 \\
\hline 55() 68 & Grounding clamp, 1 in. & 3 & ca & 1.75 & 5.25 \\
\hline 55069 & Grounding clamp, 2 in. & 2 & $\mathrm{ca}$ & 17.50 & 35.00 \\
\hline 55070 & Grounding clamp, 4 in. & 3 & ea & 27.50 & 82.50 \\
\hline 55071 & Clamp, hose, max 1-in. ID & 8 & ca & 0.34 & 2.72 \\
\hline 55072 & Clamp, hose, $\max 2$-in. ID & 2 & ca & 0.38 & 0.76 \\
\hline 55073 & Grounding strip, U-channel & 2 & $\mathrm{ca}$ & 4.00 & 8.00 \\
\hline 55079 & Shect metal screw, No. $8 \times 3 / 8(20 / \mathrm{pkg})$ & 1 & $\mathrm{pkg}$ & 0.02 & 0.40 \\
\hline 55084 & Washer, lock, No. 8 (pkg of 50) & 1 & $\mathrm{pkg}$ & 0.01 & 0.50 \\
\hline 55086 & Washer, flat, No. 8 (pkg of 25) & 1 & $\mathrm{pkg}$ & 0.01 & 0.25 \\
\hline 55() 87 & Washer, star lock, $1 / 4$ in. & 20 & ca & 0.01 & 0.20 \\
\hline 55088 & Pop rivet, $1 / 8 \times 3 / 8$ in. $(50 / \mathrm{pkg})$ & 2 & pkg & 0.01 & $1 .(0)$ \\
\hline 55089 & Tubing, Teflon, 0.034-in. ID & 2 & ea & $1 .(0)$ & 2.00 \\
\hline 55090 & Shrink tubing, $1 / 4$-in. OD $(2 \mathrm{ft})$ & 1 & ca & 0.16 & 0.32 \\
\hline 55091 & Shrink tubing, $3 / 8$-in. OD $(2 \mathrm{ft})$ & 2 & ca & 0.44 & 0.88 \\
\hline 55092 & Shrink tubing, $1 / 2$-in. OD (2 lit) & 1 & $\mathrm{ea}$ & 0.50 & $1 .())$ \\
\hline
\end{tabular}


APPENDIX A-3 (continued)

\begin{tabular}{|c|c|c|c|c|c|}
\hline \multirow{2}{*}{$\begin{array}{l}\text { Stock } \\
\text { code }\end{array}$} & \multirow{2}{*}{$\begin{array}{l}\text { Description } \\
\text { Wire, hook-up, Teflon }\end{array}$} & \multicolumn{2}{|c|}{ Quantity } & \multirow{2}{*}{$\begin{array}{l}\begin{array}{l}\text { Cost } \\
\text { cach } \\
(\$)\end{array} \\
0.12\end{array}$} & \multirow{2}{*}{$\begin{array}{l}\begin{array}{l}\text { Total } \\
\operatorname{cost} \\
(\$)\end{array} \\
4.80\end{array}$} \\
\hline & & 40 & $\mathrm{ft}$ & & \\
\hline 55094 & Braid, tinned copper & 6 & fit & 0.84 & 5.04 \\
\hline 55() 97 & Wirc, No. 4 AWG, stranded copper & 540 & $\mathrm{ft}$ & 0.25 & $135.00)$ \\
\hline 55098 & Copper strip, 3 in. wide & 16 & lit & 0.98 & 15.68 \\
\hline 55099 & Crimping tool & 1 & ca & $12 .(0)$ & $12.00)$ \\
\hline 55100 & Riveting tool & 1 & $\mathrm{ca}$ & $10 .(0)$ & $10 .(0)$ \\
\hline 55101 & Tap, thread cutting, No. 10-32 & 1 & ea & 0.25 & 0.25 \\
\hline 55102 & Drill bits, No. 21 and No. 29 (1 ca) & 1 & pkg & 0.25 & 0.50 \\
\hline 55104 & Emery cloth, sheet & 2 & shects & 0.50 & $1 .(0)$ \\
\hline 55105 & Labcl, "EMP SUPPRESSOR" (pkg of 25) & 1 & $\mathrm{pkg}$ & 0.04 & $1.00)$ \\
\hline 55106 & Wire ties, nylon, 7 in. & 100 & $\mathrm{ca}$ & 0.10 & $10.00)$ \\
\hline 55107 & Tape, electrical, $3 / 4$ in. & 1 & roll & 2.69 & 2.69 \\
\hline 55108 & Adhesive, RTV (3-oz tube) & 1 & tube & 3.25 & 3.25 \\
\hline 55109 & Conductive epoxy, $1 / 2-1 \mathrm{~h}$ jar & 1 & set & 25.00 & 25.00 \\
\hline 55117 & Bolt, $1 / 4-20 \times 1 / 2$ in. & 20 & ea & 0.10 & 2.00 \\
\hline TBP & Nut, $1 / 4-20$, hex & 20 & ea & 0.10 & 2.00 \\
\hline TBP & Clamp, for 5/8-in. ground rod & 3 & ea & 8.00 & 24.00 \\
\hline TBP & Split bolt, for No. 4 AWG wire & 20 & $\mathrm{ea}$ & 1.60 & 32.00 \\
\hline TBP & Hub, grounding, per ORNL design & 1 & ea & $20(0.00$ & 200.00 \\
\hline TBP & Manifold, grounding, per ORNL ${ }^{a}$ design & 1 & ea 7 & $7(0) .00$ & $7(0) .00)$ \\
\hline
\end{tabular}


APPENDIX A-3 (continued)

\begin{tabular}{|c|c|c|c|c|c|}
\hline \multirow{2}{*}{$\begin{array}{l}\text { Stock } \\
\text { code }\end{array}$} & \multirow{2}{*}{$\begin{array}{l}\text { Description } \\
\text { Copper tubing, } 1 / 4 \text { in. }(50 \mathrm{lt})\end{array}$} & \multicolumn{2}{|c|}{ Quantity } & \multirow{2}{*}{$\begin{array}{l}\begin{array}{l}\text { Cost } \\
\text { each } \\
(\$)\end{array} \\
14.00)\end{array}$} & \multirow{2}{*}{$\begin{array}{l}\text { Total } \\
\text { cost } \\
(\$)\end{array}$} \\
\hline & & 36 & rolls & & \\
\hline ТВP & Ell, copper, $1 / 4$ in. & 10 & $\mathrm{ca}$ & 0.96 & 9.60 \\
\hline TBP & Tee, copper, $1 / 4$ in. & 35 & $\mathrm{ca}$ & 1.50 & 52.50 \\
\hline ТВP & Cross, copper, $1 / 4$ in. & 25 & ca & 2.00 & 50.00 \\
\hline Tl3P & Coupling, copper, $1 / 4$ in. & 35 & $\mathrm{ca}$ & 0.50 & 17.50 \\
\hline TBP & Solder, rosin eore & 2 & lb) & 9.00 & $18 .(0)$ \\
\hline \multirow[t]{2}{*}{ TBP } & Cement, plastic roofing & 5 & gal & $6 .(0)$ & 30.00 \\
\hline & & \multicolumn{3}{|c|}{ TOTAL } & $4,523.94$ \\
\hline
\end{tabular}

${ }^{a}$ ORNL = Oak Ridge National Laboratory 


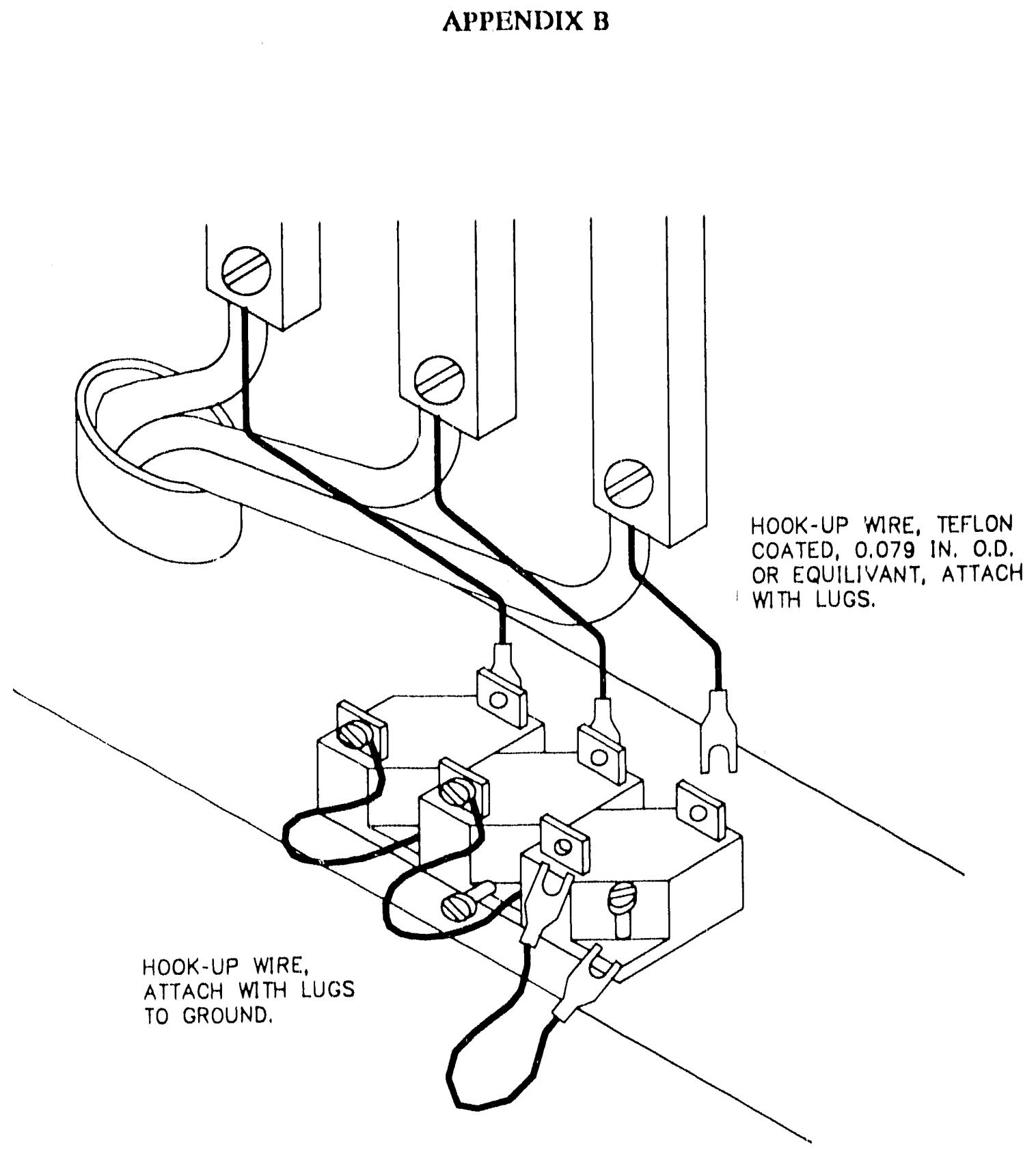

Fig. B.1. Installation of HE-Serics MOVs in a panel. PA-Series MOVs are installed in a similar manner, with the mounting tab used for ground. Keep all lead lengths as short as possible to minimize inductive voltage drops. 


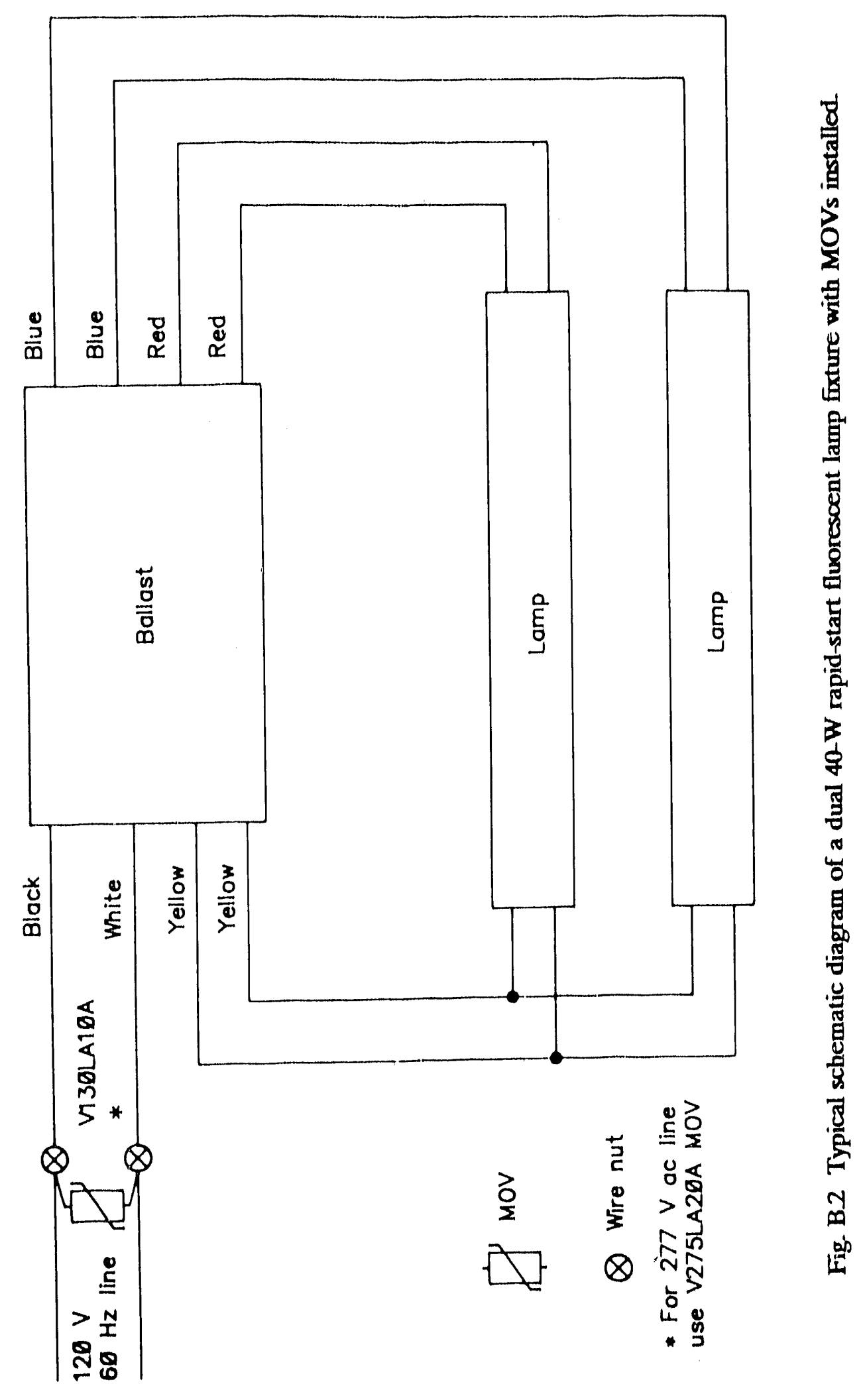




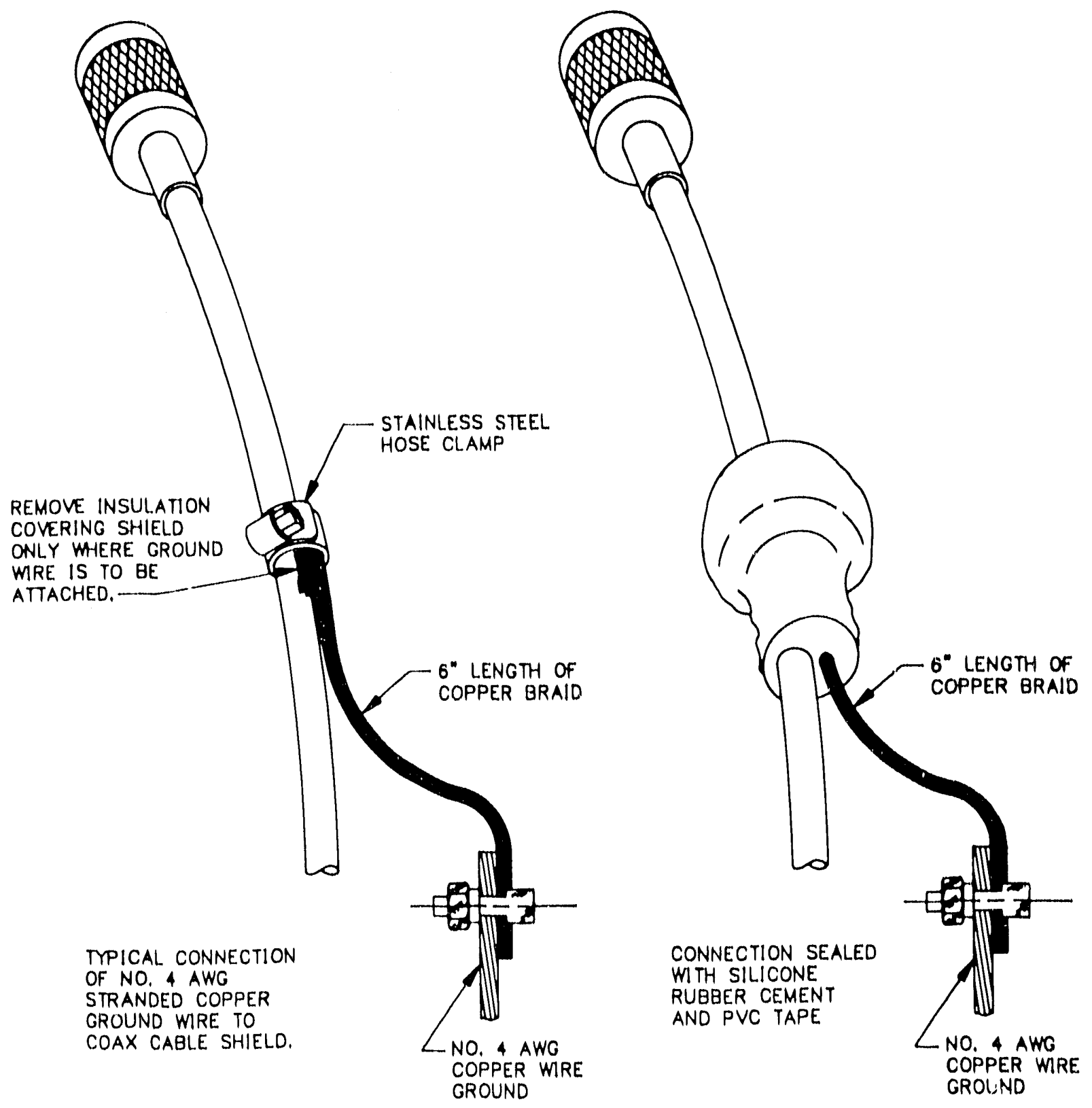

Fig. B.3 Typical installation of a grounding conductor to a coaxial cable shicld. 


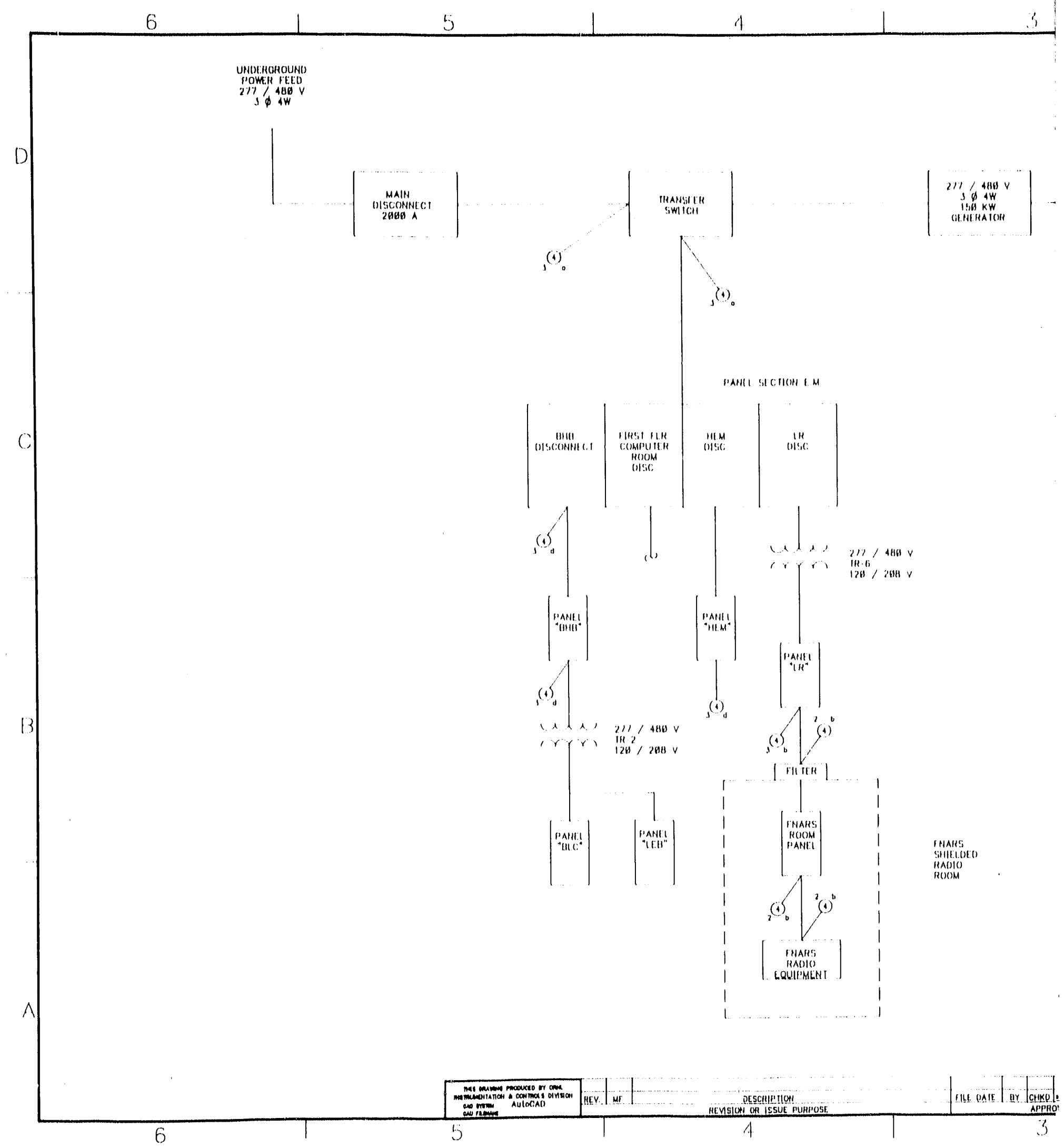


r.t StCHON L.M

\begin{tabular}{|c|}
\hline $\begin{array}{l}271 \text { S } 486 \mathrm{~V} \\
\text { ISS } 4 \mathrm{KW} \\
\text { OENEHAIOR }\end{array}$ \\
\hline
\end{tabular}

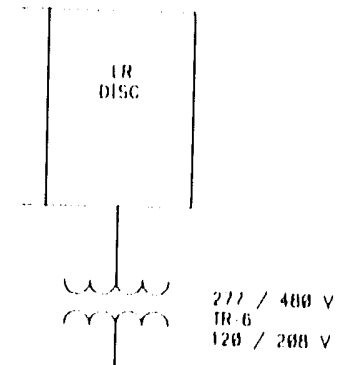

('ANIII

${ }^{1} \mathrm{LN} \mathrm{R}^{4}$

$\lambda_{2}$

(4) $\int^{2}$

filier)

$[$ PANAS

ROOM

NARS

\begin{tabular}{l|l}
1 & $\begin{array}{l}\text { RAOIOI) } \\
\text { ROOH }\end{array}$
\end{tabular}

121 ROOH

3

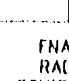

TNARS
PAOIO

CQUIEMLETI
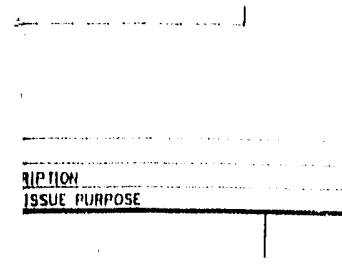

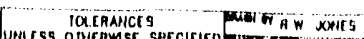

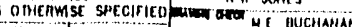

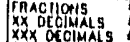

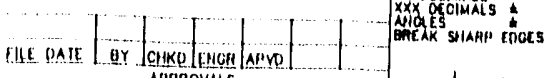

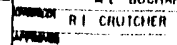

Mimorac onamaros

EDERAL, EMERGENCY MANAGEMENT AGENCY

IDAHO STATE EMERGENCY OPTRATING CENTEN SINGLE. LINE ELECTRICAL

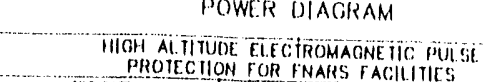

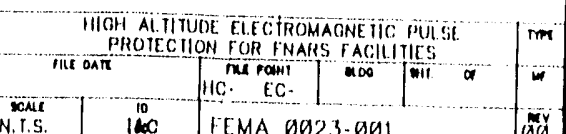

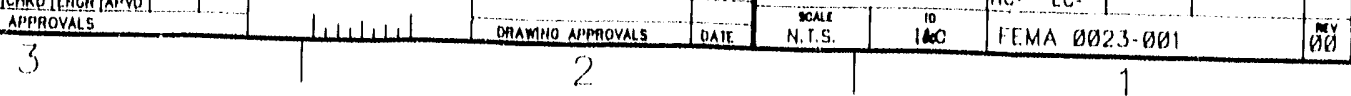




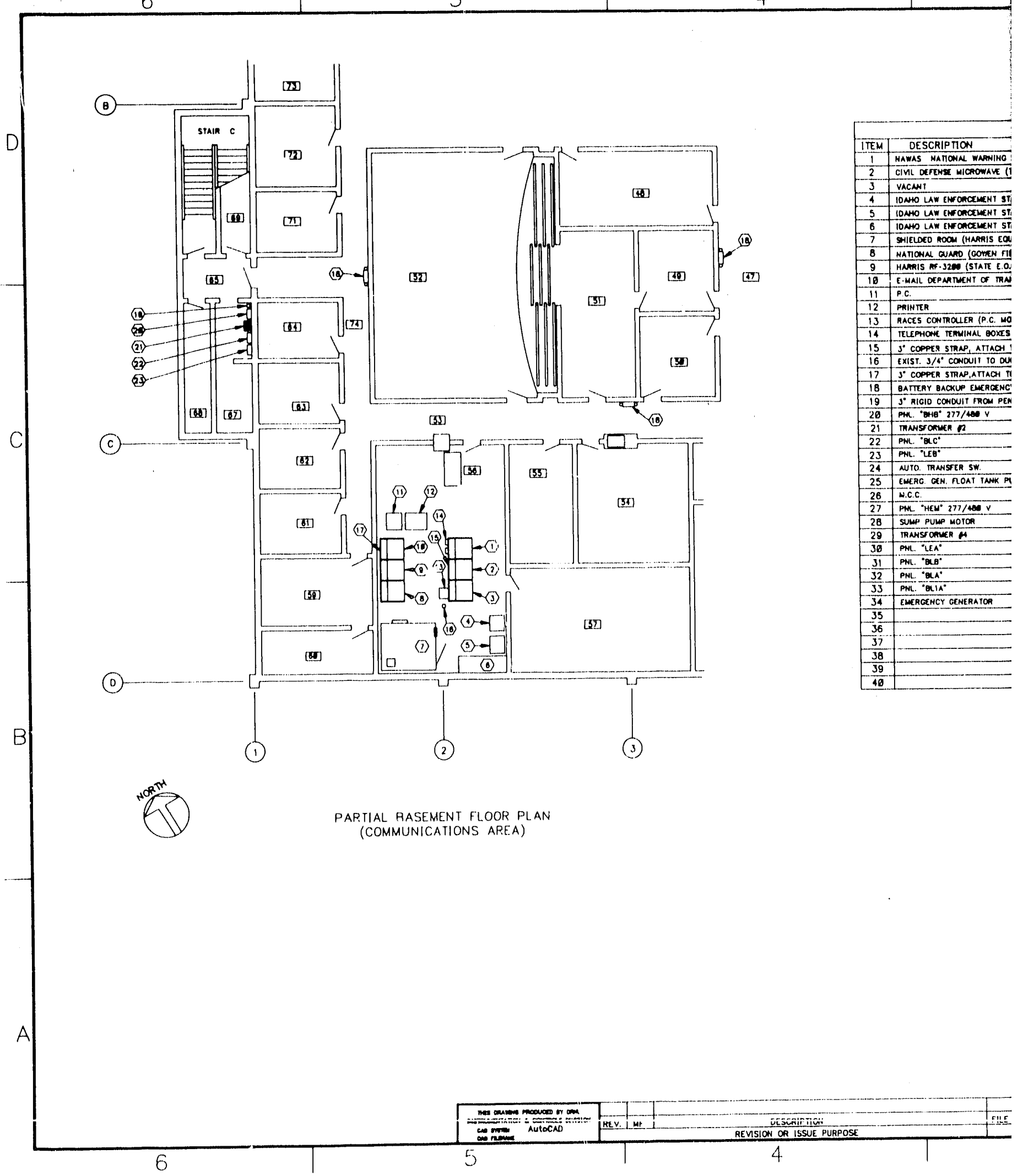




\begin{tabular}{|c|c|c|}
\hline IIEM & DESCRIPTION & CONNECTION \\
\hline 1 & HAMAS HATIOWN WAANIHO STSTEM STATIOON & 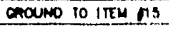 \\
\hline 2 & CIVL DCTCNSE MICROWAK (THNSPPORIATION) STAMON & GoOWO $10 \mathrm{KRE}$ nS \\
\hline 3 & VACANI & \\
\hline 4 & IOAHO LAW EMFOMCEMENT STATION (PAINTER) & \\
\hline 5 & 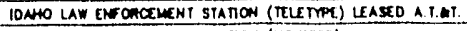 & \\
\hline 6 & DONHO LAW ENF OMCEMENT STATION (MONITOR) & \\
\hline 7 & SHILLOEO MOOM (HARRIS EQUIPUENI) & \\
\hline 8 & NATONNA GUAPO (GOWON FILLO) RACES STAHION & OROUNO IO ITEM $\mathrm{n}$ ? \\
\hline 9 & HANAIS RF J20 (STATE C.OC. BASE) STAIION & CAOU+O 10 ITE a? \\
\hline 10 & 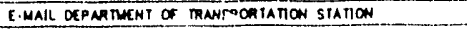 & COOUNO 10 ITEM QI? \\
\hline 11 & P.C. & CROCUNO TO ITEM $n$ \\
\hline 12 & PRINTER & CROUND TO IRM M? \\
\hline 13 & AACES CONTROLIER (P.C. MOOEM, ETC) & GOUNO 10 ITE ns \\
\hline 14 & TELEPHONE TEMUIMAL BOXES & GOUNO TO $1 \mathrm{im}$ ns \\
\hline 15 & 5 COPPIR STRA, ATIACH TO REAR of CuBlaLS & \\
\hline 16 & EXIST, J/10 CONOUIT TO DUCT BNMK IN SUB-ASUT. & \\
\hline 17 & J COPPER STRNAATTACH TO REAT OF CUDIOES & \\
\hline 18 & BATTERY BACKUP EMEROENCY LOHT FIXTMAES & \\
\hline 19 & 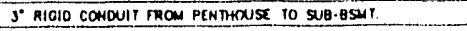 & \\
\hline 20 & $\mathrm{PM} \cdot \mathrm{BH} \mathrm{\theta}^{\circ} 277 / 40 \mathrm{~V}$ & \\
\hline 21 & mansSORWER $n$ & \\
\hline 22 & PNL. ${ }^{\circ} \mathrm{OC}$ & \\
\hline 23 & PAN $2 \angle 0^{\circ}$ & \\
\hline 24 & AUTO RRANSTLR SW & \\
\hline 25 & EMERO GEN. ROAT INAK PIMU MOTOR & \\
\hline 26 & W.C.C. & \\
\hline 27 & PFA HEW $277 / 400 \mathrm{~V}$ & \\
\hline $2 \mathrm{~B}$ & SUMP PUMP MOTOR & \\
\hline 29 & TRANSF OANGE $\mathrm{M}$ & \\
\hline 30 & PML ${ }^{\circ} \mathrm{LA} \mathrm{A}^{\circ}$ & \\
\hline 31 & PNL. $2 \theta^{\circ}$ & \\
\hline 32 & $\mathrm{PNL} \cdot \mathrm{aA}$ & \\
\hline 33 & PAI $B$ BIA & \\
\hline 34 & EWERGENCY GENERATOR & \\
\hline 35 & & \\
\hline 36 & & \\
\hline 37 & & \\
\hline 38 & & \\
\hline 39 & & \\
\hline 48 & & \\
\hline
\end{tabular}

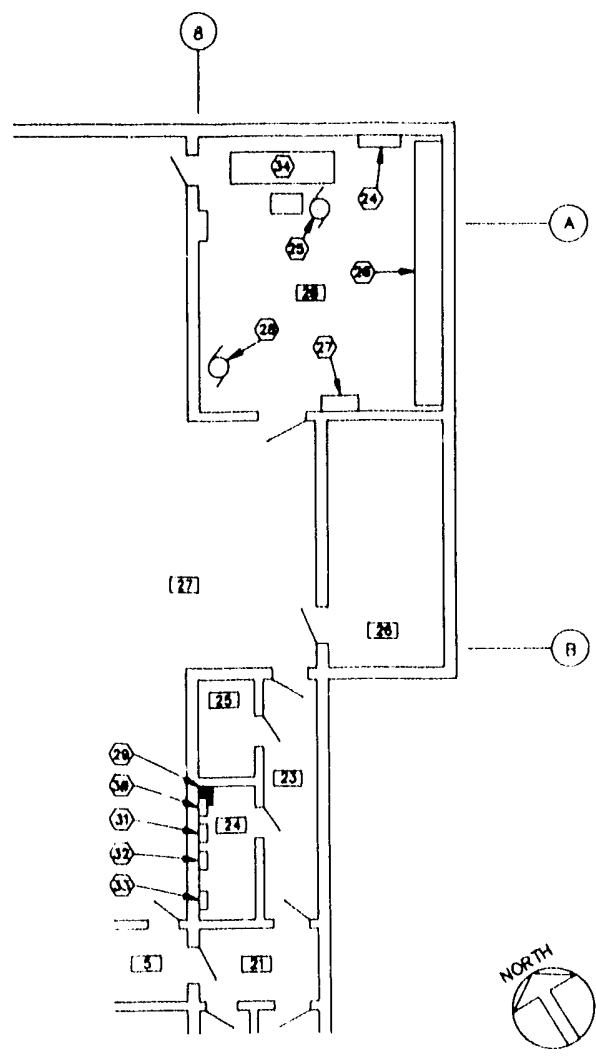

PARTIAL BASEMENT FLOOR PLAN (EMERG. GEN. \& ELECT. EQUIP. AREA)

IDAHO STATE EMERGENCY OPERATINO CENTER PARTIAL BASEMENT \& COM. ROOM EQUIPMENT GROUNDING SYSTEM HIGH ALTTUTOE ELECTROMAGEETC PULSE
PROTECTION FOR FNARS FACILITES

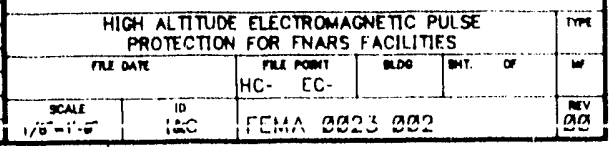




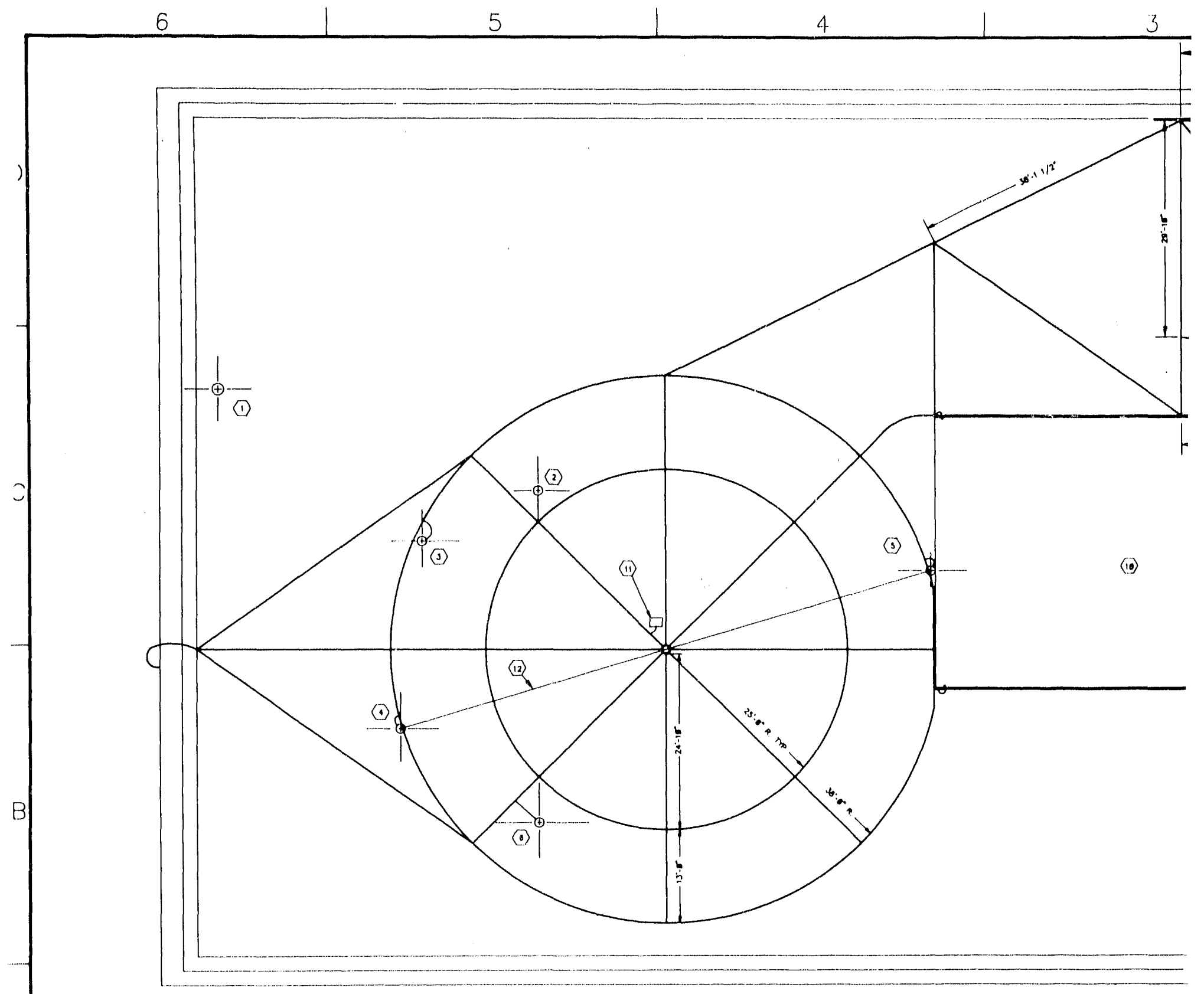

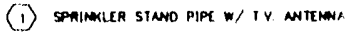
(2) REWOTE RADIATION Detrecioa

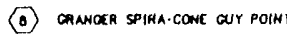

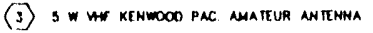
(0) Anterwa aur polmt not used
(1) ROOO NTD. MAST FOR TN DCUREET NMTEHAA
(10) Pentrouse encosupe
(ii) GNLIN FOR FAN DOUDCLT ANTINNA

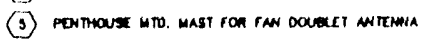
(12) TAN DOUDCET NHTHNA
(5) a.e. an un wrinata
(19) Existing roof penetration

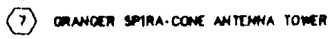




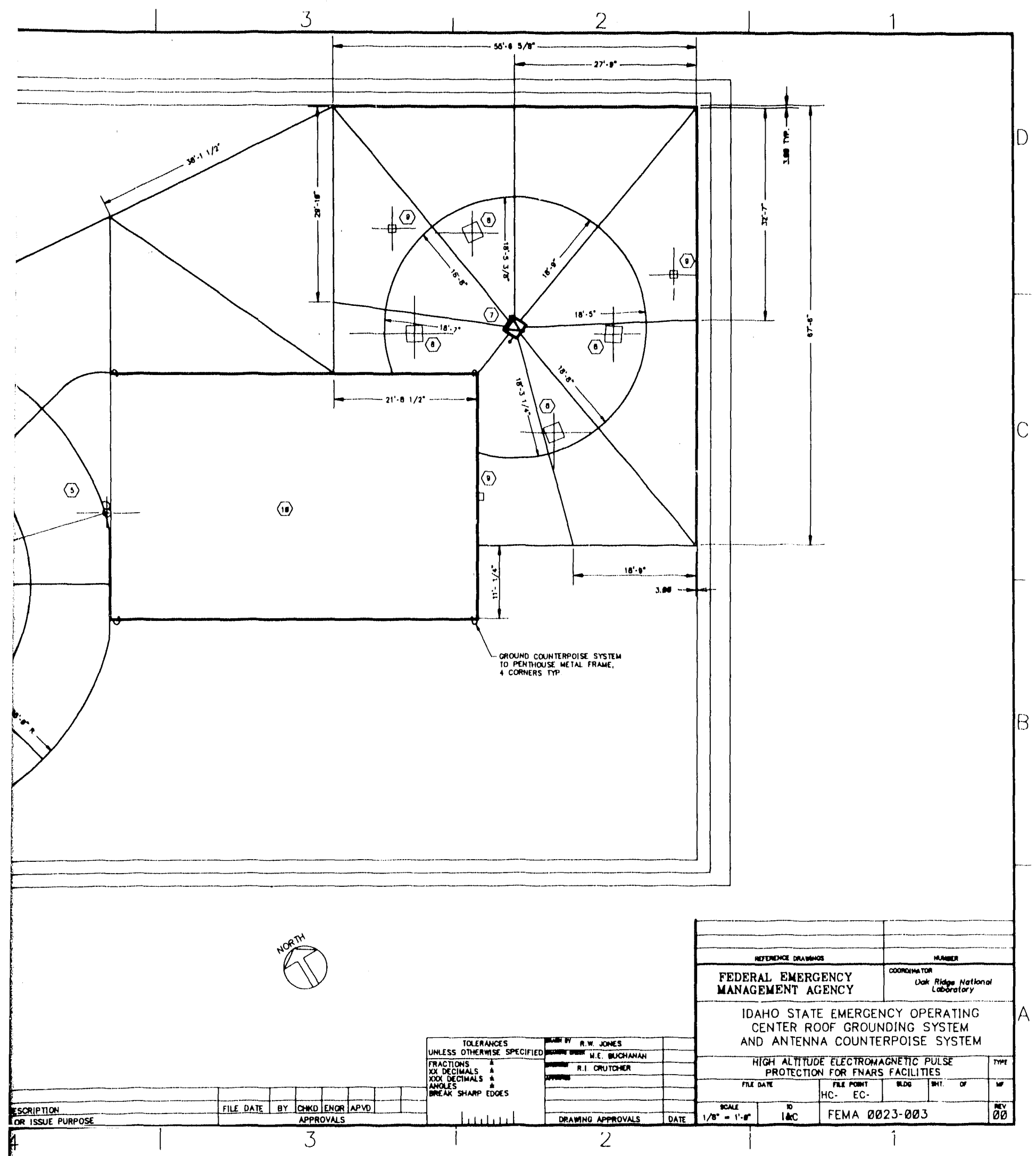




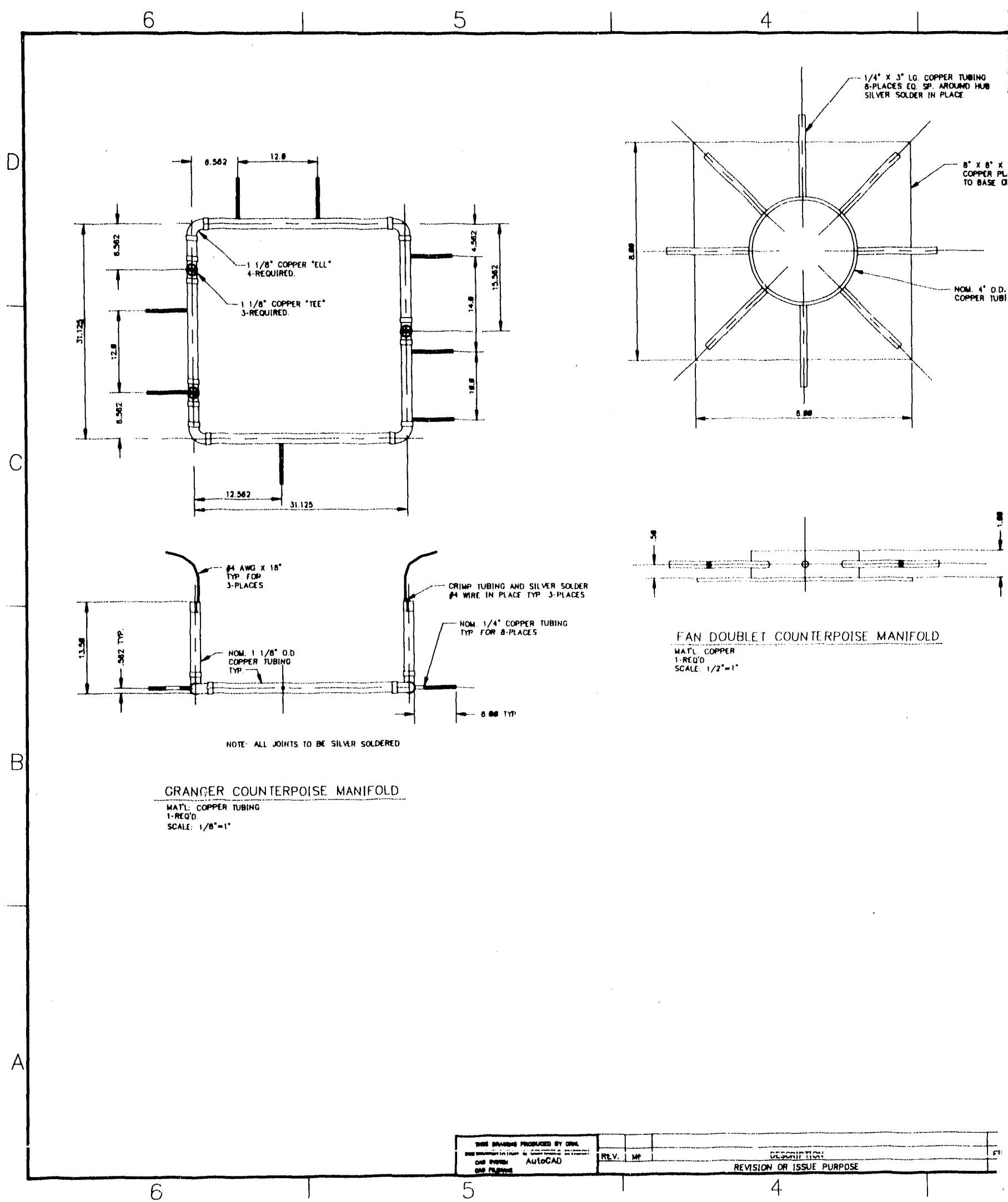



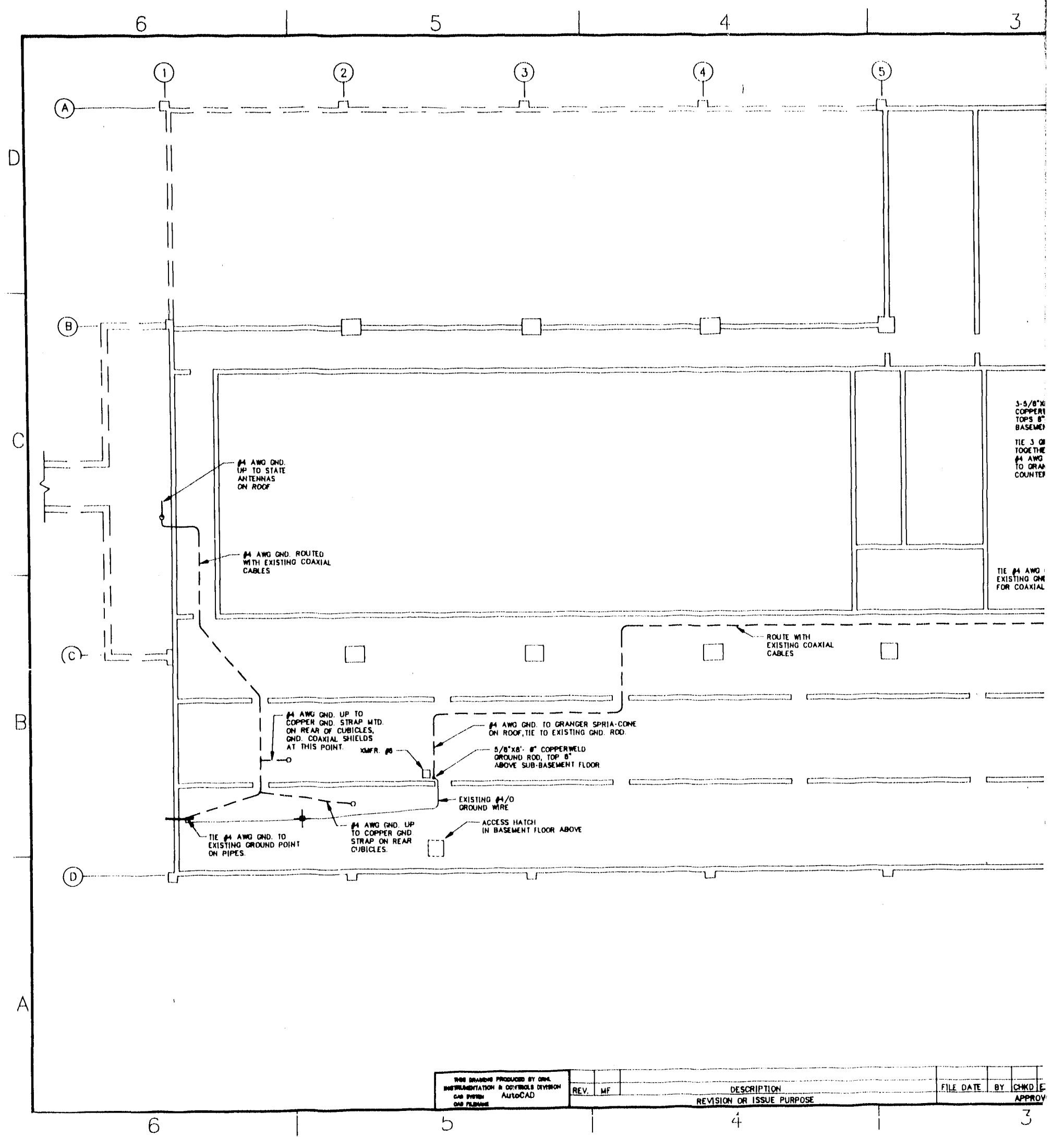


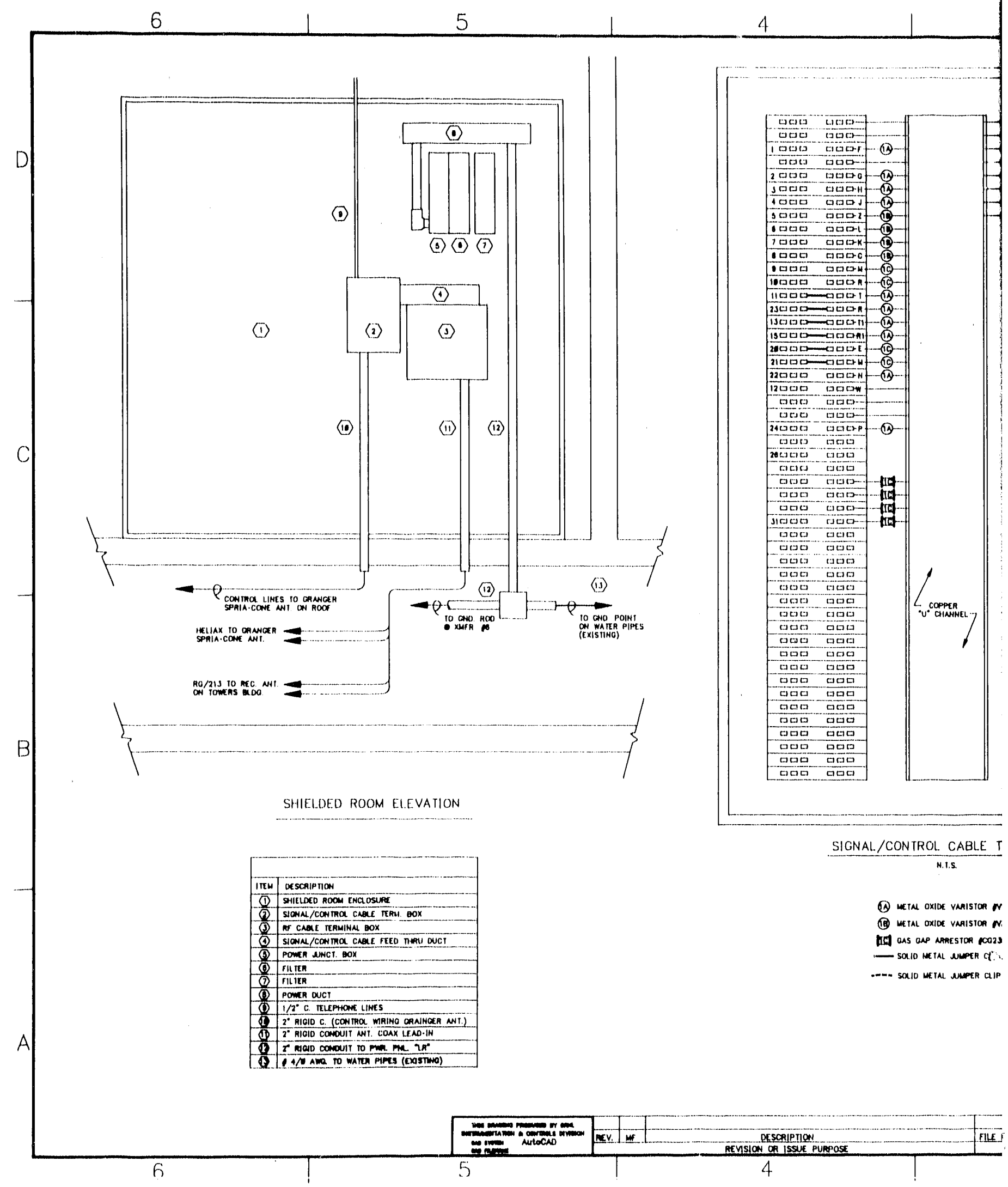




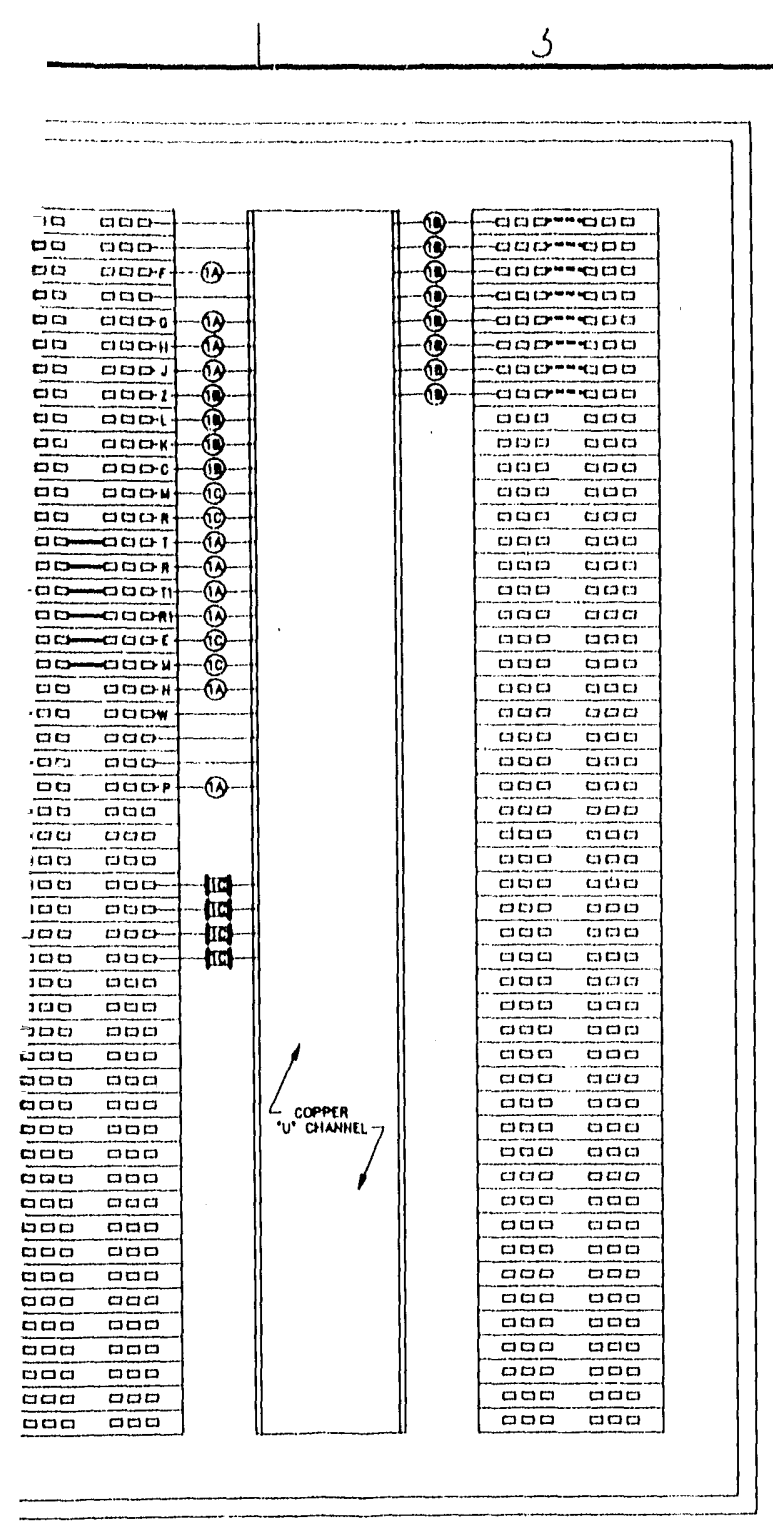

SIGNAL/CONTROL CABLE TERM. BOX
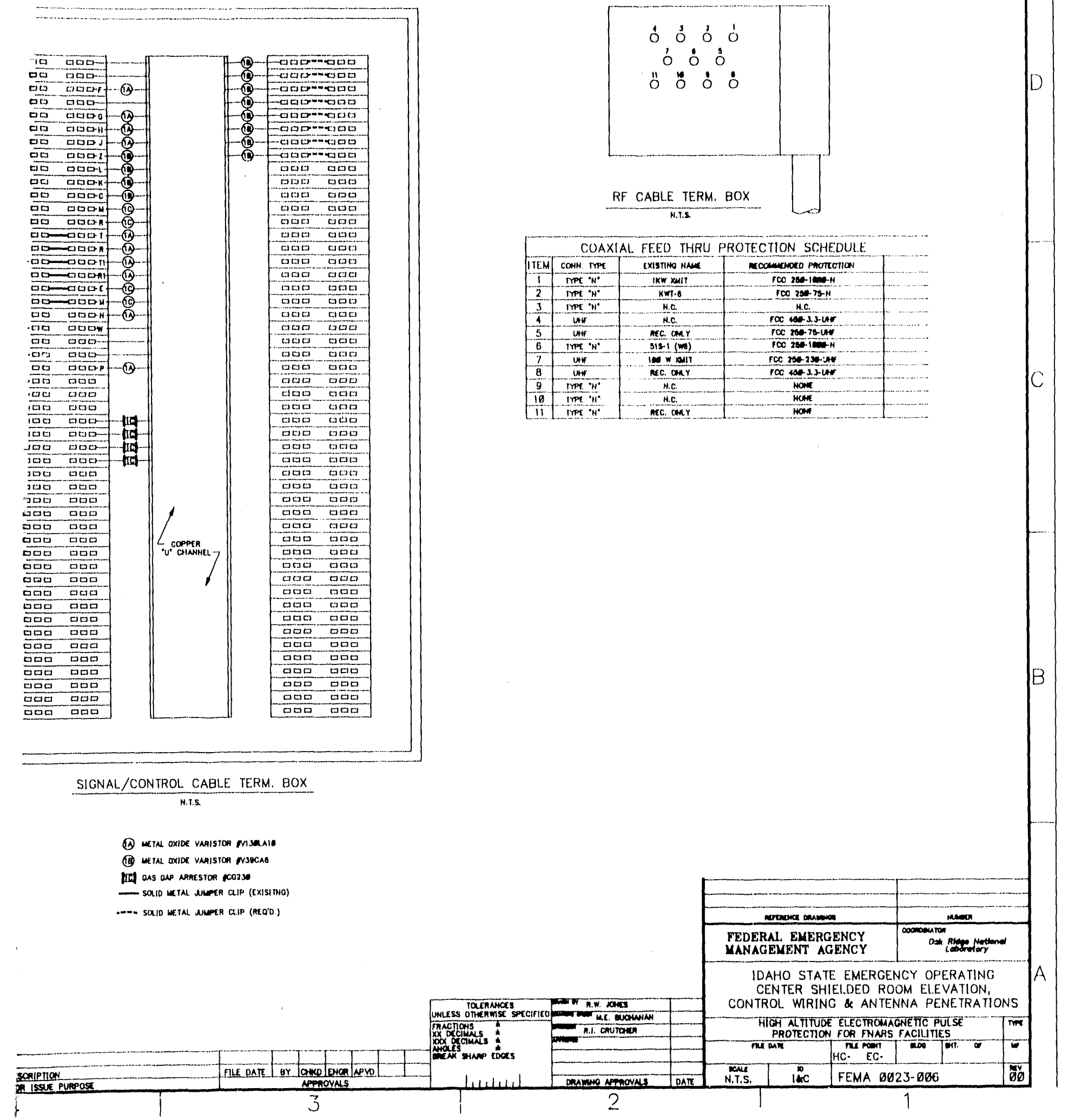


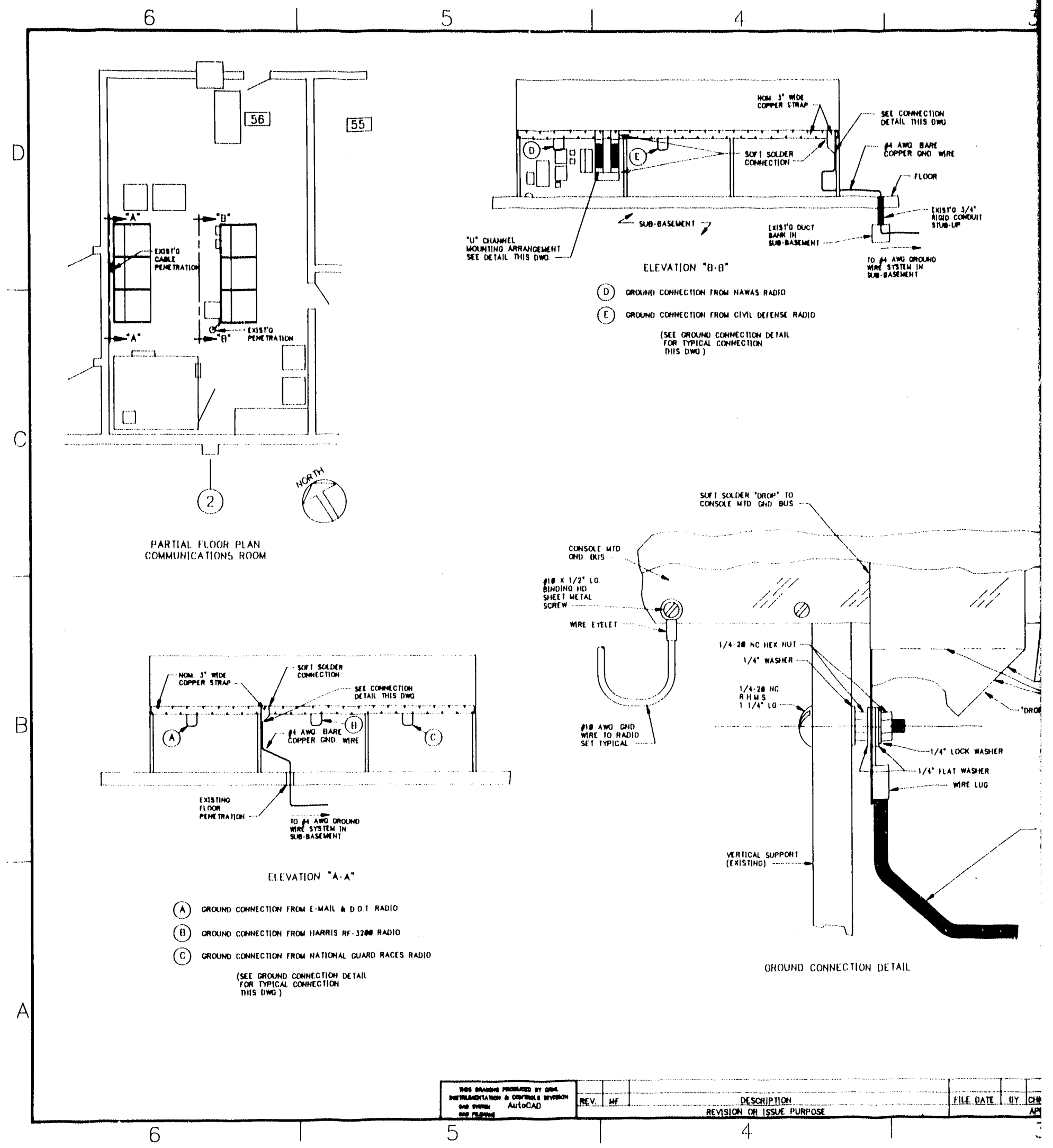




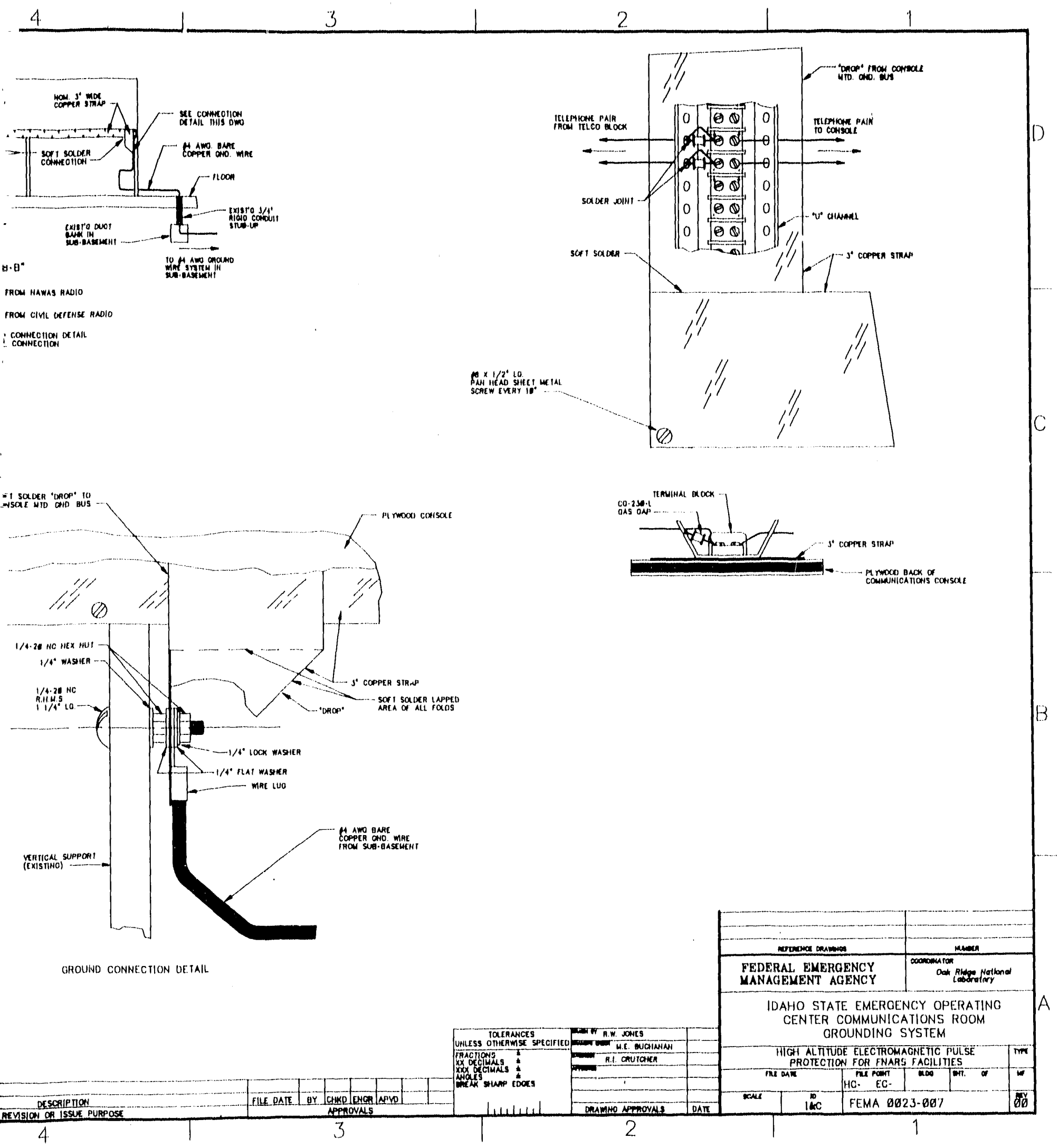




\section{INTERNAL DIS'TRIBUTION}

1. H. R. Brashear

2-5. M. E. Buchanan

6-7. R, 1. Crutcher

8. B. G. Eads

9. D. N. Fry

10. R. $\dddot{W}$. Jones

11. D. W. McDonald

12. D. R. Miller

13. C. H. Nowlin

14. R. E. Uhrig

15. A. Zucker
16. J. B. Ball, Advisor

17. B. Chexal, Advisor

18. T. B. Shoridan, Advisor

19. R. M. Taylor, Advisor

20-21. Central Rescarch Library

22. Y-12 Technical Ref'erence Section

23-24. Laboratory Records

25. Laboratory Records ORNL-RC

26. ORNL Patent Section

27. I\&C Publications Oflicic

\section{EXITERNAL DISTRIBUTION}

28. Assistant Manager for Encrgy Rescarch and Development, U.S. Department of Energy, Oak Ridge Fleld Office, P.O. Box 2(0)1, Oak Ridge, TN 37831 86()$)$.

29-39. R. P. Gates II, Federal Emergency Management Agency, Room 608, 5()) C Strect SW, Washinglon, DC 20472

40-41. Pat Frischmuth, State of Idaho, Bureau of Disaster Services, 650 West State Strect, Boise, ID 83720

42-43. Andrew Hendrickson, Federal Emergency Management Agency, Region X, 130 228th Street SW, Bothell, WA 98021

44-45. Olfice of Scientific and Technical Information, U.S. Department of Energy, P.O. Box 62, Oak Ridge, TN 378.31 

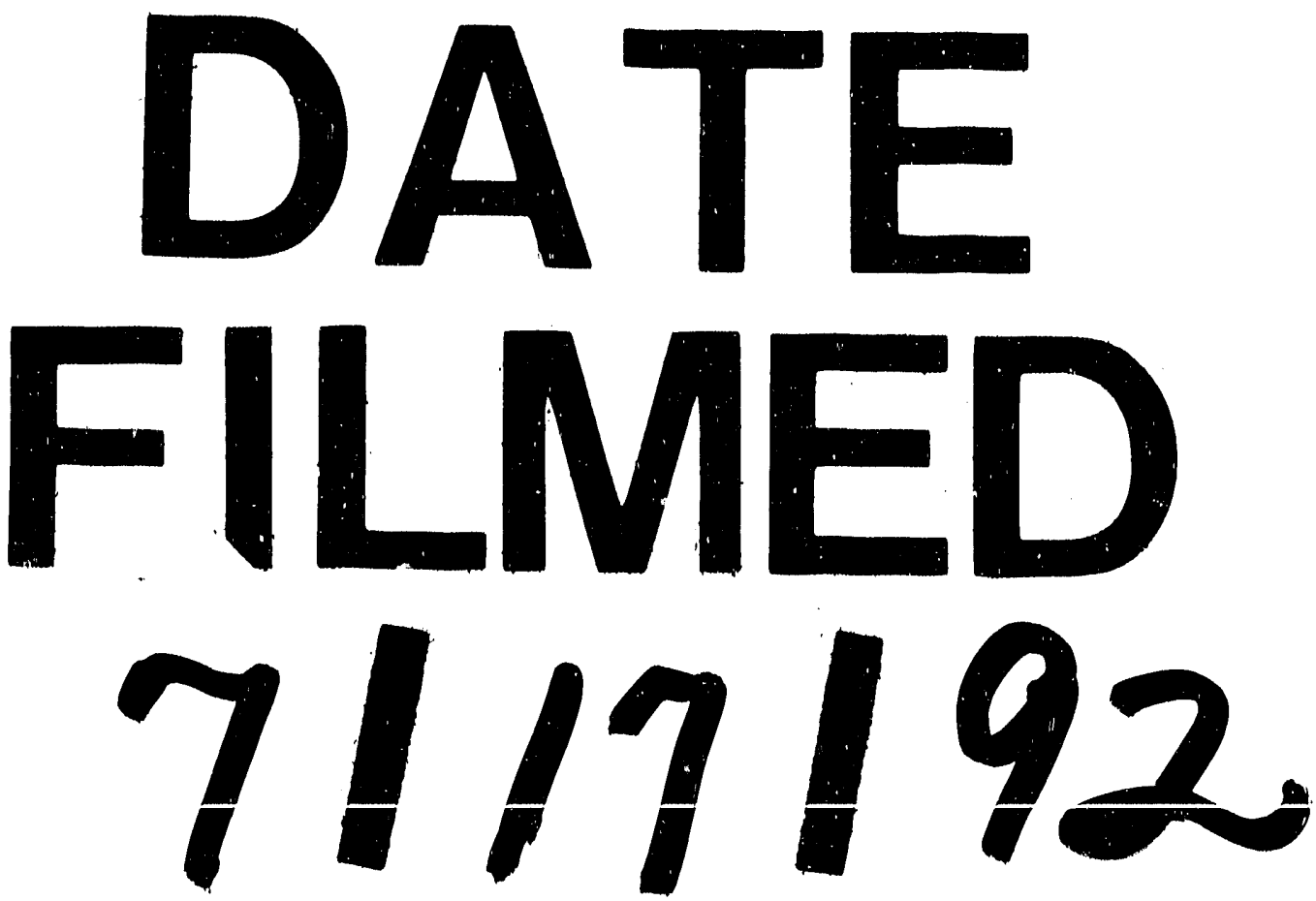